\title{
Preconditions for long-term stability of treatment
}

\author{
M. Martin
}

DFO specialist in private practice

\begin{abstract}
This paper focuses on adolescent orthodontic treatment. It should be stressed that a retainer appliance, of whatever sort, is only useful once the planned result, and especially the occlusal objective, has been achieved. A review of Tweed technique objectives is also presented.

Prognosis depends on quality of finishing, acquisition of normal function and neuro-muscular adaptation, to minimize risk of relapse. Nonetheless, relapse seems inevitable in the long term as regards individual crowding, except if retention is maintained for a very long time. Many clinical situations, in different pathologies and with 5 to 22 years' follow-up after active treatment will be described illustrate progress in retention strategy, as it is difficult to assess real stability after only 1 year's retention, as can be seen from the orthodontic literature.
\end{abstract}

\section{KEYWORDS}

Retention, prognosis, stability, relapse, occlusion, treatment goals

To be successful, orthodontic treatment needs, from the practitioner, a precise diagnosis, adapted and rigorous treatment strategy and an assessment of prognosis. From the patient, it requires cooperation, which it turn supposes knowledge of the pathology in question, its causes, the treatment to be implemented and its inevitable demands, estimated duration and subsequent care to maintain results. Patient information should be clear, complete and adapted, to secure adherence. This is vital, to create a climate of mutual trust in which treatment can be completed, with minimal risk of failure, loss of motivation, conflict or abandonment.
End of treatment is always a moment of great satisfaction for patient and family, who can see the progress made from the various pre-treatment documents: frontal and lateral photographs of the face, intraoral photographs, molds and X-rays.

More recently, we have added frontal and three-quarter smiling views, to include a much more dynamic aspect and be able to judge the smile line and symmetry and also muscular maturation and facial expression, which are the best indices of the gradual change from childhood-adolescence to adulthood. With a better integrated smile, the face expresses all of the balance achieved by treatment.

Address for correspondence:

Michel Martin

11 Rue d'Estrées

Article received: 06-02-2015.

64320 Idron Accepted for publication: 11-05-2015.

France

E-mail: mmpau@orange.fr

This is an Open Access article distributed under the terms of the Creative Commons Attribution License (http://creativecommons.org/licenses/by/4.0), which permits unrestricted use, distribution, and reproduction in any medium, provided the original work is properly cited. 
We also always encourage patients to have a check-up with their family doctor, to whom we send a reminder of the initial situation.

The present paper focuses on orthodontic treatment in adolescents with permanent dentition.

We shall recount how our posttreatment attitude has evolved over the years.

The devices employed were 22×28 Tweed brackets without angulation or torque.

Treatment objectives were consistently to optimize function, esthetics and facial harmony. The hoped-for stability of outcome depends on respecting the limits of the dentition, both anterior and posterior, and intercanine distance, following the Tweed criteria $^{48}$. We shall return to these therapeutic principles in detail below.

In the 1980s and '90s, we decided to use little or no retention, in the light, among other things, of the literature.

Studies conducted by the University of Washington confirmed a wellknown fact. In 1981, in Little's first studies $^{31}$, of 65 cases very successfully managed by the classic edgewise technique, with 4 extractions, $70 \%$ showed incisor crowding 10 years after end of retention, although no factors for relapse emerged to provide an explanation or prognosis. In 1983, a new study compared progression between extraction (with good results) and abstention: reduction in intercanine distance was 3-fold greater in the treatment group, and malpositioning twice as frequen ${ }^{52}$.

The various studies stress the longterm influence of mandibular growth in anterior rotation, which, when it continues after treatment, may lead to recurrence of incisor closed bite and anteroinferior overlap, although no predictive or explanatory factors have been found.

The conclusion of a report on relapse ${ }^{10}$ mentioned that the evolution of human dentition between the ages of 12 and 25 years leads to or aggravates mandibular incisor crowding. Many authors cited in the report considered retention not to be indispensable: for Englert (1960), it was unnecessary; for Burstone (1979), not always useful; for Begg (1978) it failed to prevent but does direct relapse; for the Tweed Foundation (1984), retention was undesirable, as orthodontists do not know all the determinants of the patient's occlusion and so cannot impose at the outset an "ideal" occlusion at the end of active treatment. In case of malocclusion, the cards need reshuffling, for individual occlusion to develop.

Williams ${ }^{55}$ argued that retention was unnecessary if certain principles were respected during multi-ring treatment: notably, anteroposterior superior and inferior incisor positioning and intercanine distance; for this, he recommended increasing the rate of extraction.

In the Tweed technique, occlusal balance and good cusp meshing were seen as a natural retention system and (overoptimistically, in our view) muscle balance would follow from occlusal balance.

Ortial ${ }^{42}$ referred to "dynamic retention": not immobilizing the arcades in the position in which treatment left them, but rather a stage from which the revised dental system will progress toward a physiological 
architecture governed by all the determinants of dynamic occlusion specific to childhood.

Posterior malocclusion and anterior hypercorrection, which remove certain posterior obstacles to correction of occlusion that might maintain the existing muscular and articular pathology, avoiding prematurities liable to deviate the mandible, result from treatment objectives ${ }^{39}$. Tweed's global occlusion concept was intended to contribute to restoring stable functional balance, without need for retention. "Recovery" was the watchword: a return to functional occlusion, from which soft tissue remodeling should follow ${ }^{20}$. The pathologies had all been hypercorrected, and transitional occlusion would progress toward individual physiological occlusion.

It was more or less a dogma of the time that the position of the mandibular incisor was the keystone in Tweed's orthodontic concepts: repositioning it should guarantee the stability of the final results of treatment ${ }^{16}$.

Many adepts of this philosophy reported cases of various pathologies, managed according to Tweed's principles, without any post-treatment mandibular retention ${ }^{1-17-18-24-28-29-46-49}$.

When no retention device was fitted at end of active treatment, we always asked the patient to pay us a visit annually, to check stability or detect any slight occlusal relapse or incisor irregularity, which would obviously be a factor of dissatisfaction for the patient, as the incisors are especially exposed to view and thus the center of attention for patient, family and friends. Nowadays, in a society driven by image and look, the esthetic demands of adults, bent on delaying aging, are supported by media and magazine pictures of men and women with nearly perfect anatomy and faces. This inspires the esthetic demands of teenagers, for whom outward appearance has taken on prime importance, reinforced by their social environment and by social networks: any esthetic blemish that can be seen is important. For this, it is indispensable to have before-andafter treatment documents to show the patient and compare any posttreatment recurrence of esthetic abnormalities with the pre-treatment state of affairs (Patient 1, figs 1a to $2 f$ (start and end of treatment) and fig. 3a-g (long-term follow-up)). Likewise, the family doctor who referred the patient to the orthodontist is going to take any relapse very badly: he or she may be the first to see signs of recurrence and has to deal with the patient's concerns and questions. For the orthodontist, occlusion may be the priority; but for the patient the main issue is incisor alignment. The patient needs explanations and reassurance; perhaps simple realignment of the area in question, notably inferior incisor/canine, may be considered (Patient 2, figs $4 a$ to $5 e$ (start and end of treatment) and figs 6 a to $7 f$ (longterm follow-up)).

We have always felt abstention to be the wisest course if there were no supplementary issues except slight incisor crowding without associated malocclusion. If treatment was nevertheless undertaken, the patient had to be warned of the risks of relapse. 


\section{Patient 1}

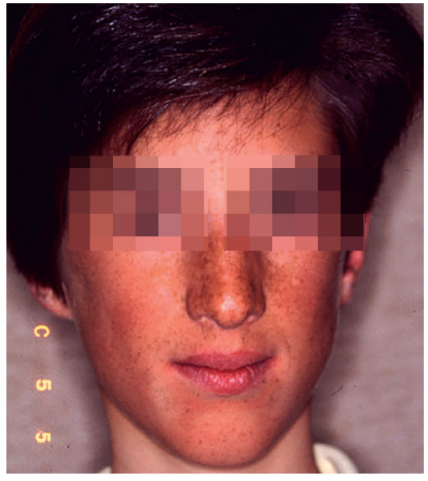

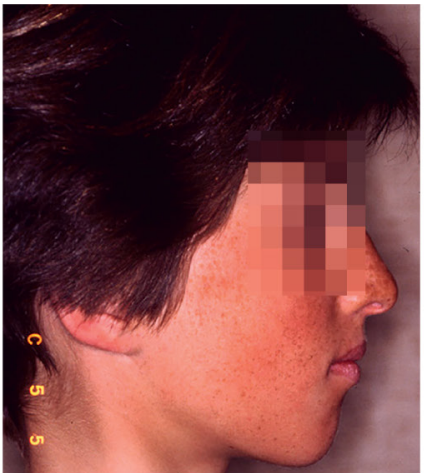

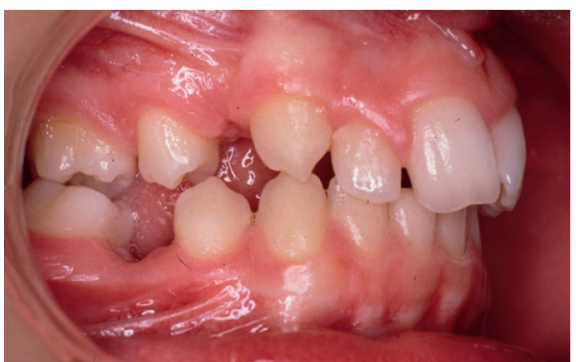

C

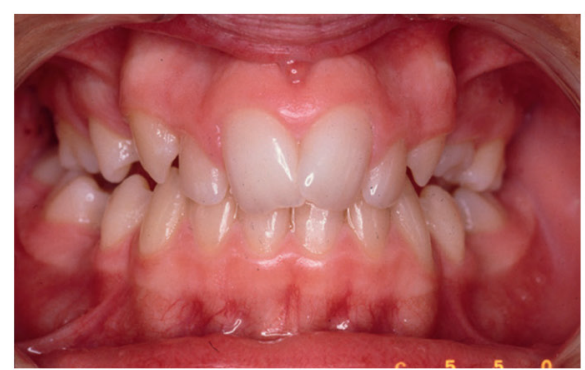

d

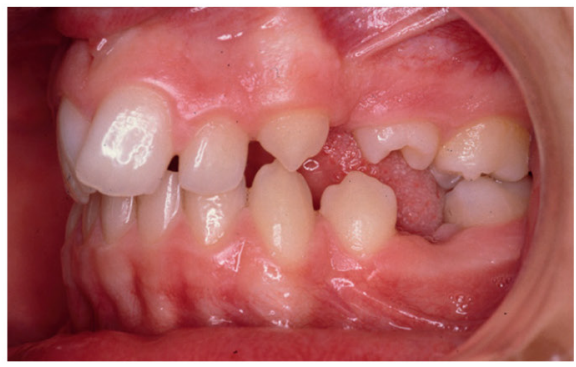

Figure 1a-e

Hyperdivergence with straight upper lip, enlarged labio-mental level, mandibular retrusion. Class II division 1 with rotation of 25, and 35 agenesis requiring extraction of 14244575.

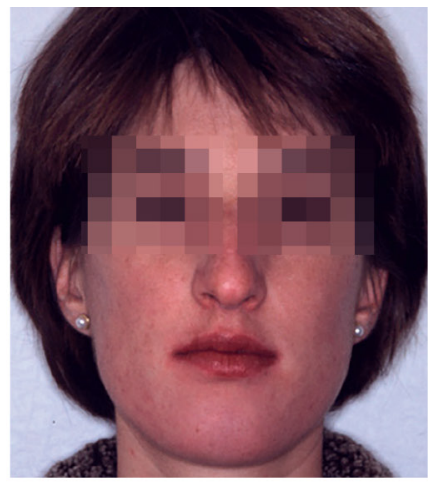

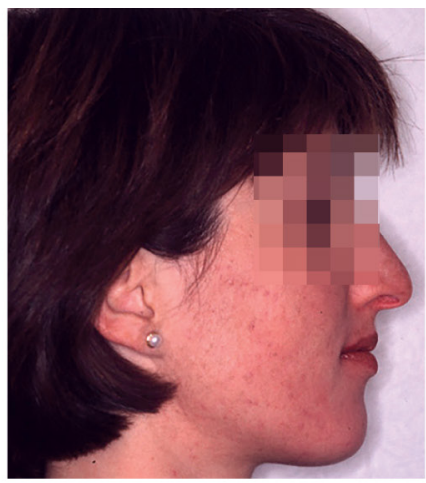

b

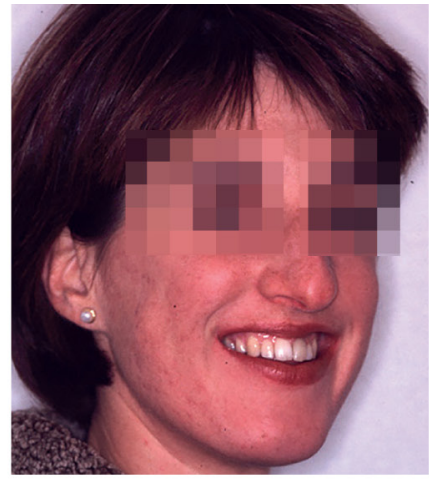

C

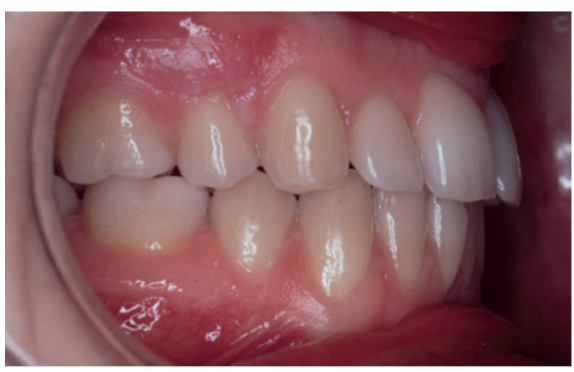

d

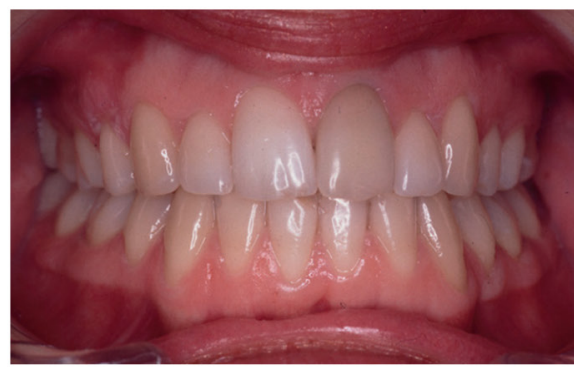

e

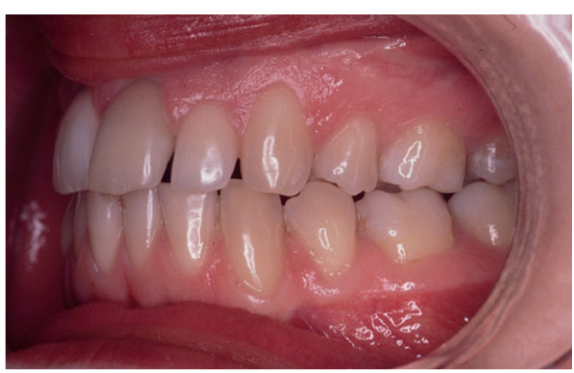

f

Figure 2a-f

End of treatment. Vertical control has improved chin position. 21 appears necrotic. No retention was applied. 


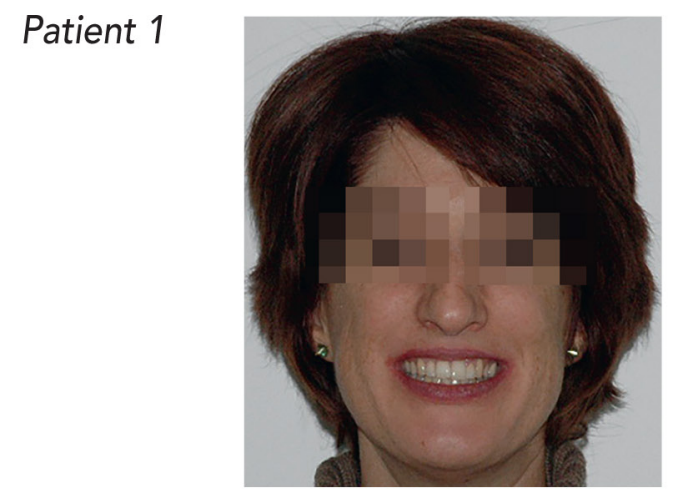

a

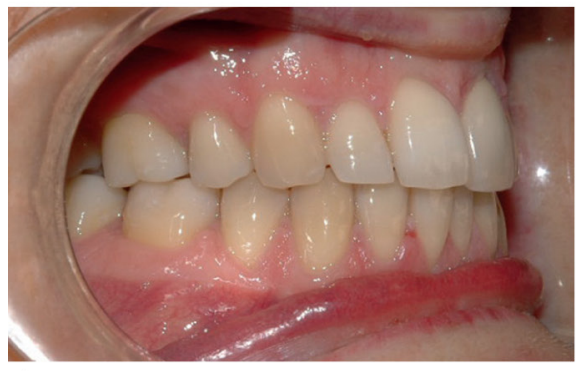

d

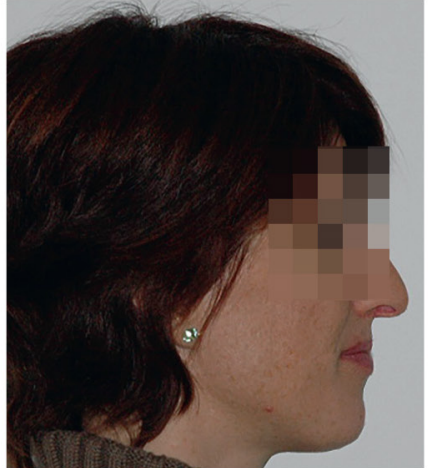

b

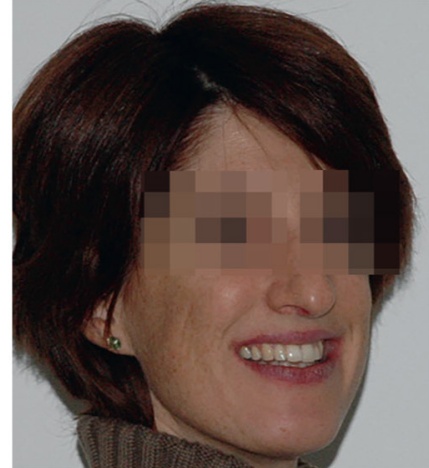

C

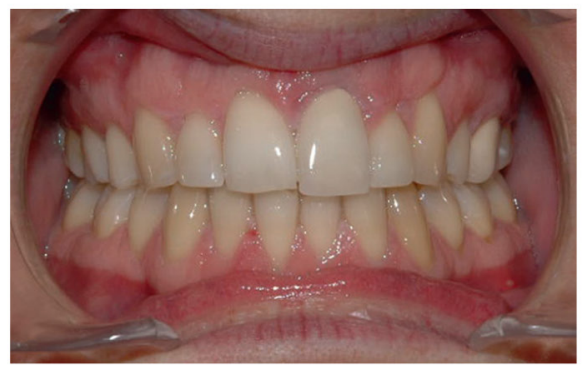

e

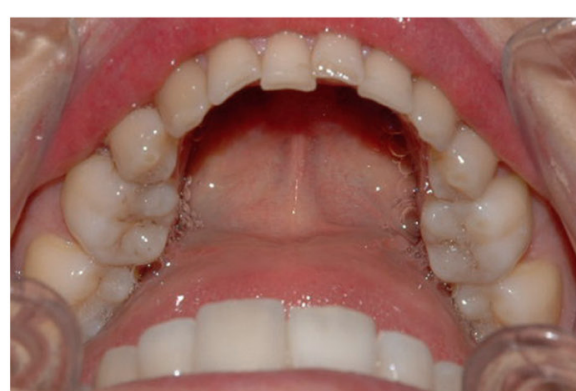

Figure 3a-g

Situation 22 years after end of treatment. Prosthesis on 21 and onset of slight inferior incisor malposition (reason for consultation).

Starting in the 1990s, we began almost systematically to use retainers, no doubt in view of the onset or recurrence of incisor malpositioning, which is always unacceptable to the patient and family, a neuromuscular environment that often failed to adapt to now normalized function, unhelpfully continuing growth, and certain persistent harmful habits, notably including labio-lingual dysfunction, atypical swallowing and oral respiration. We therefore thought best to stabilize the teeth while the tissues reorganized themselves, a period of facial change that can be very long and not always associated with excellent final occlusion. In our view, it is difficult to foresee functional balance between arcades and muscular 


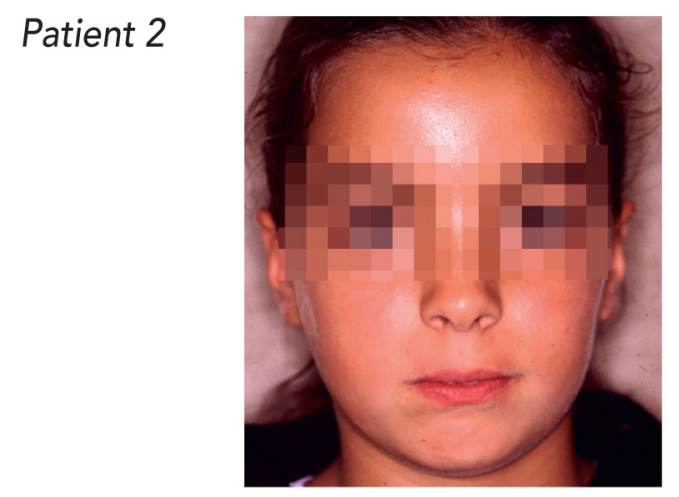

a

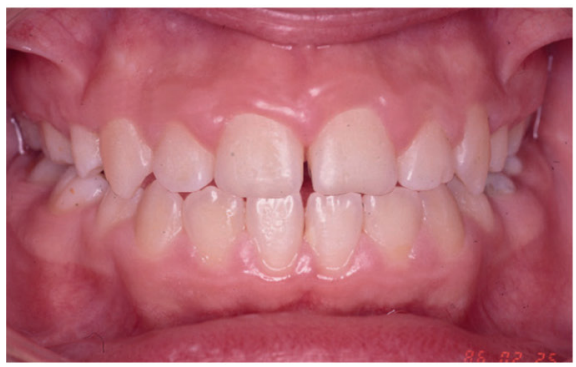

d

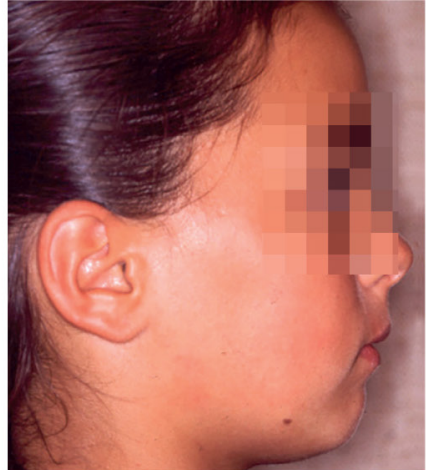

b

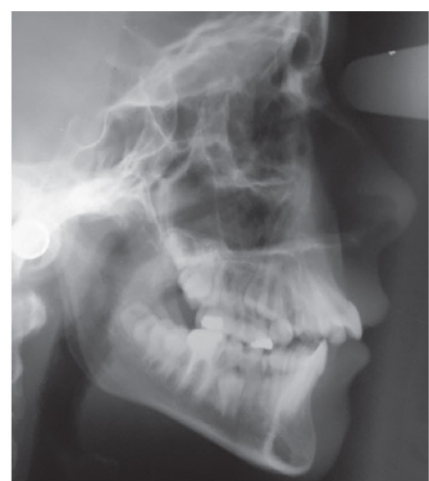

C

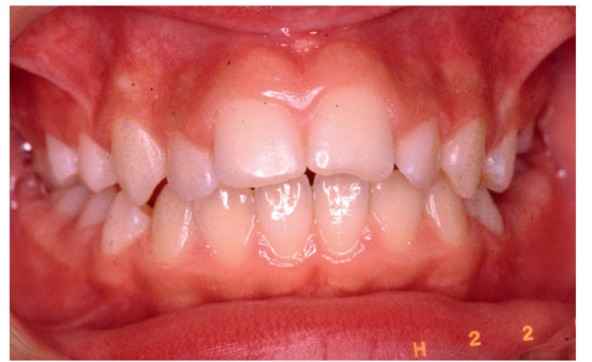

e

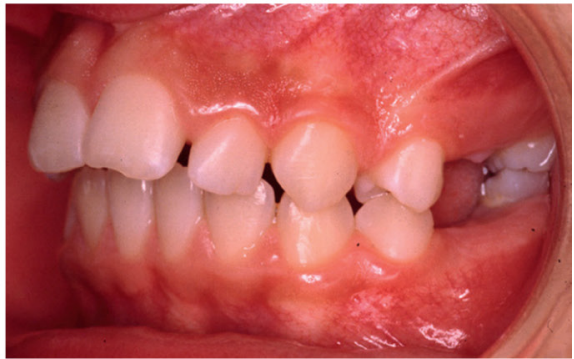

f

Figure 4a-f

Retrusive profile with lower-lip eversion and slight chin muscle contraction. Teleradiograph and intraoral photographs show class II, especially anteriorly.

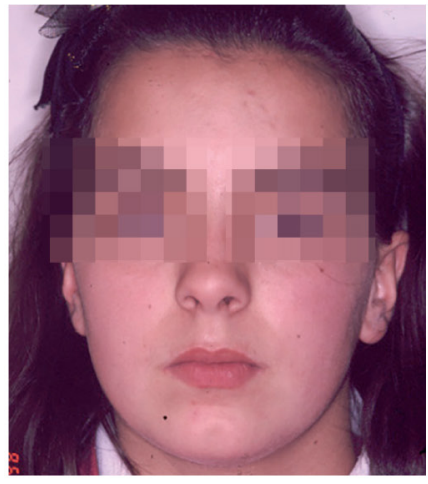

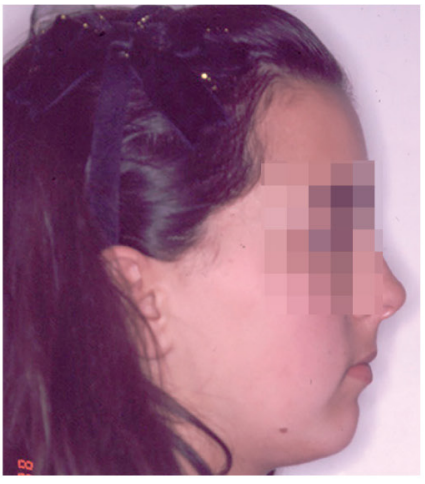

b

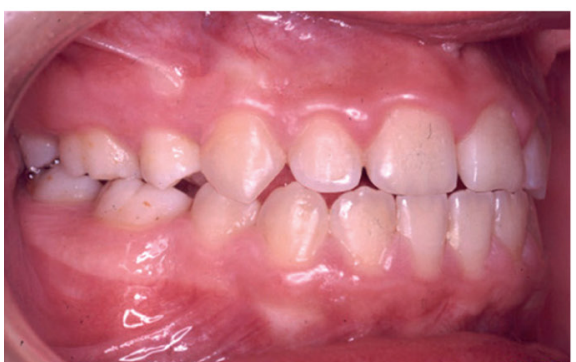

C

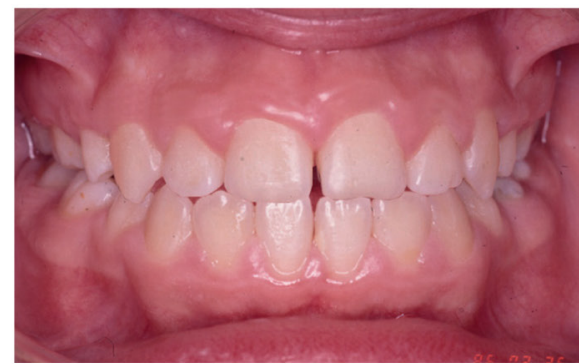

d

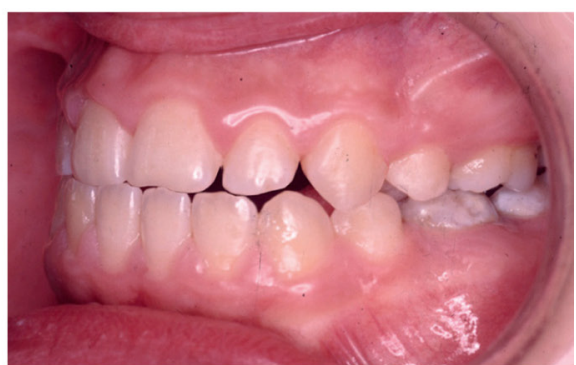

Figure 5a-e

After extraction of 142435 45, occlusal hypercorrection with lack of finishing. No retention was applied. 


\section{Patient 2}
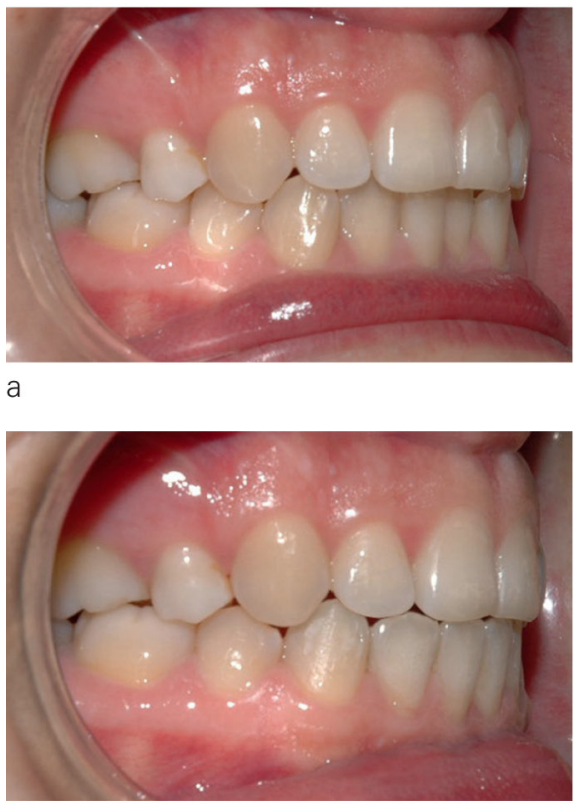

d

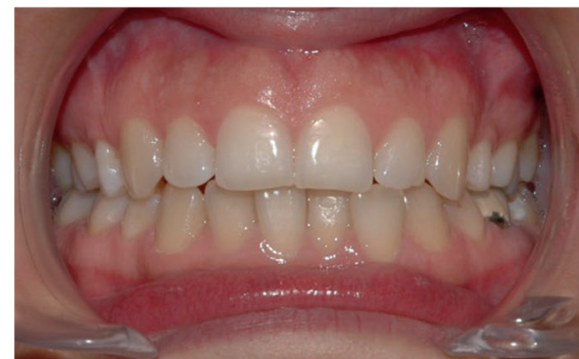

$b$

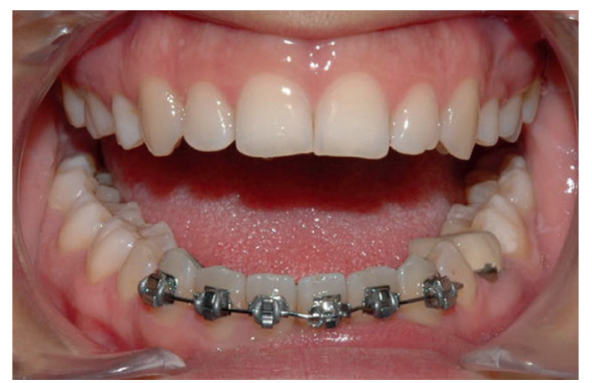

e

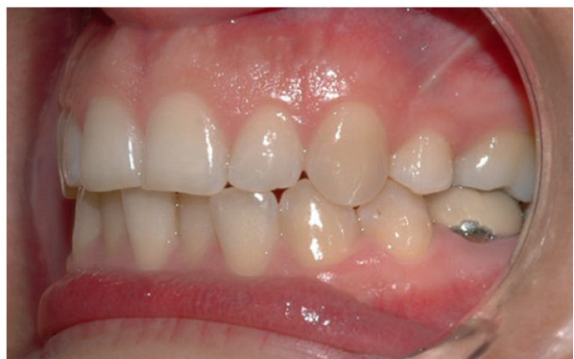

C

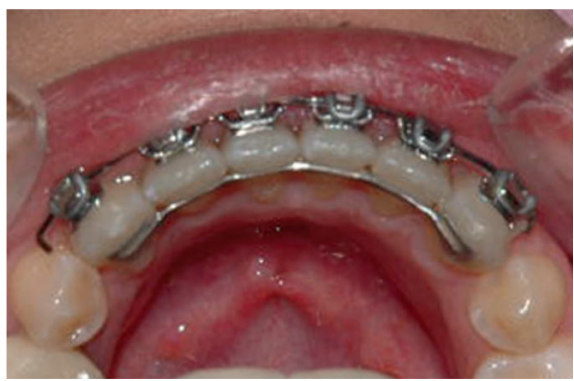

f

Figure 6a-f

Lateral occlusion was perfectly stable 17 years after end of treatment, but onset of inferior incisor malpositioning required realignment at the patient's request associated to very slight enamel reduction, followed by fixed 3/3 mandibular retention, exceptionally fixed to each tooth. The wisdom teeth are in the arcade.
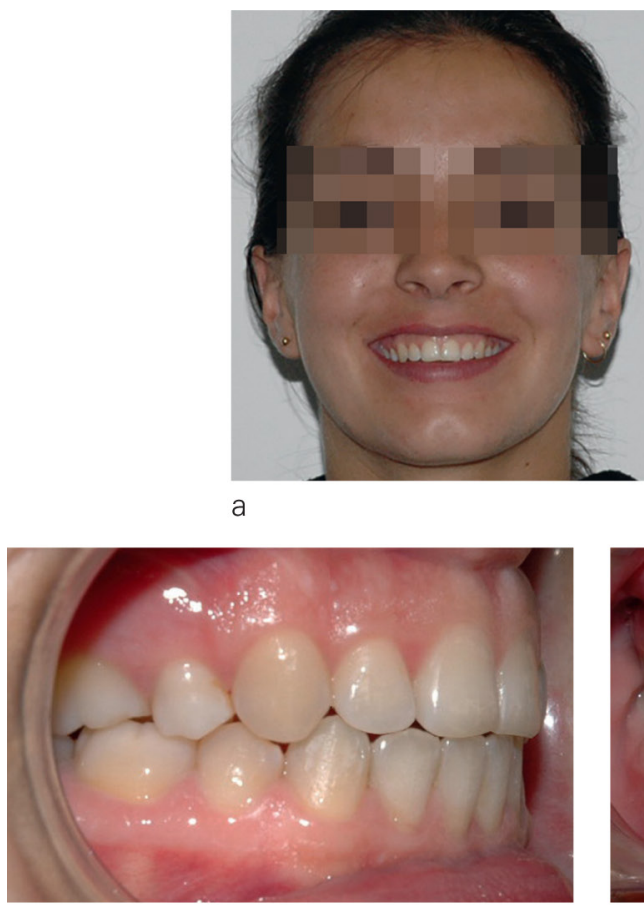

d

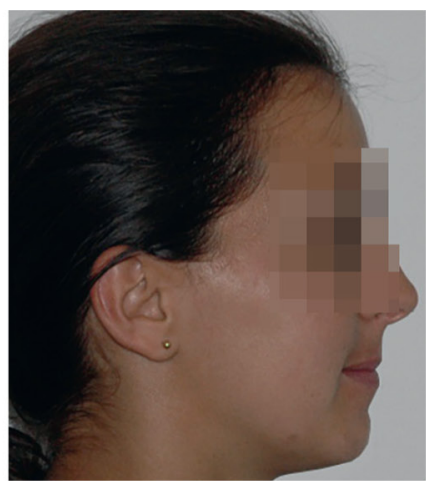

b

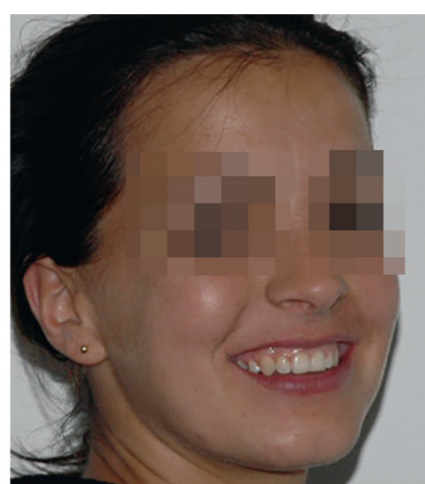

C

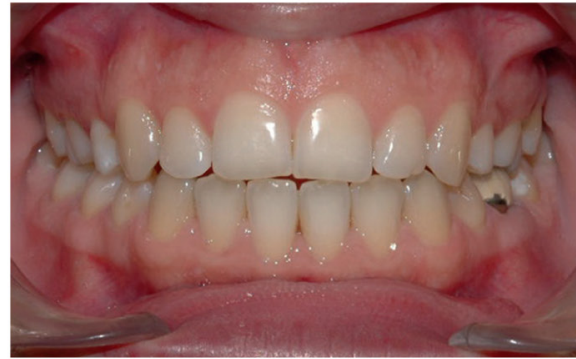

e

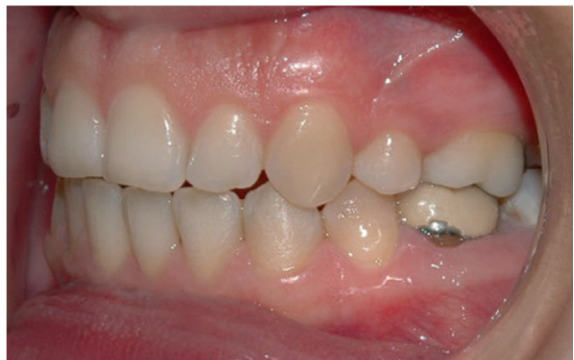

f

Figure 7a-f

Simple, quick realignment satisfied the patient. 
environment, with considerable lifelong alterations.

The literature bore out our posttreatment attitude: retention aims to maintain occlusion by stabilizing the teeth during tissue reorganization, but also to limit the impact of growth continuing after treatment.

The evidence is grim: many studies testify to recurrence of crowding in subjects who have undergone treatment ${ }^{3-4-5-8-10-15-31-33-37-45-47-52}$. New studies from Little's team ${ }^{32}$ reported 31 cases that had been perfectly well managed by the classic edgewise technique, with 4 extractions: 20 years after end of retention, only $10 \%$ still showed acceptable alignment; the authors recommended lifelong retention. In another study ${ }^{33}$, they found not only incisor malalignment 10 years after end of retention, but also reduced intercanine distance, and concluded that maintaining perfect mandibular incisor alignment was not in the realm of the possible ${ }^{34}$. In a later study of 78 cases of class II division 1 with good occlusion results, alignment was satisfactory in less than $50 \%$ of cases 14 years after end of retention ${ }^{3}$.

Boley $^{7}$, in over-30 year-old patients treated by scheduled extraction, found the same alterations after retention as did Little ${ }^{35}$, although stability was better. In other studies ${ }^{8-9}, 10$ years after retention he found slight crowding in $80 \%$ of cases.

According to Quaglio ${ }^{45}$, however, stability over time is better in superior than inferior incisors, as confirmed by another study of 52 female patients, at a mean 24 years after end of treatment ${ }^{15}$.

Most of the above authors also agree that, in non-treated subjects, crowding increases while perimeter, arcade length and intercanine distance decreases $^{2-7-8-25-33-35-37-54-55-56}$. Longitudinal studies showed that normal occlusion according to Angle usually progresses toward crowding in the long term ${ }^{12}$.

Other hypotheses highlight posttreatment onset of late mandibular incisor irregularity and crowding, corresponding more to continued growth than to relapse. Post-treatment bone modifications and growth can be considerable, up to adulthood, and play an important part in relapse $e^{4-8-43}$. Behrents $^{4}$ and Boley ${ }^{8}$ stressed softtissue changes and recommend continuing retention up to 30 years of age if possible, as did other authors ${ }^{37-51}$ who recommended systematic lifelong retention, which seems to us to be rather unrealistic, at least for treatment implemented in adolescence. Growth continues much longer in the mandible than in the maxilla, well after active treatment, so that anterior mandibular rotation may induce incisor straightening.

The resulting recurrence of closed bite leads to anteroinferior overlapping 4-8-10-25-43-54. Superior incisor palatal relief may be considerable, and the free edge of the inferior incisors tilts on the crests, inducing rotation ${ }^{56}$. As the maxillary incisors are thicker cervically than occlusally, increased anterior overbite pushes the mandibular incisor backward. In class II division 2 , the superior central incisors often have a particular coronal shape on the palatal side, probably from functional causes; the palatal side is often strongly concave, while the vestibular side shows very variable convexity, from flat to highly convex ${ }^{40}$.

Kohaut $^{26}$ suggested a different hypothesis: modern humans in an 
industrial environment use their teeth differently: the anterior teeth no longer serve as tools; the incisor tip-to-tip position is often used as a kind of pliers by primitive peoples, and this prehensile function, requiring mandibular advancement, no longer applies.

Thus, if closed bite and the resulting crowding have become the rule, this is due to the disappearance of the functional role of the anterior teeth in prehension and incision.

It is clear that mastication has been completely transformed these last decades. In infants, feeding bottles have replaced much more dynamic breast-feeding, and in children and teens the food served at home has gotten softer, exercising teeth and muscles much less.

One cause of crowding is mesial drift due to alveolar apposition and resorption remodeling, with tension shifting anteriorly ${ }^{12-43}$. The centripetal shift in the dental system characteristic of humans derives from the development of muscular balance: as muscular tonus matures, the lips lower, exerting pressure on the incisor edges, pressure increases on the teeth as the fatty mass of the tongue decreases. These changes begin during mixed dentition, with very gradual predominance of the outer functional envelope. According to Cretot ${ }^{11}$, the incisors descend during growth and dr aw back during aging: the incisor profile evolves centripetally. The weakening of alveolar support with aging means that lip tonus overcomes lingual resistance and the interincisor angle flattens with advancing age.

Head statics may also be disturbed. It changes over life and especially in old age, inevitably impacting facial envelope position and behavior. Moreover, the nose keeps getting longer and the tip drops throughout life (Patient 3, figs 8a to 9f (start and end of treatment) and fig. 10a-f (longterm follow-up)).

It is generally agreed that perioral muscle function is implicated in malocclusion and stability of out-

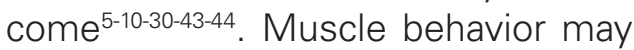
be affected by morphological change, onset or resolution of pathology such as bruxism, or abnormal tongue volume or tonsillar hypertrophy forcing the tongue forward with phonation disorder.

Suction disorder, abnormal swallowing with lingual interposition, and lip non-occlusion due to orbicular weakness or short lips enter into diagnosis and should be detected at the first consultation, to improve prognosis. Changing tooth position and arcade architecture in the hope that underlying function will spontaneously normalize may lead to relapse.

We have an essential role to play in resolving such abnormalities ahead of treatment. If oral breathing is detected, we always recommend specialist consultation to rule out any anatomic cause if need be, so as to "clear up" the muscular environment. Treatment may be associated, to raise the patient's awareness and to normalize impaired function more quickly with physiotherapy exercises, and rehabilitation of the tongue and labial muscles (fig. 43a-b).

In our opinion, neuromuscular development is a prime issue, especially as soft-tissue behavior changes with time and the results of 
functional rehabilitation are unreliable in the long term. The teenage face changes with the passing years, and facial expression changes, changing muscle function.

While muscle action may progressively change during treatment and as spatial organization changes around the arcades, with resolution of malocclusion, the desired behavioral change may not happen, despite the patient's best efforts; this is, for example, frequent for nocturnal tongue pressure (Patient 4, figs 11a to $12 \mathrm{f}$ (start and end of treatment) and fig. 13a-g (long-term follow-up)).

Such movement of the teeth cannot be considered simply as relapse, but rather as a natural progression under changing neuromuscular balance with aging. Our organism changes constantly from birth, and later declines. New functions appear, others change then disappear. Teguments, bones and hair change. The media are forever showing us perfect faces, but also changes over time in the faces of actors, singers and other celebrities. It seems to us to be inevitable that the teeth, which lie right inside this strategic crossroads formed by the bones, muscles and skin, should undergo change over time, which need not be a problem if the architectural occlusal construction set up by the orthodontist remains stable.

Recurrent crowding, impairing the satisfactory result seen after retention, seems more or less inevitable and has to be accepted ${ }^{5}$. In conclusion, all these results converge and were summed up by Boese ${ }^{6}$ : whatever the type of treatment, the length and width of the arcade and intercanine distance diminish with time; in- cisor crowding increases in the period following retention, however long; adhering to cephalometric norms does not guarantee their stability; no predictive factors help the clinician to find a procedure ensuring long-term stability of results.

Individual mandibular malpositioning was found to have a strong tendency to relapse, and we therefore maintain long-term mandibular retention, at least until the wisdom teeth begin to progress, if indeed they are able to; growth can then be considered more or less finished. So long as the patient is not bothered by the mandibular retention, and its benefits have been explained, we advise keeping it as long as possible, without intending it to be lifelong.

The possibility of individual variations after treatment should be mentioned to the patient and parents preventively and, if they occur, be objectively assessed in their initial context.

Patient and family need to understand the limits of our treatments and the patient's own role in maintaining results ${ }^{37}$. The orthodontist should not use the above arguments, however realistic they may be, as an easy way out, an excuse for the results or as a reason for deviating from treatment objectives.

Having said all this, the quality of cusp intermeshing remains the natural system of retention: no device can make up for a poor occlusal result. Lax objectives lead to imperfections, which are the main source of relapse ${ }^{13-27}$. Unrealistic objectives and "hype" on the part of the orthodontist lead to unrealistic attitudes and 


\section{Patient 3}
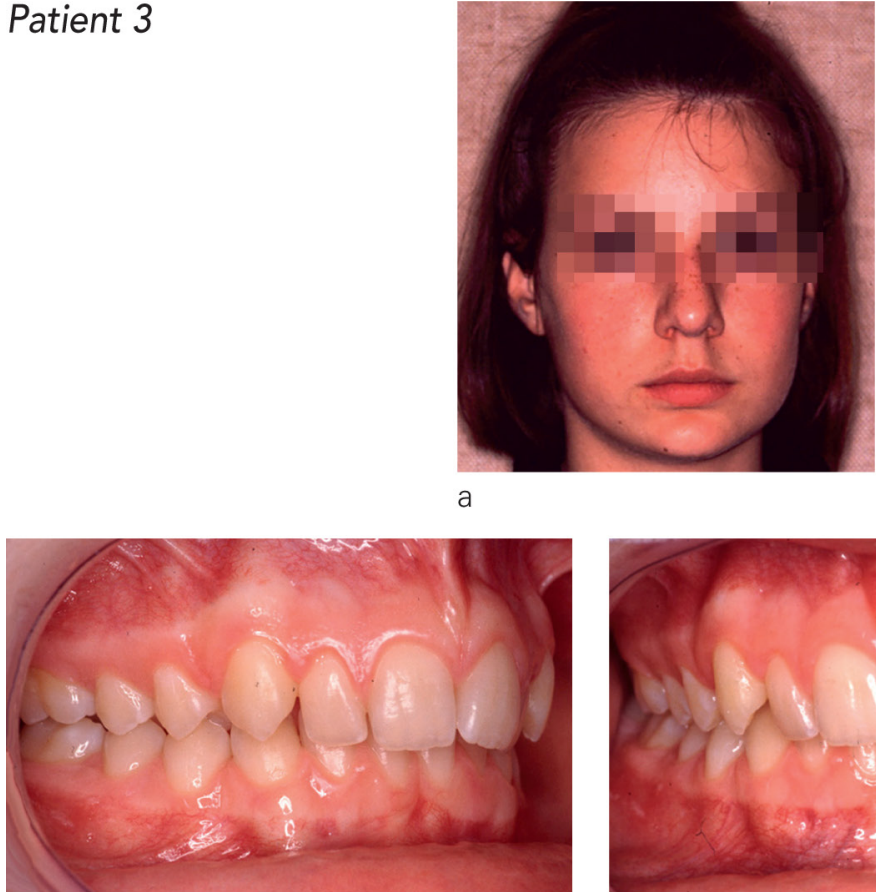

C

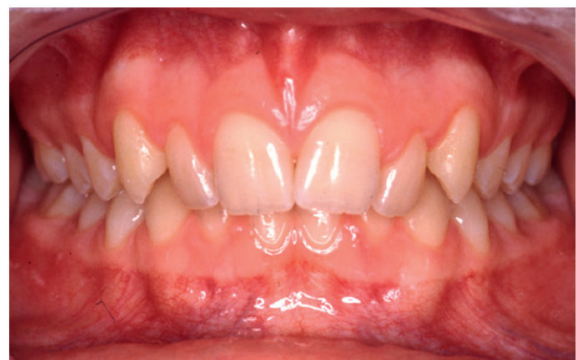

d

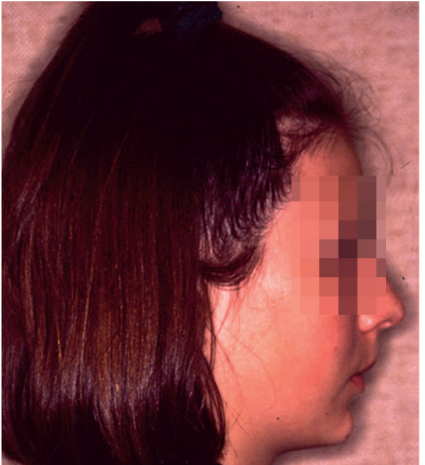

b

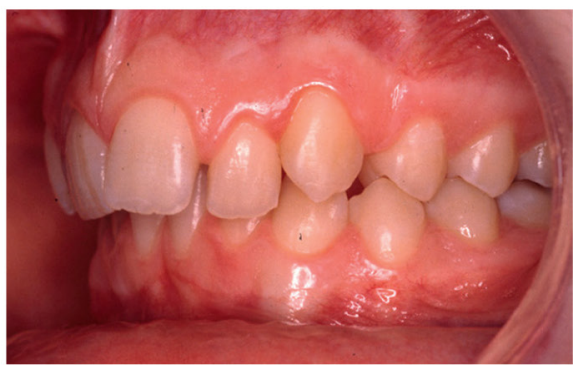

e

Figure 8a-e

Lateral view: straight upper lip, retrusive mandible attenuated by progenia. Intraoral views show class I/ division 1 with closed bite.
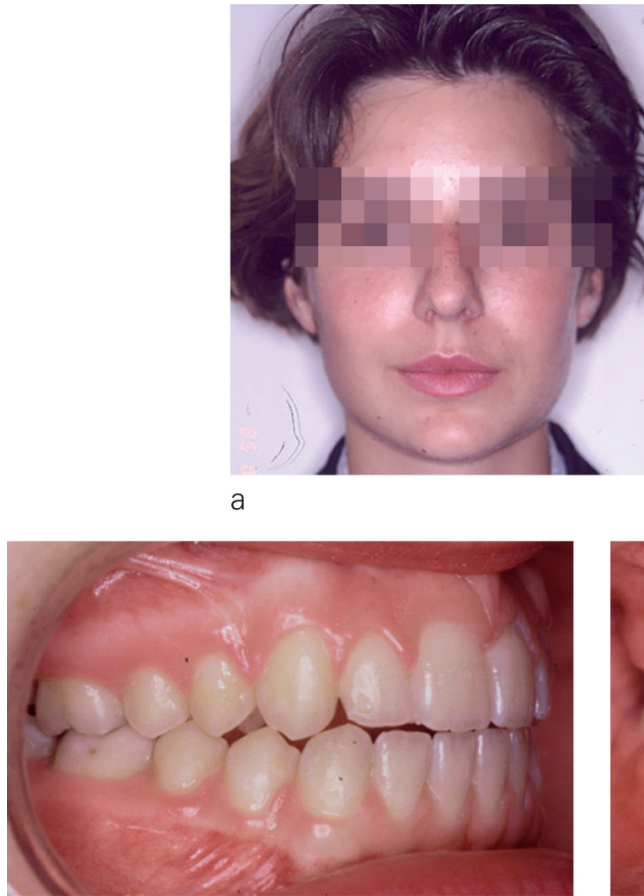

d

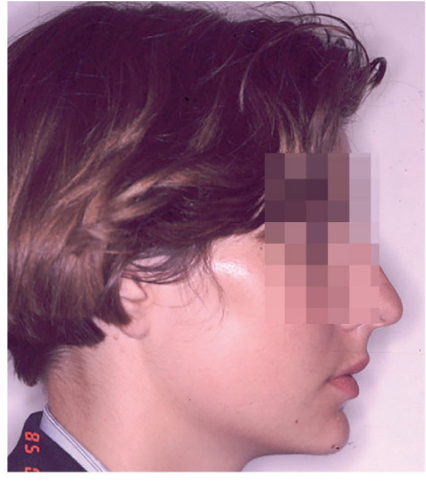

b

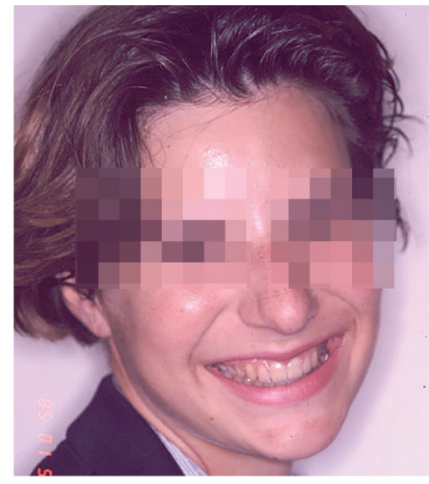

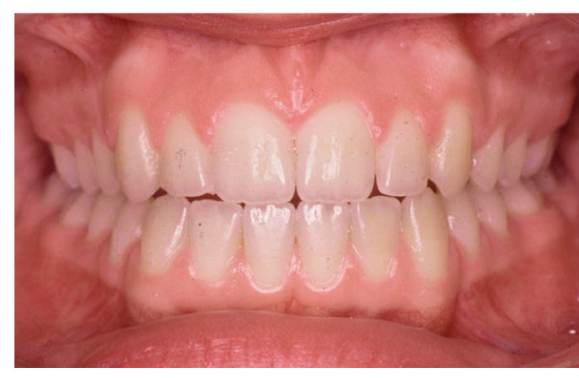

Figure 9a- $f$

Harmonious face; chin jutting but well positioned. Occlusion hypercorrected anteriorly. Retention by Hawley plate and mandibular 3/3. 
Patient 3

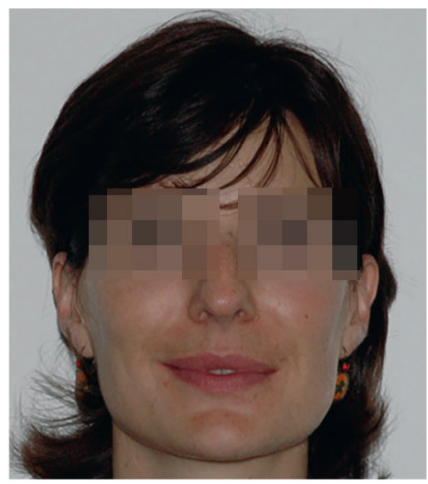

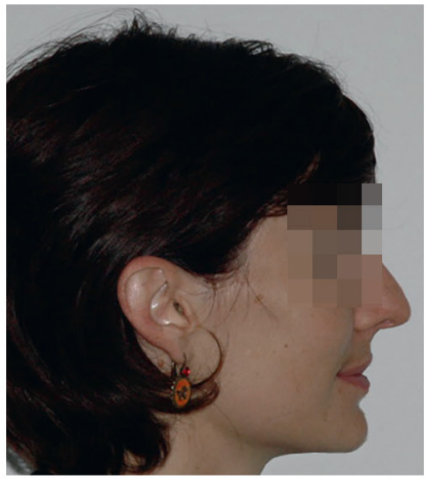

b

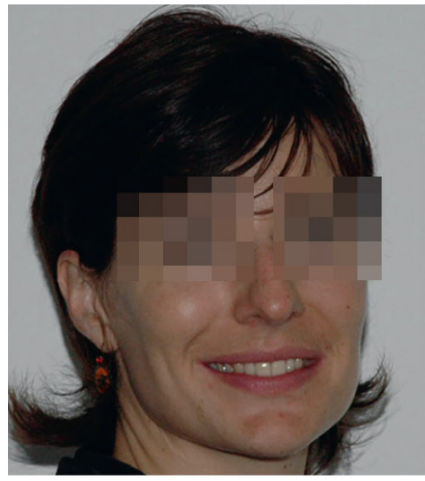

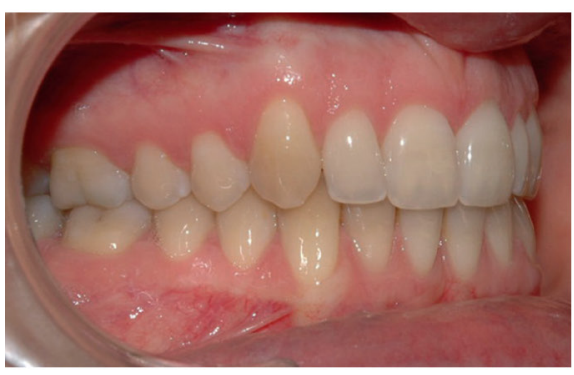

d

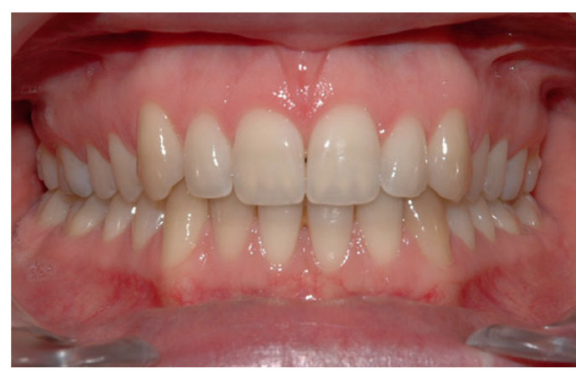

e

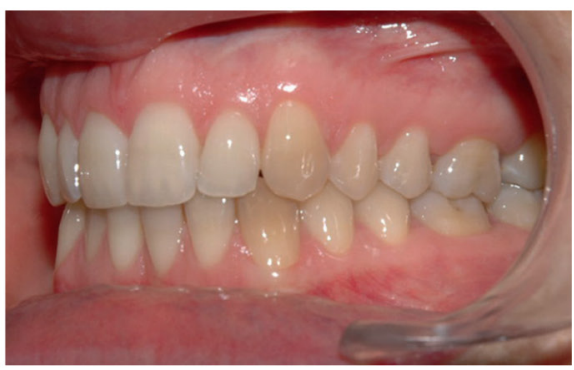

f

Figure 10a-f

Just over 16 years after end of treatment, labio-mental profile remains harmonious, but with pointed tip of the nose, even though treatment involved no extraction.

expectations on the part of the patient.

It is essential to have precise, individualized objectives that are fully integrated in the treatment strategy, and finishing of appropriate quality to prevent lesions, restore "normality" and achieve occlusion that is not only static but above all dynamic and functional so as to ensure stability.

The specifically dental objectives of occlusal reconstruction should be associated to objectives for skeletal reharmonization, reducing anteroposterior offset and controlling the vertical dimension so as to achieve esthetic objectives and facial reharmonization.
* The dental and occlusal objectives aim not only at perfect alignment (the patient's main concern), rotation correction (we have never performed fibrotomy on supra-alveolar desmodontal fibers) and resolution of all interarcade problems such as axis parallelism and space closure in non-extractive treatment, but also and above all interarcade problems by restoring class / static canine and molar occlusion.

Deep and well-intermeshing intercuspation, with long and deep cusps (fig. 14a-b) and excellent interarcade coordination, have a positive impact on the quality and stability of meshing. in the posterior area and 


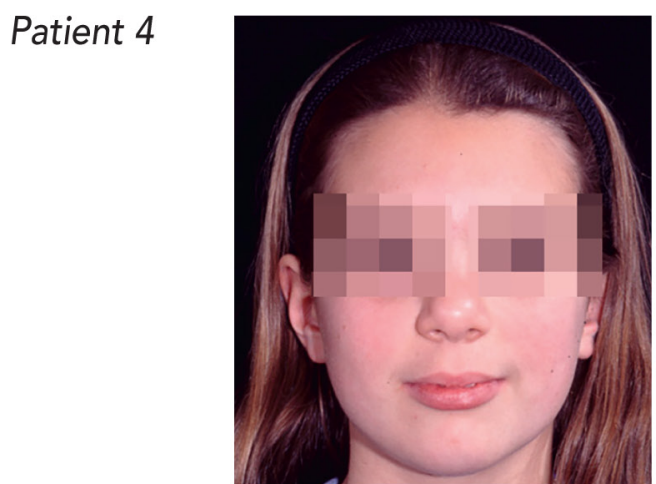

a

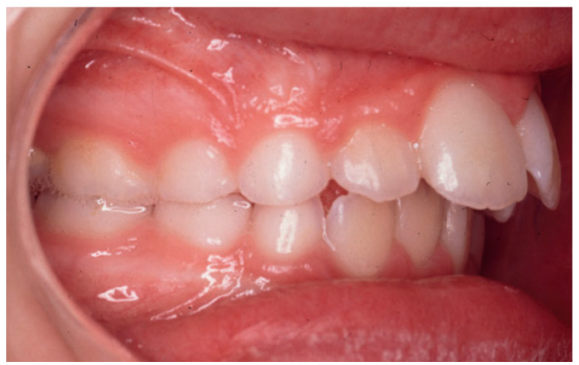

d

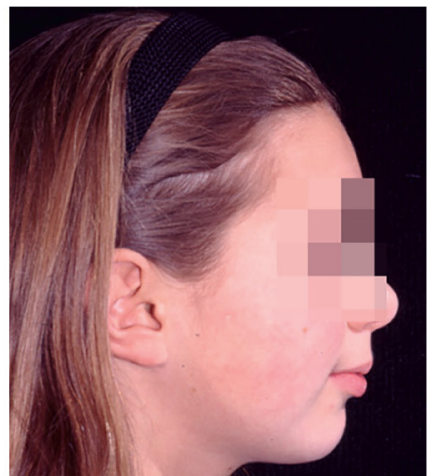

b

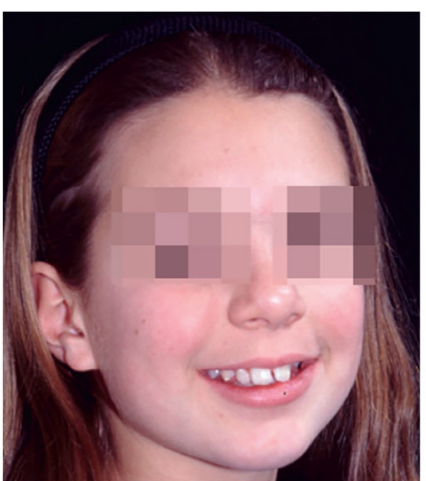

C

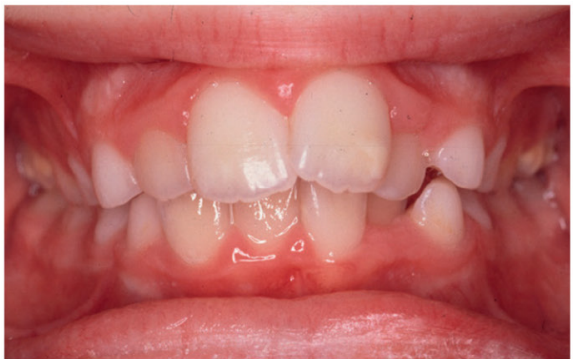

e

Figure 11a-f

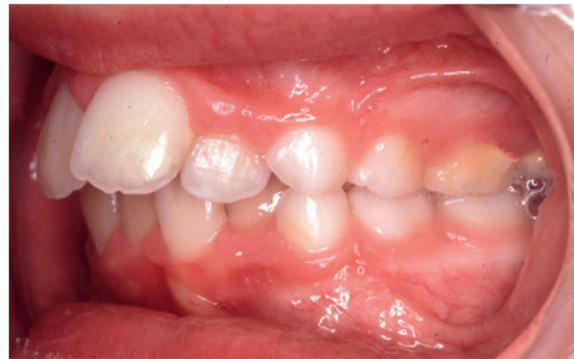

f

Class II division 1 with malpositioning. Awaiting progression of permanent teeth and after complete diagnosis, scheduled extraction was planned. A little later, just before fitting devices, a straight upper lip and retrusive mandible can be seen. Lower lip eversion, providing good labial contact, is due to interarcade offset.
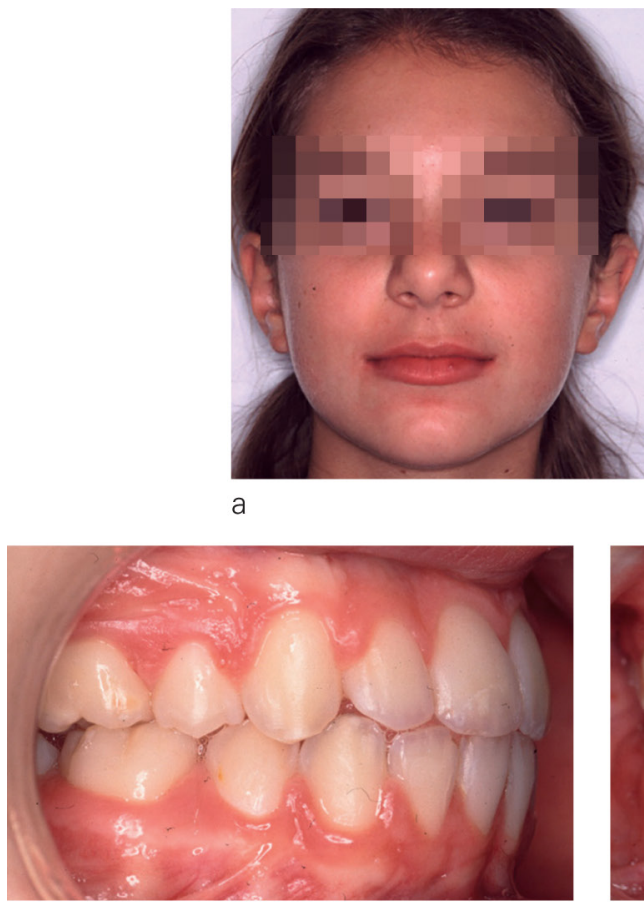

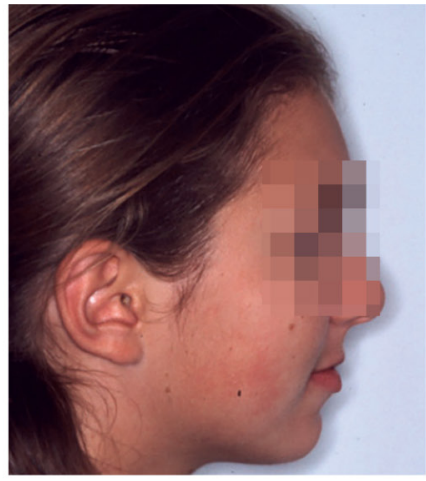

b

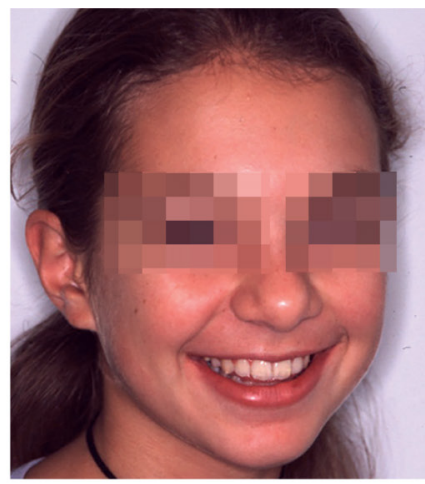

C

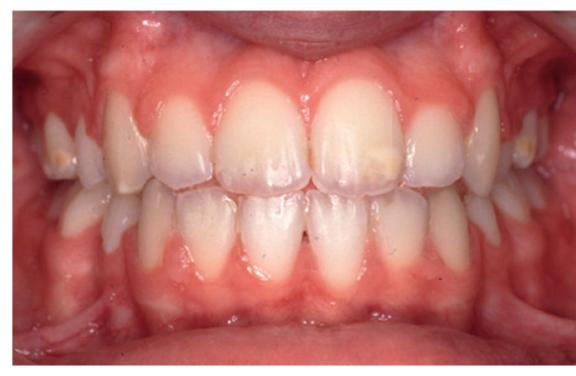

e

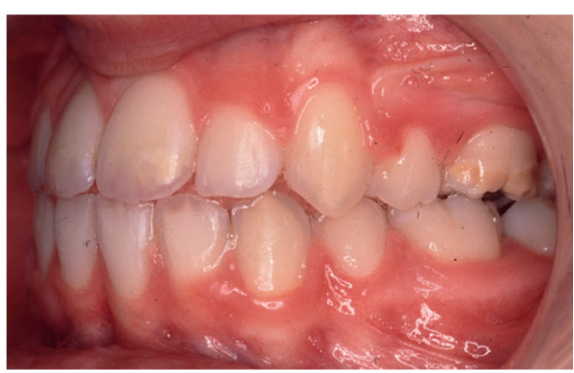

$f$

Figure 12a-f

After extraction of 142435 45, facial balance is improved; anterior occlusion is hypercorrected, with the premolars ensuring good occlusion. 
Patient 4
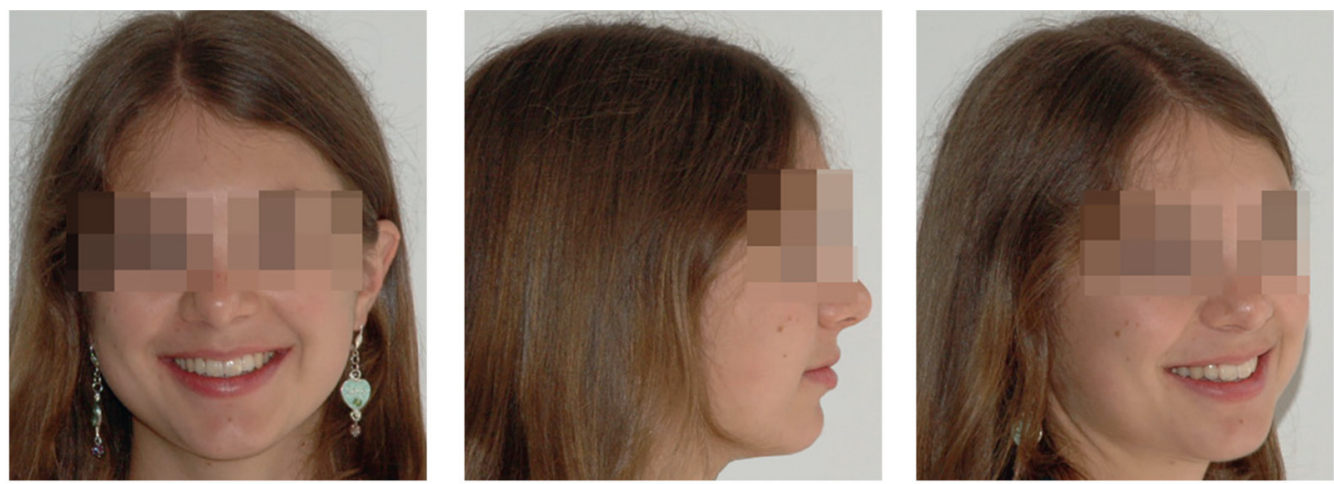

b

C
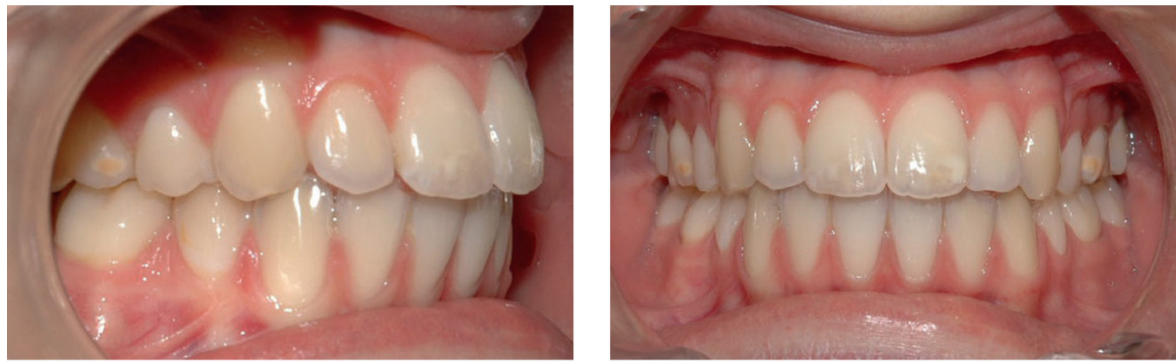

e

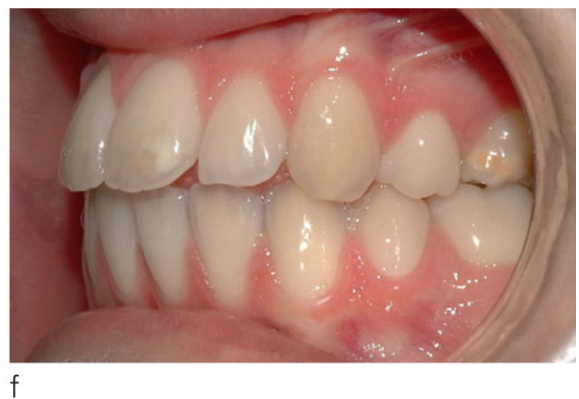

d

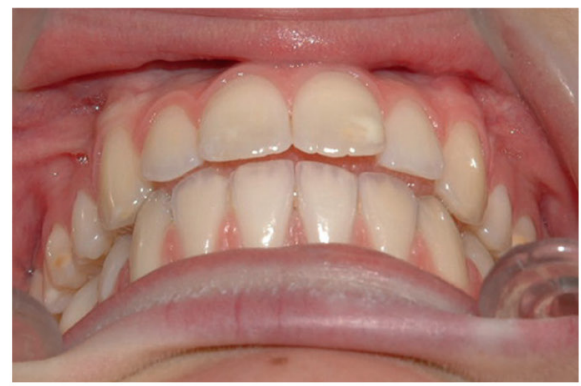

g

Figure 13a-g

5 years after end of treatment, the face is pleasant and occlusion is stable. However, tongue position and nocturnal tongue pressure may lead to slight anterior relapse in time. Mandibular 3/3 remains, awaiting wisdom tooth progression. Better first-order curve control would have avoided the slight lateral incisor offset by excessive "inset", although this did not bother the patient, not being visible.

in molds, the vertical and transverse match between maxillary lingual molar cusps and mandibular vestibular molar cusps should be checked (figs 15 a to $16 \mathrm{c})$.

In treatments requiring intermaxillary elastic bands (especially class II division 1), specific surveillance should be continued so as not to settle for misleadingly convenient occlusion.

Restoring static class I occlusion needs to be completed by examination of mandibular function and movement, so as to be dynamic. Balanced prefunctional occlusion should be obtained without posterior contact in propulsion 
by immediate posterior disocclusion, and without contact on the non-working side in lateral movement. It is reproducible, enabling individualization of the patient's occlusion according to individual functional determinants ${ }^{21-23}$. It can evolve: what is called "recovery" is the restoration of functional occlusion on the basis of therapeutic occlusion, as seen in the cases reported here. Mandibular movement contributes to arcade stability; at end of treatment, it should be checked that these movements are easy and symmetrical.

Retention is thus a period of functional education or rehabilitation26 [Patient 5, figs 17a to 18k (start and end of treatment), fig. 19a-e (mandibular functional kinematics) and fig. 20a-j (long-term follow-up)].

To meet these occlusion objectives, we always sought Tweed-type therapeutic occlusion, with anterior hypercorrection and posterior disclusion, facilitating interarcade sliding (figs 21 a to 24c). Hypercorrection anticipates inevitable relapse and should be considerable in initial class II and especially class III. As desirable as it may be to standardize general mechanical procedures so as to be reproducible, it is indispensable to individualize arch production according to pathology and typology using a nonpreformed technique (fig. 13c)..

First-order curves determine arcade form, so enough canine convexity should be left to allow some mandibular "play"; second-order curves provide necessary vertical control, and third-order curves control the axial position of the incisors, which is fundamental in class II division 2.

In hyperdivergence with anterior open bite, overbite should be greater than the ideal $2 \mathrm{~mm}$, with maxillary incisors relatively vertical. Artistic bends are not too pronounced, as the roots are not very convergent19 (Patient 6, figs. 25a to 26g (start and end of treatment) and fig. 27a-f (longterm follow-up).

In contrast, in hypodivergence with cross-bite, vertical tip-to-tip contact is sought and torque and artistic bends are pronounced ${ }^{19}$. Stability depends on anterior finishing, entirely dependent on control of superior incisor torque and functional positioning of the inferior incisor40. Hypercorrection of closed bite is probably useful clinically, as most relapse is postretention ${ }^{25}$. Retention must be fixed on the mandible, maintained over the long term and associated with awareness of the neuromuscular environment ${ }^{40}$ (Patient 7, figs 28a to $29 \mathrm{~g}$ (start and end of treatment), fig. 30a-f (long-term follow-up)).

\section{* Leveling the Spee curve}

This sagittal arcade curve is architecturally fundamental to the face and one of the intra-arcade components of the abnormalities seen, reflecting one of the underlying pathologies. In most situations, we try to eliminate it temporarily, as it will reappear with recovery during retention, depending on the patient's individual parameters. Leveling the Spee curve should be associated to arcade symmetrization (figs. 31a to 32h).

Spee curves are generally considered to be expressed in the medial area, where they are measured in most reports. Theymay, however, be expressed in any area, anterior, medial or posterior. We have to solve it appropriately, treating all teeth, including of course the second molars, 


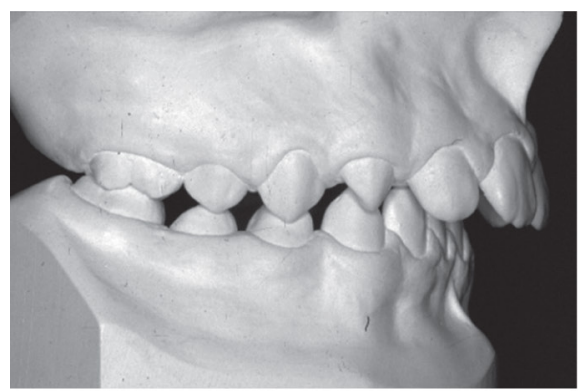

a

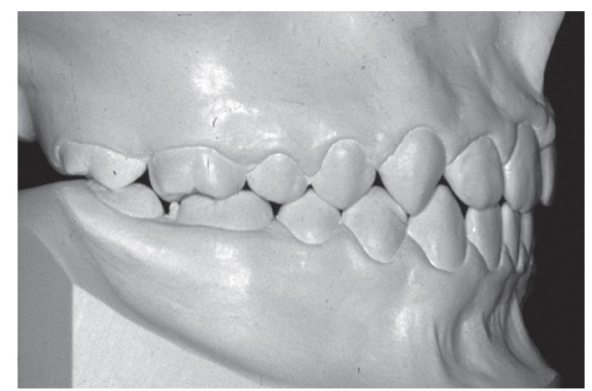

b

Figure $14 a-b$

Severe class II division 1 before treatment and after 1 year's retention. Strong cuspation enhances occlusal stability.

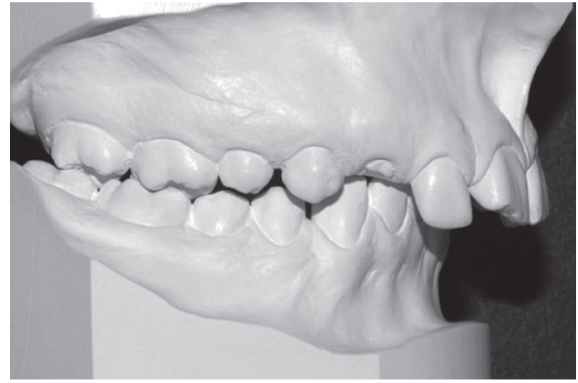

a

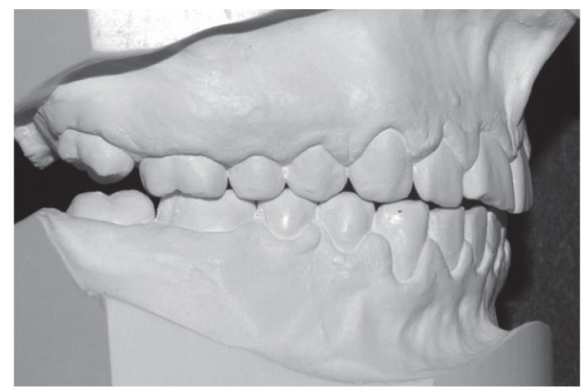

b

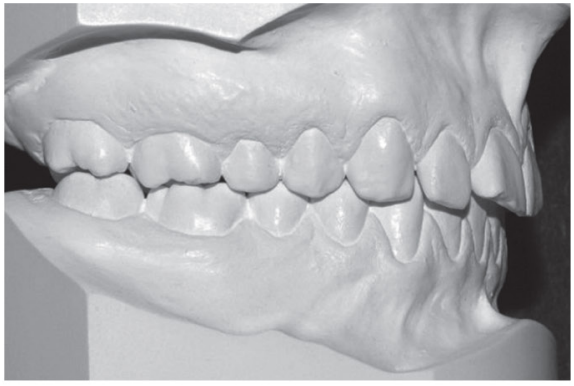

C

Figure $15 a-c$

Severe class I/ division 1 before and after treatment and after retention. Posterior molar disocclusion and anterior hypercorrection at end of treatment; 1 year later, spontaneous recovery of second molar occlusal contact and incisor overbite.

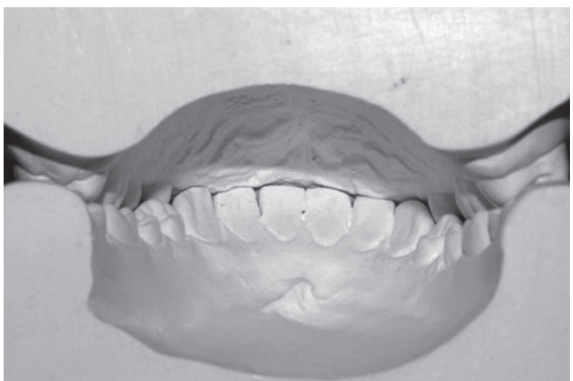

a

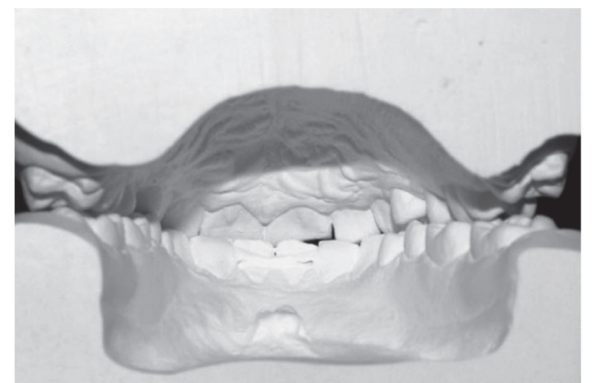

b

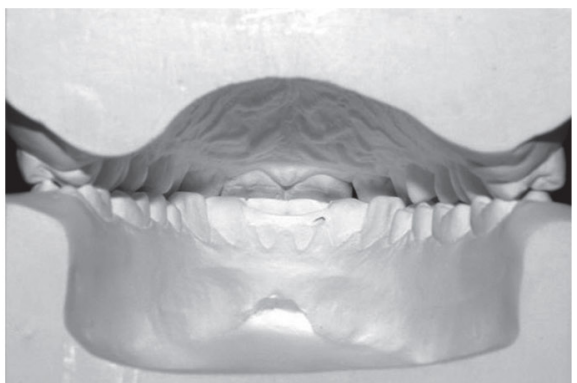

C

Figure 16a-c

Posterior views of same molds at 3 stages, showing transverse and vertical maxillary palatal and corresponding mandibular vestibular molar cusp relations. Natural progressive recovery toward normal occlusion. 
and avoiding parasitic effects, especially anteriorly. The Spee curve is fundamental to analysis of the medial area, but not exclusively 38 (figs 33 a to 35b). Leveling should be performed in the appropriate part of the arcade and be individualized in analysis and treatment, to conserver dentition limits and meet objectives.
* Occlusion key on 5, seeking contact between the superior second premolar vestibular cusp and the gap between inferior first and second premolar vestibular cusps (fig. 18e-f).

* Respecting anteroposterior dimension

In the anterior area, the objective is functional incisor positioning. The key

\section{Patient 5}

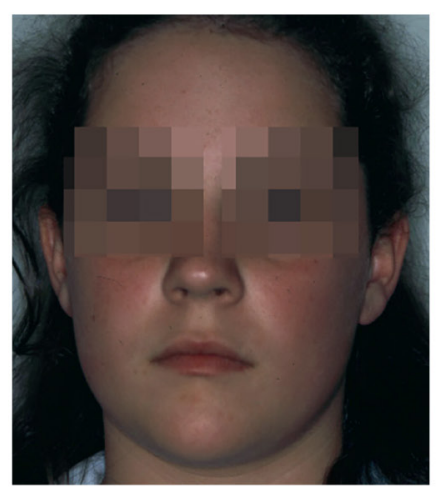

a

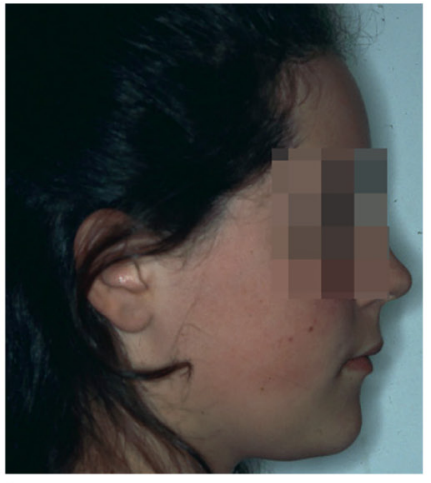

b

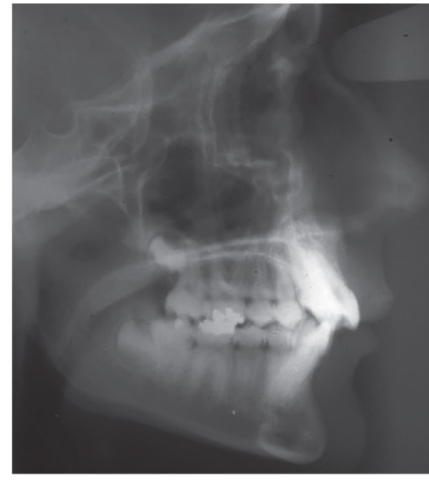

C

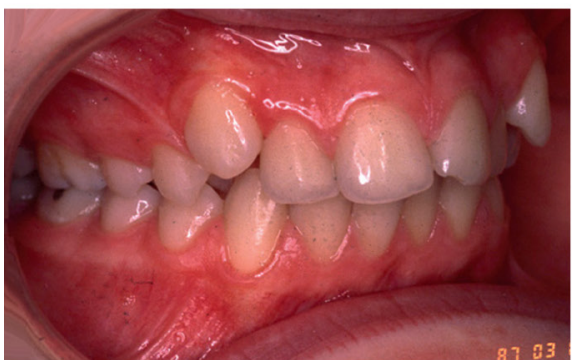

d

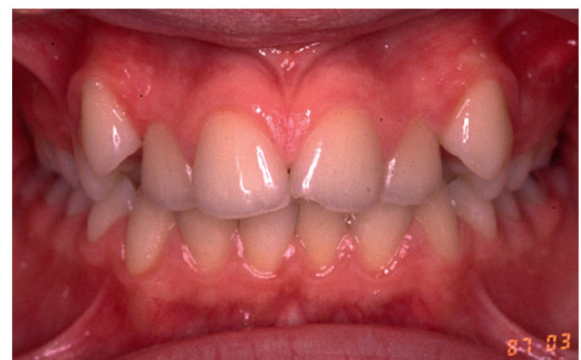

e

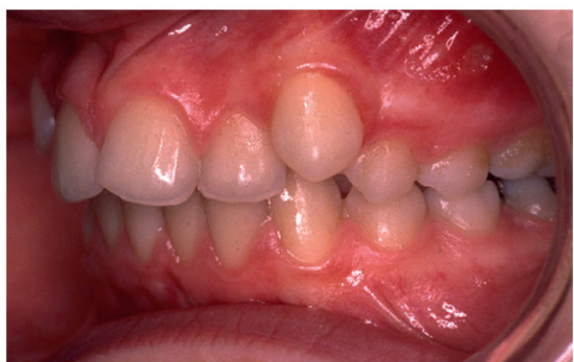

f

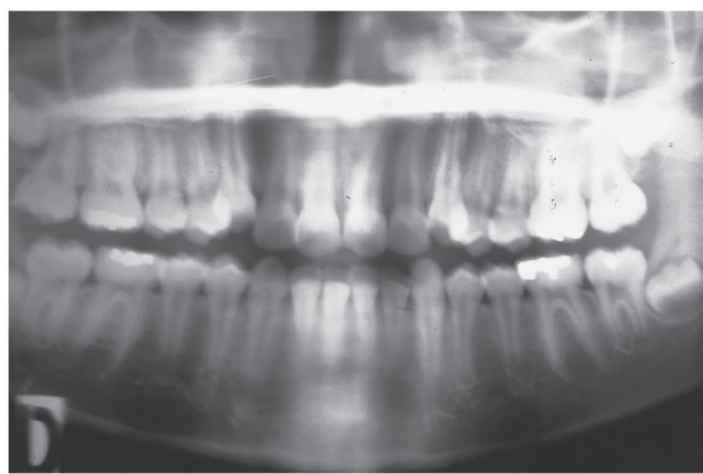

g

Figure 17a-g

Notable class I/ division 1 with bilabioversion, canine ectopia, and slightly retrusive mandible. Severe posterior crowding on radiographs. 


\section{Patient 5}

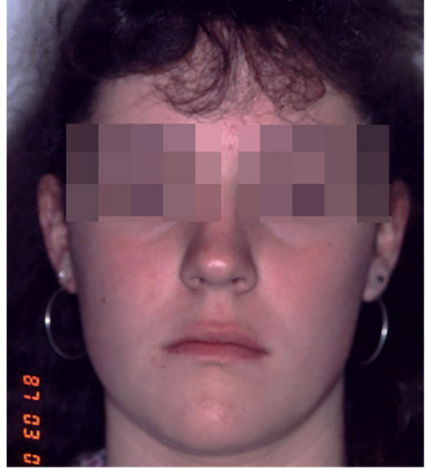

a

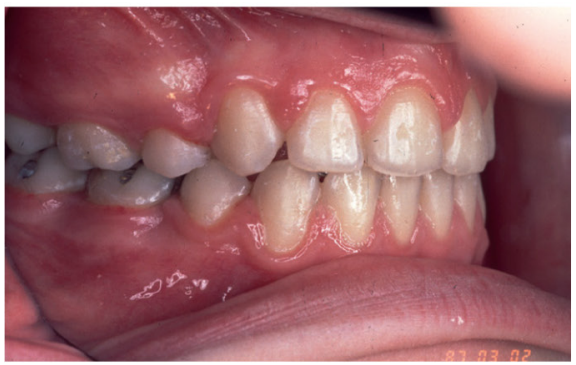

e

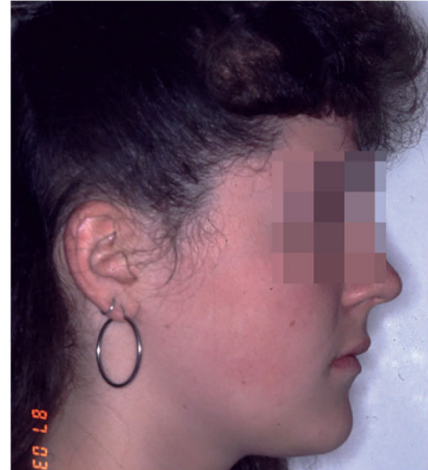

b

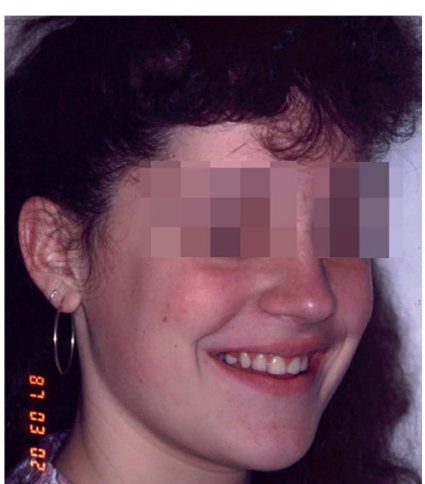

c

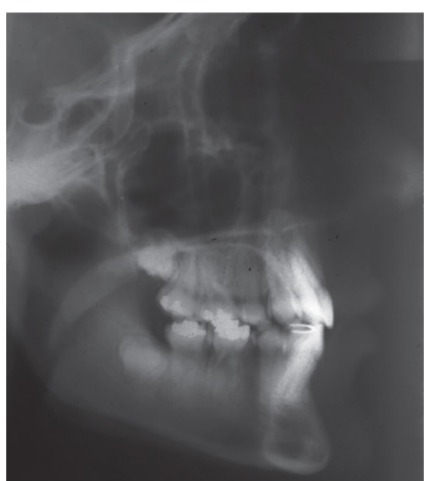

d
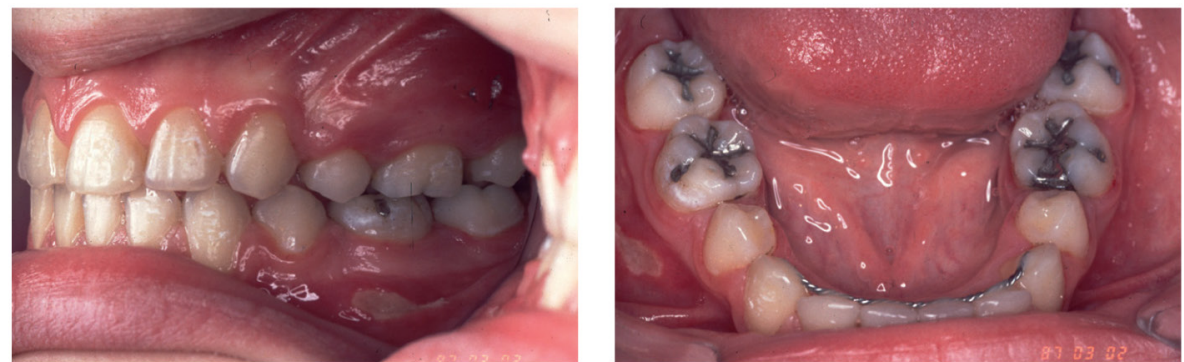

g

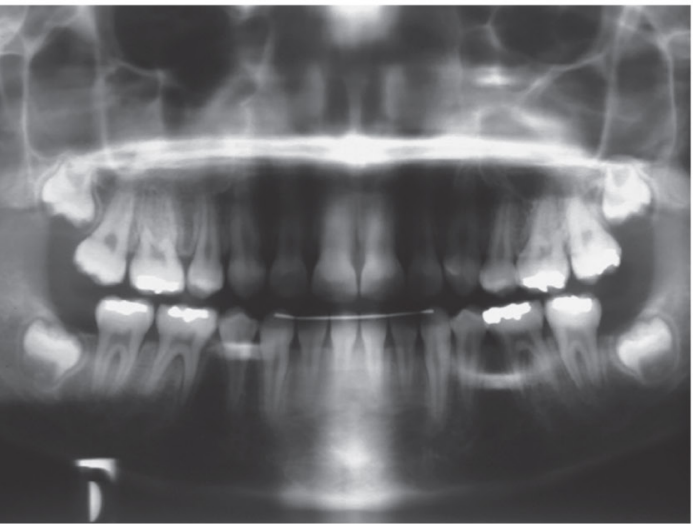

h

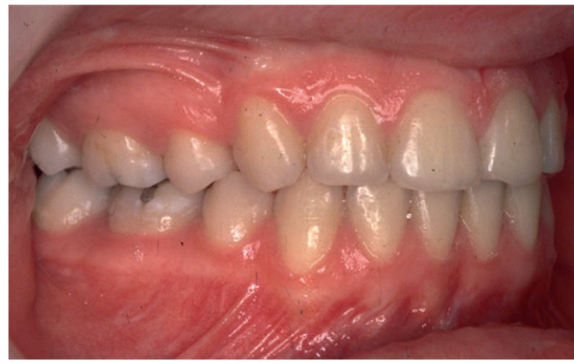

i

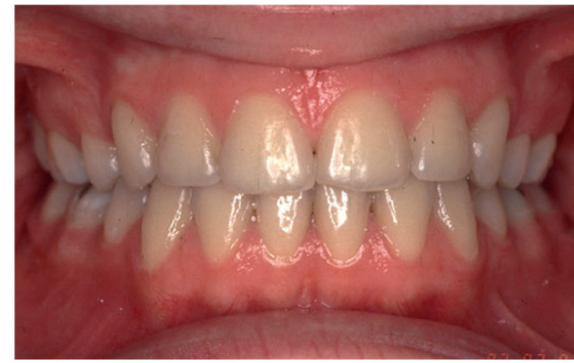

j

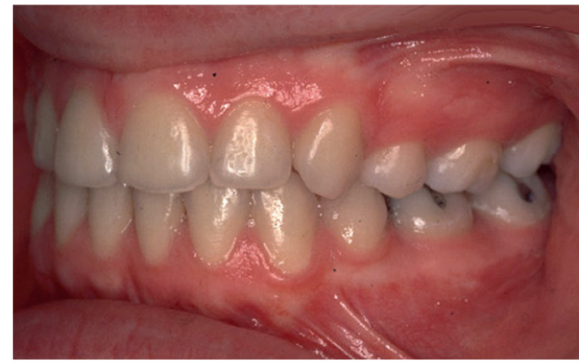

k

Figure 18a-k

End of treatment after extraction of 142435 45: anterior hypercorrection, slight molar disclusion, Occlusion key on 5. Extractions freed posterior space. Retention by mandibular 3/3 twisted wire and maxillary Hawley plate. 


\section{Patient 5}

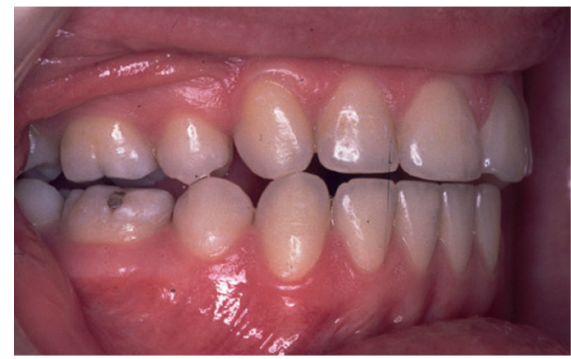

a

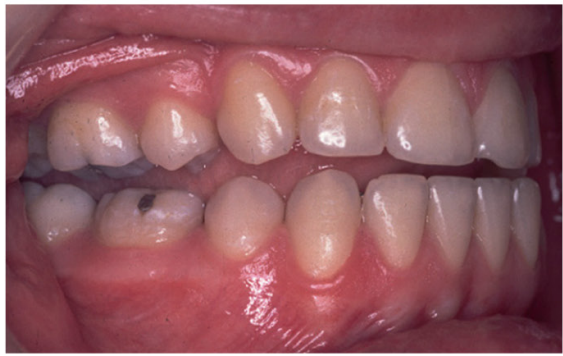

d

b
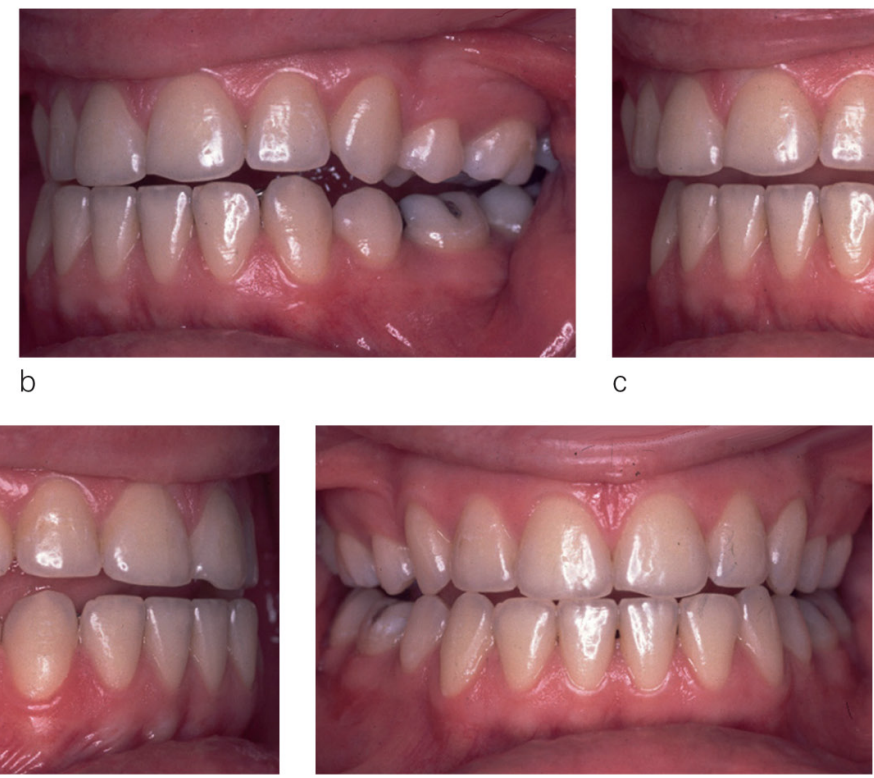

e

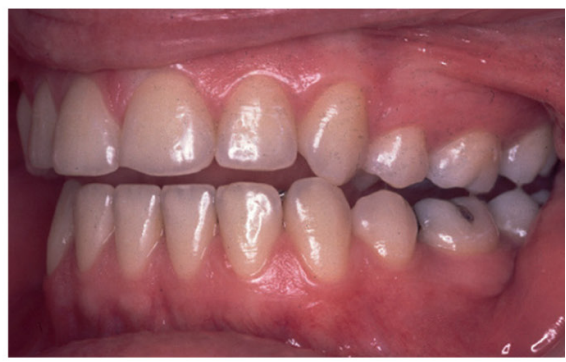

C

Figure 19a-e

Left and right lateral movement, with canine contact on working side and no contact on other side; propulsion without posterior contact.

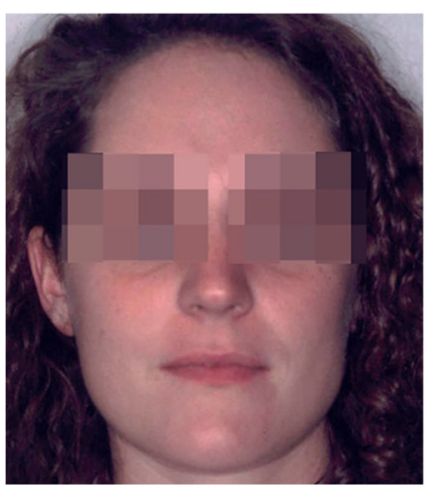

a

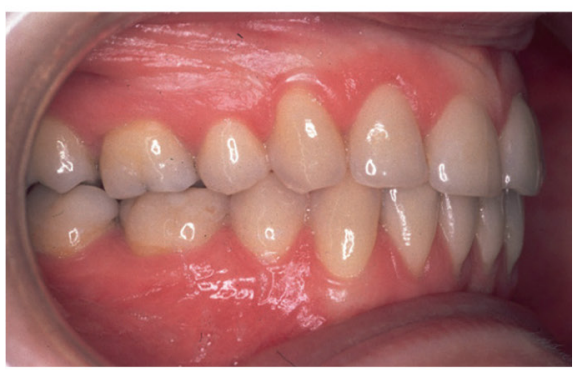

e

b
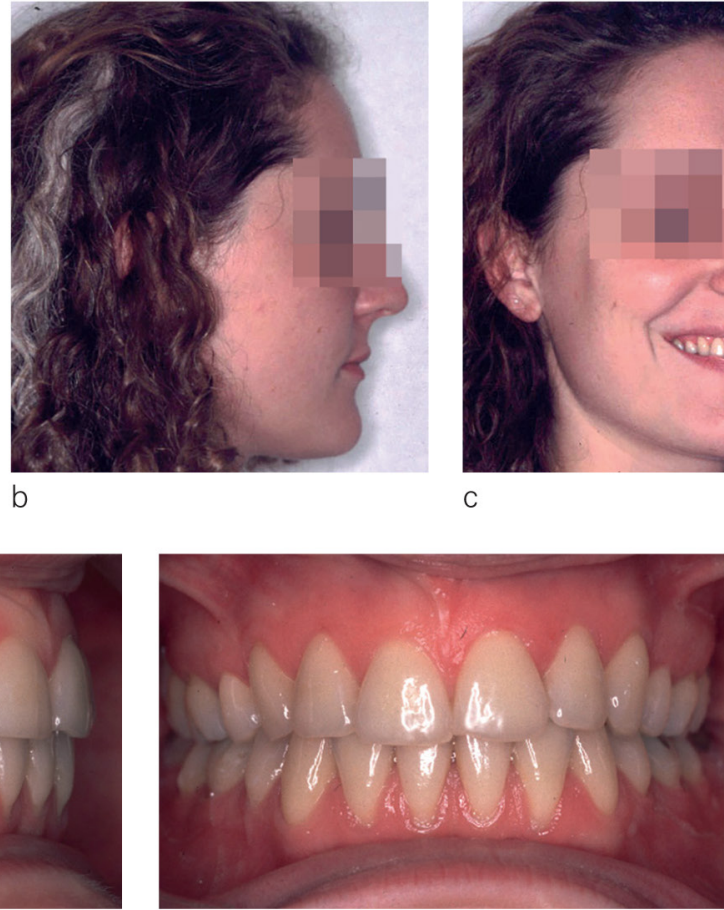

f

C
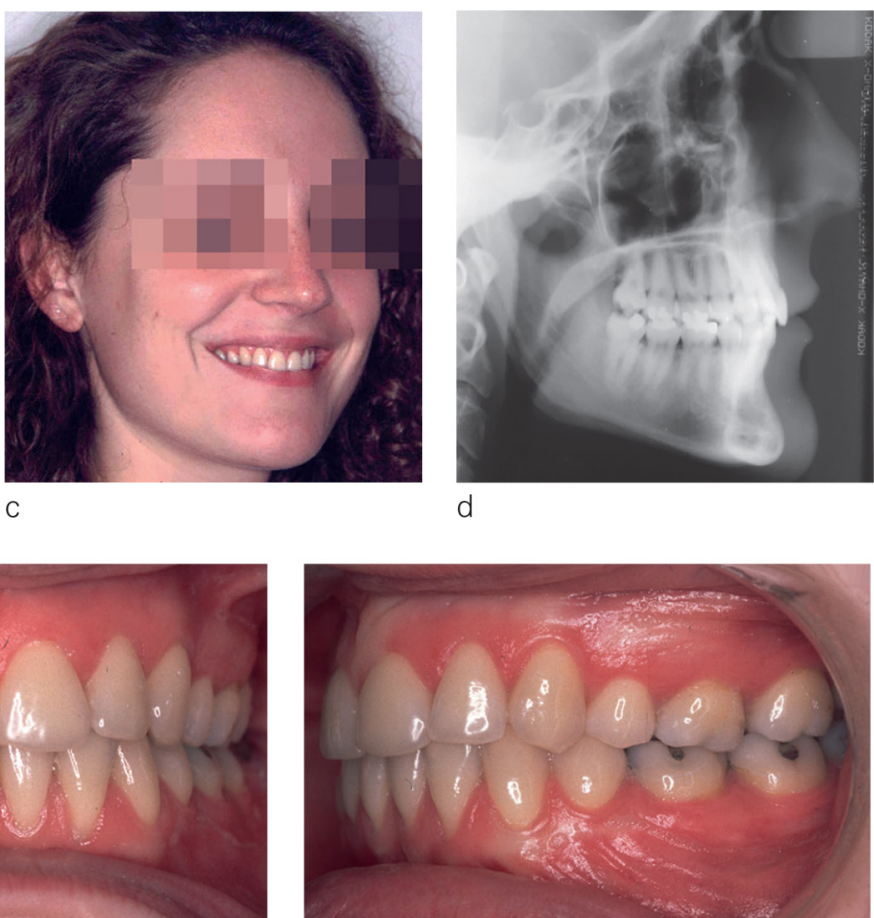

g

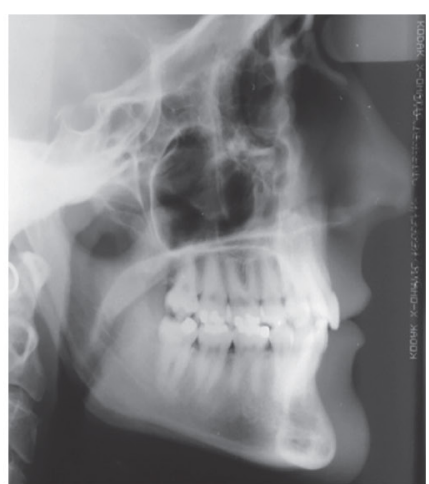

d

Figure 20a-g

7.5 years after treatment, pleasant face, perfectly stable occlusion, and functional wisdom teeth. 


\section{Patient 5}

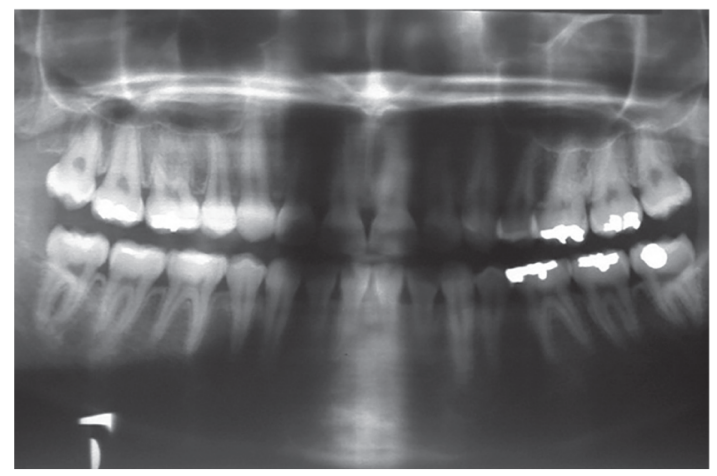

h
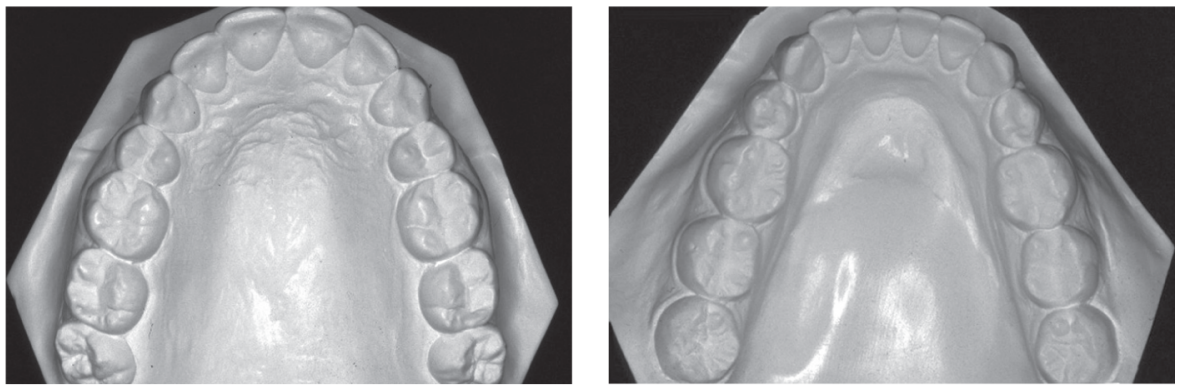

i

j

Figure 20h-j

Retention was stopped on patient's request when wisdom teeth, now well included in either arcade, first appeared.

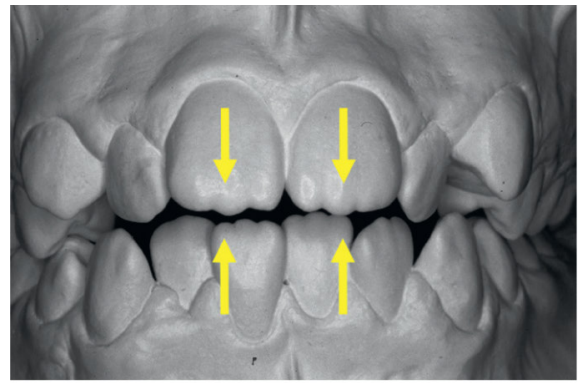

a

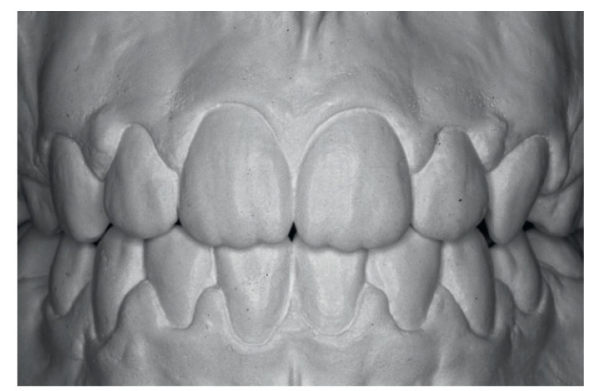

b

Figure $21 a-b$

Anterior hypercorrection, seeking maximal overbite in case of initial open bite. 


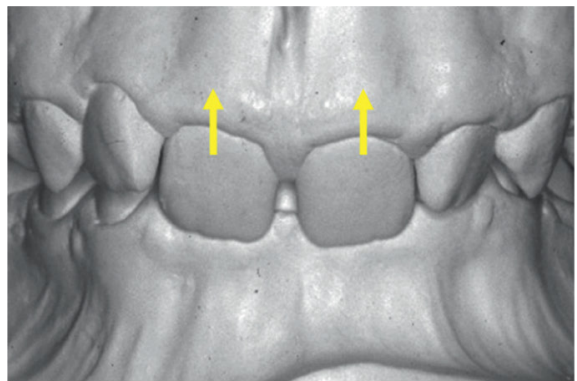

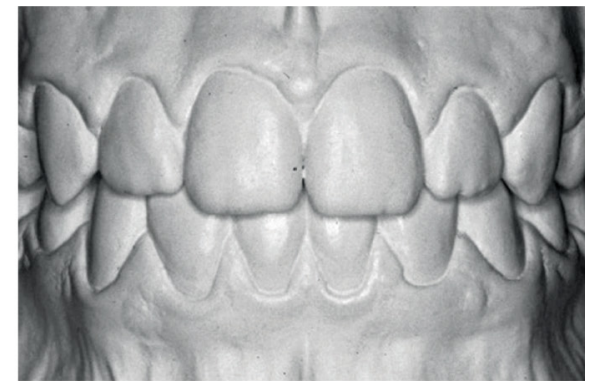

b

Figure 22a-b

Anterior hypercorrection, seeking minimal overbite and ideal torque in case of initial closed bite.

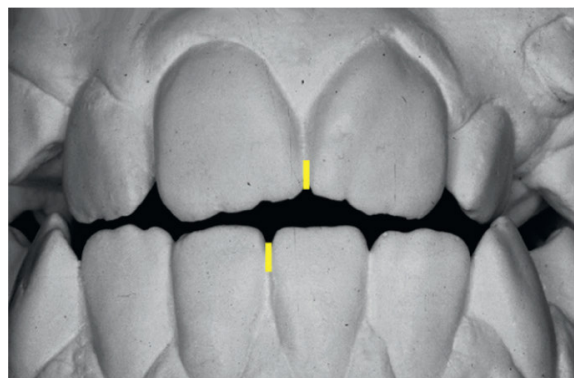

a

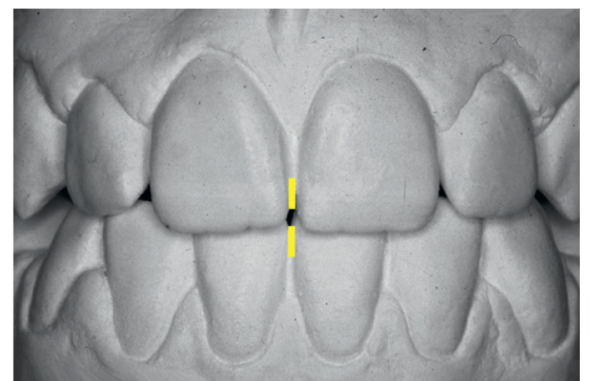

b

Figure 23a-b

Anterior hypercorrection, with center correction and arch symmetrization.

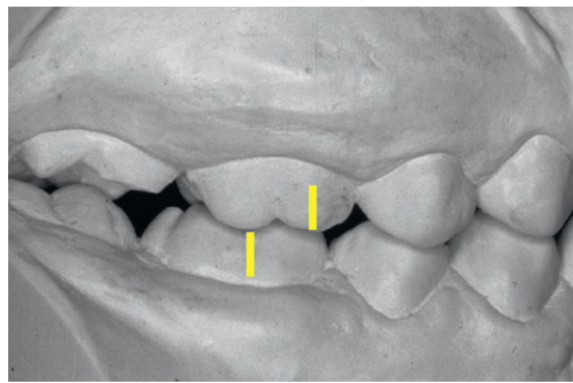

a

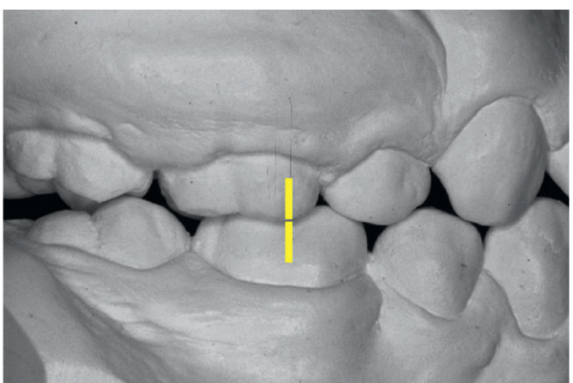

b

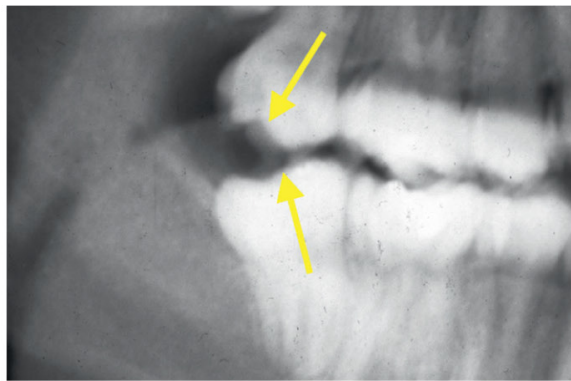

$\mathrm{C}$

Figure 24a-c

Molar disclusion facilitating interarcade sliding, especially as required for anchorage, notably in dental class II.

to dental balance is often inferior incisor positioning, but for facial balance the superior incisor is critical ${ }^{22-45}$.

Inferior and superior incisor positions have to correlate, with a functional interincisor angle for stable anterior occlusion, although vigilance is called for, especially in class II division 2 and class III associated with facial hyper- or hypo-divergence.

Without nowadays being dogmatic, if the inferior incisors are in vestibular version with degraded profile, uprighting is necessary and improves, 
Patient 6

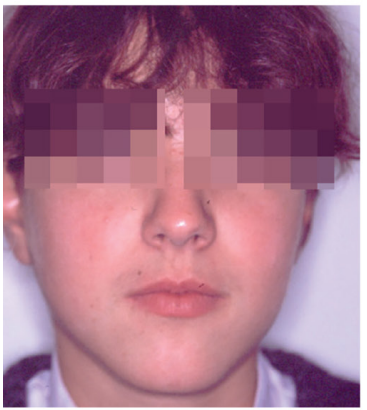

a

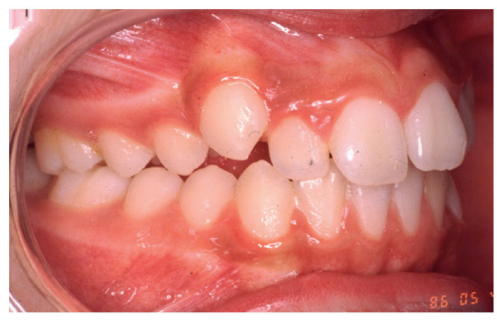

e

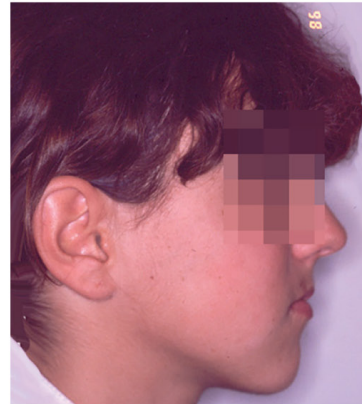

b

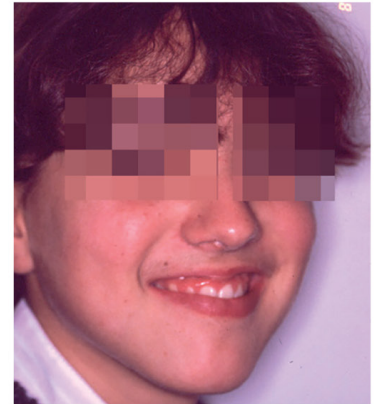

c

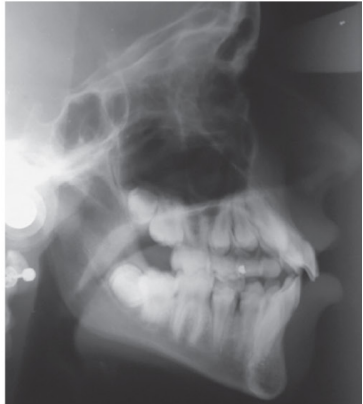

d

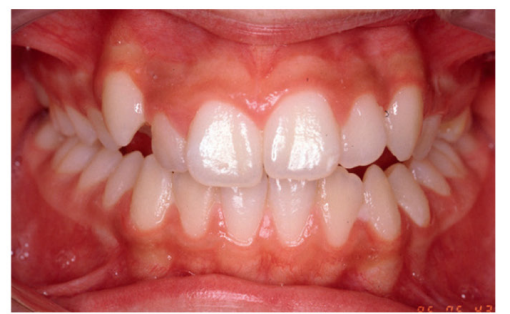

$f$

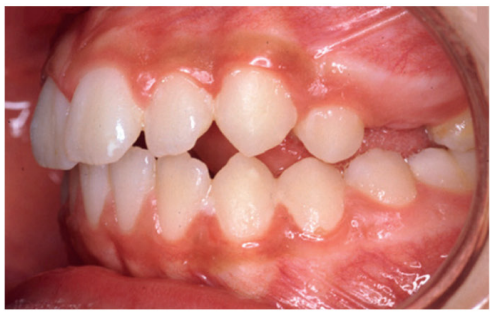

g

Figure 25a-g

Increased naso-mental level and slightly gingival smile. Teleradiograph shows vestibular incisor positioning and labial incompetence, and the first treatment situation after cessation of finger-sucking (by sheer will-power). Slight alveolar protrusion within a hyperdivergent pattern and posterior crowding indicated extraction of 14243444.

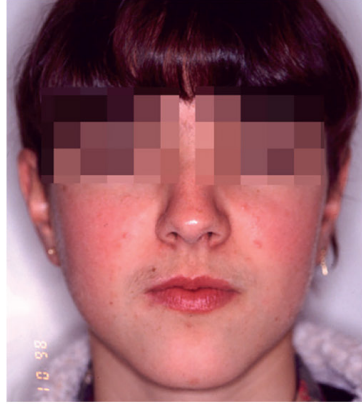

a

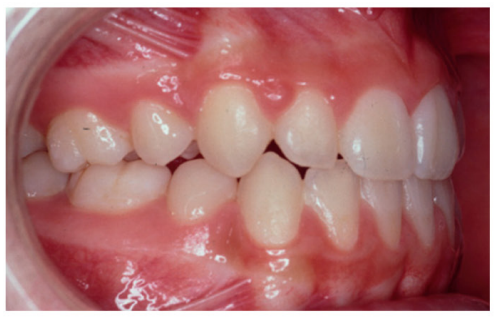

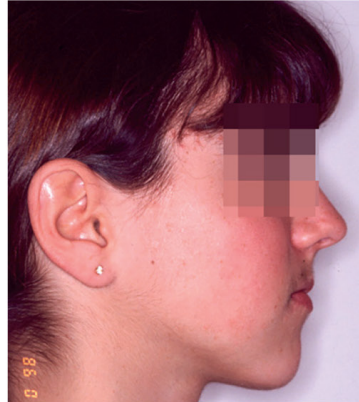

b

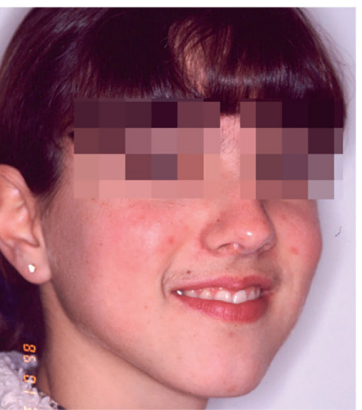

$\mathrm{C}$

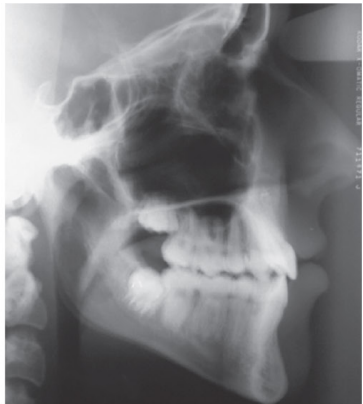

d

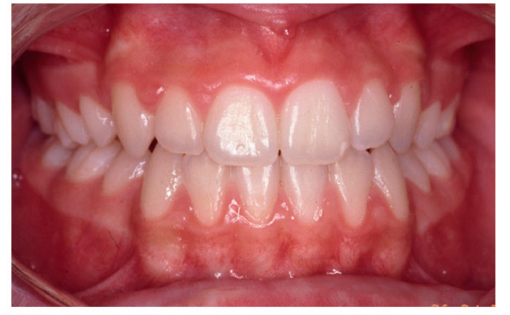

$f$

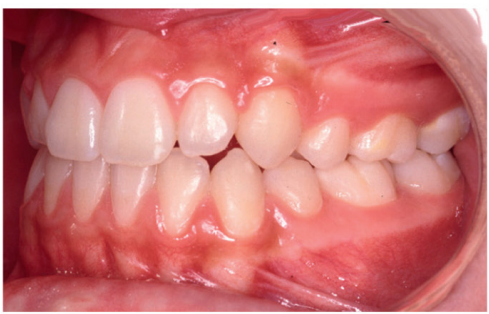

g

Figure 26a-g

Necessary incisor repositioning, with improved labial esthetics, especially clear on teleradiography. At end of treatment, posterior disclusion is almost abolished; no interarcade intervention was needed and the pattern was hyperdivergent. No retention was applied. 


\section{Patient 6}

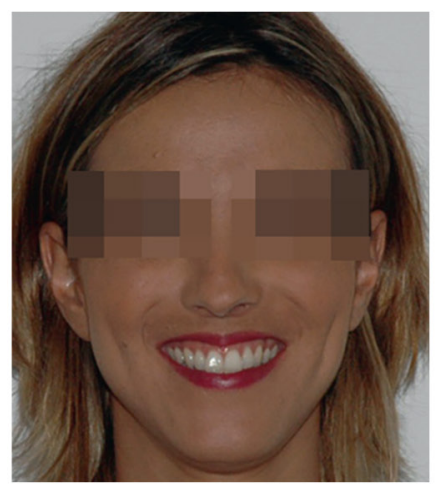

a

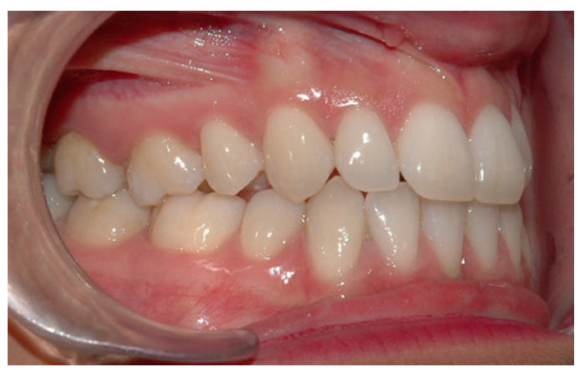

d

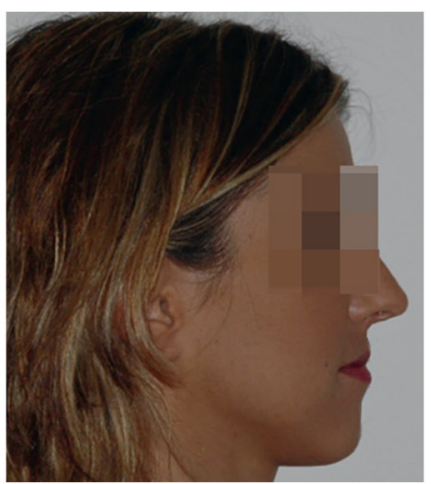

b

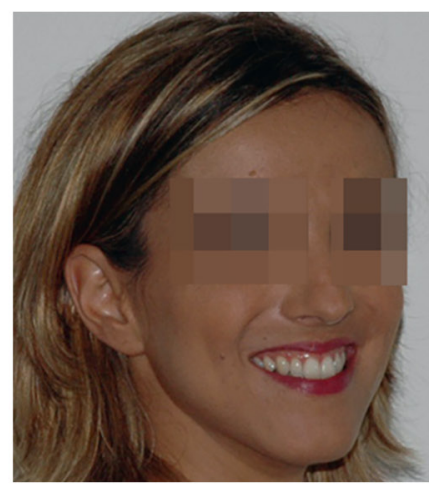

C

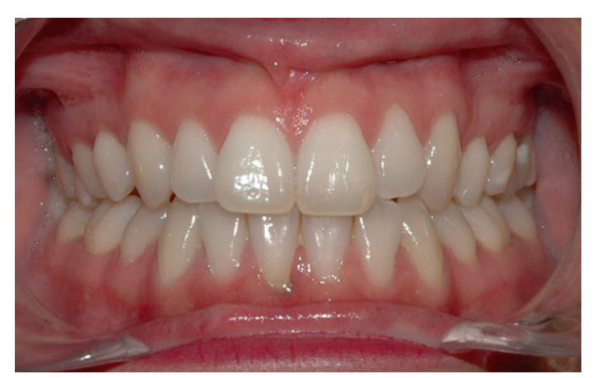

e

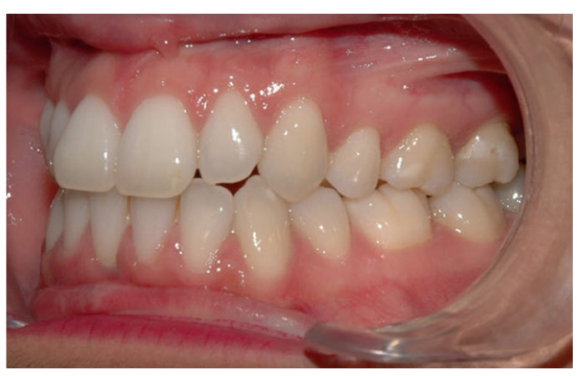

f

Figure 27a-f

17 years later, the patient brought her daughter to consult. Occlusion was stable, although with persistent occlusal insufficiency: non-occlusion of 15, excess canine lateral torque hampering mandibular movement, and insufficient artistic bends in superior lateral incisors. Functional wisdom teeth.

their position on the mandibular bone base, while normalizing lip position to restore lip function and esthetics, reducing the impact of aging on soft tissue (fig. 36a-b). It is widely agreed that incisor vestibular version impairs the stability of overbite and especially inferoanterior stability in the long term ${ }^{2-8-9-14-25-37-56}$. Misdiagnosis and faulty treatment decisions lead to unstable results that no retention device can remedy [Patient 8 , figs 37 a to $38 \mathrm{f}$ (start and end of treatment), 39a to $40 f$ (relapse and revision treatment), and 41a-h (long-term follow-up)].

Treatment cannot be said to be finished until both arcades have been taken into account as a whole. The posterior inferior arcade requires con- tinual attention (treatment and need to upright second molars, leveling of Spee curve that may be expressed here, as seen above). We take growth into account, with theoretic increase in posterior arcade distance up to 16 years in girls and 18 years in boys; among other things, this enables the possibility of wisdom tooth progression, if detected on X-ray, to be assessed.

Long-term follow-up shows that the classic Tweed criteria are subject to great individual variation and lack reliability. In case of doubt, there are no grounds for systematic wisdom tooth germectomy; regular surveillance is wiser, associating the family doctor [Patient 9, figs $42 \mathrm{a}$ to $43 \mathrm{~h}$ 


\section{Patient 7}

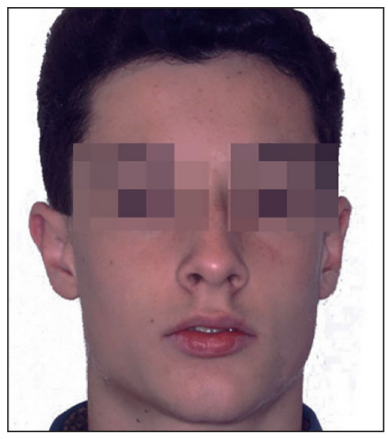

a

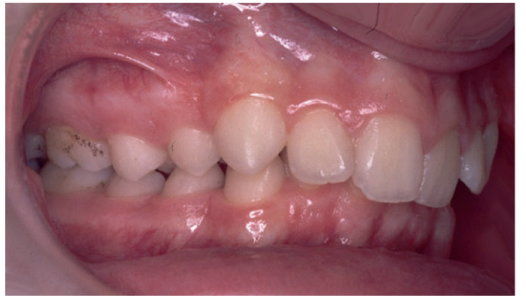

e

b
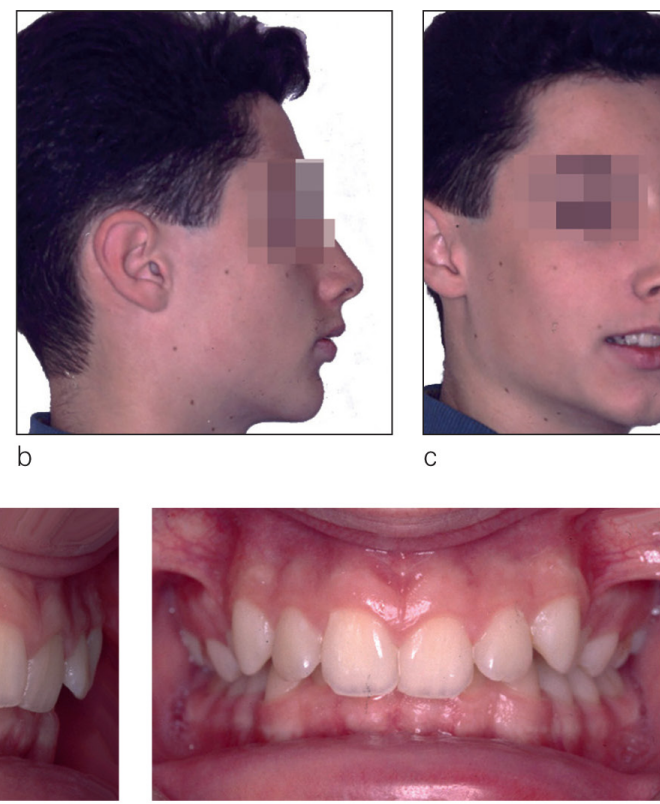

f

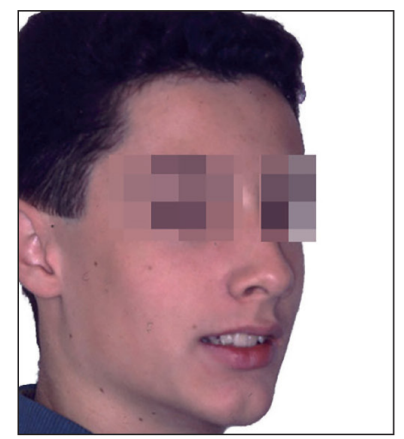

C

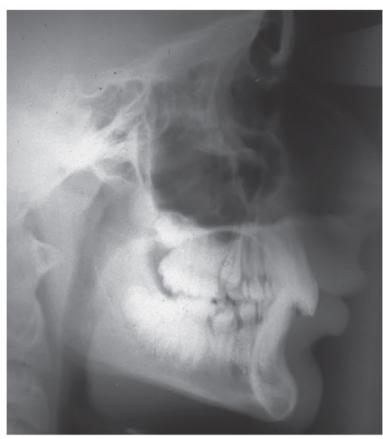

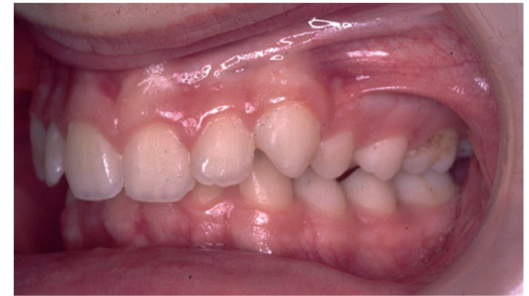

g

Figure 28a-g

Slightly retrusive profile, compensated for by progenia. Severe incisor closed bite, complete occlusal class II, both canine and molar. Moderate dysharmony and Spee curve indicated treatment without premolar extraction. reassessment of residual class II after resolution of closed bite was needed to confirm this choice.

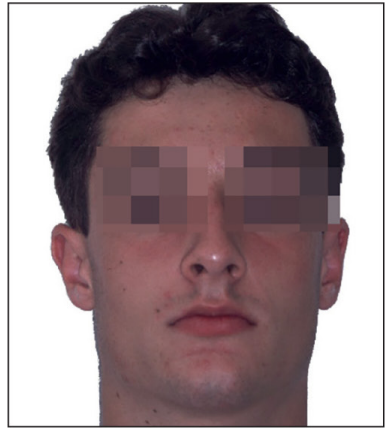

a

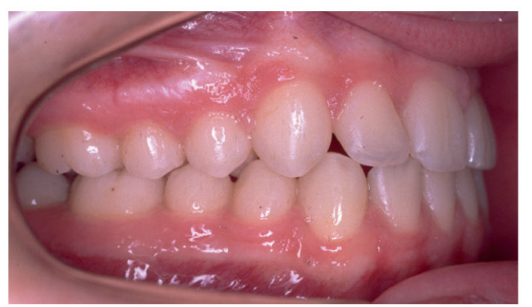

e

$\mathrm{b}$
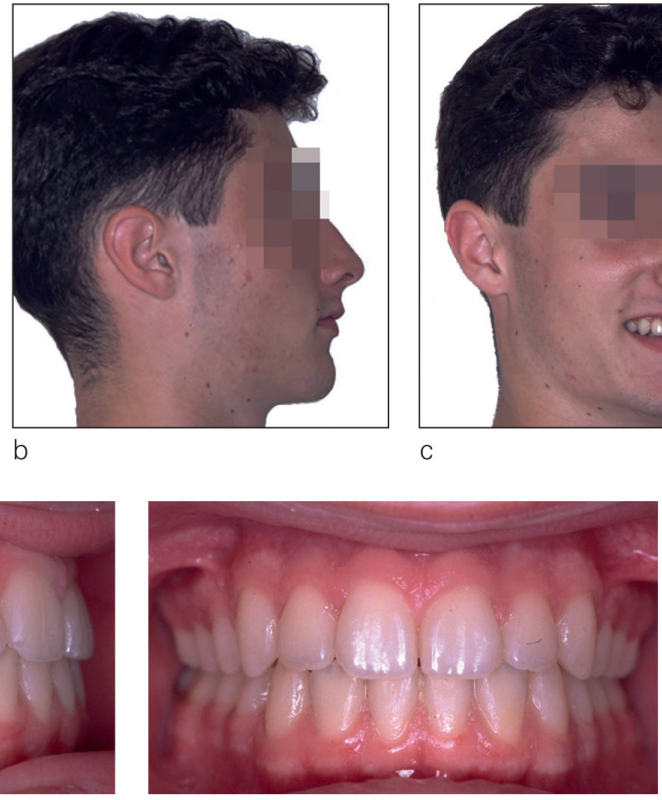

f

C
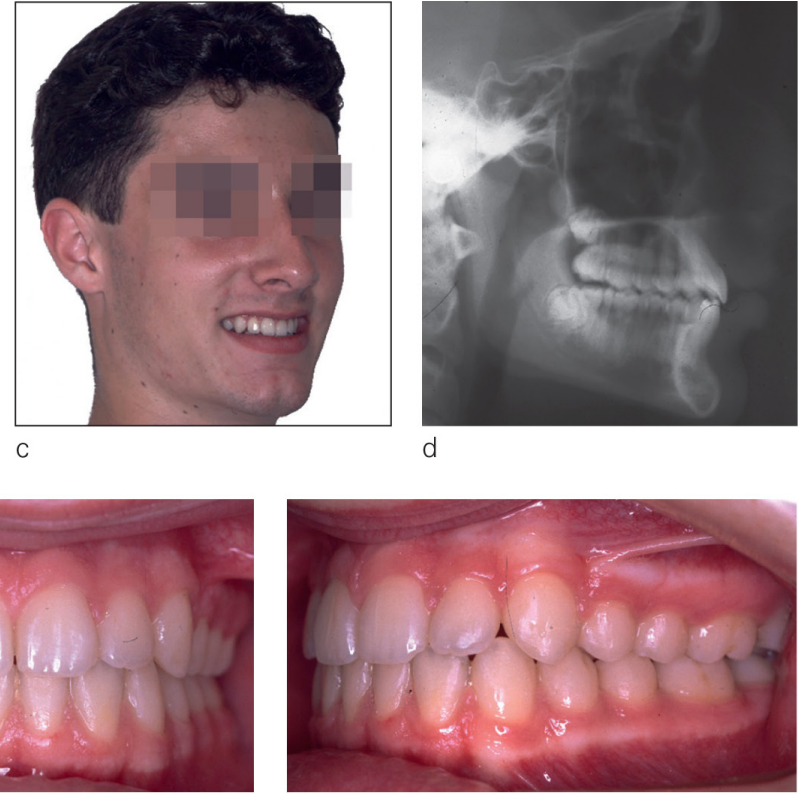

g

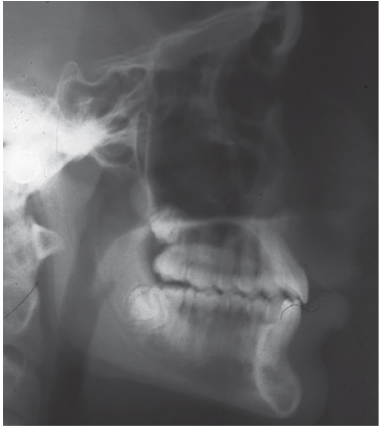

d

Figure 29a-g

More harmonious profile and smile; reduced interincisor angle. Vertical and anteroposterior hypercorrection and arcade leveling freed occlusion and reduced dental and skeletal offset. Retention comprised mandibular 2/2 and maxillary Hawley plate; wisdom tooth germectomy was prescribed. 


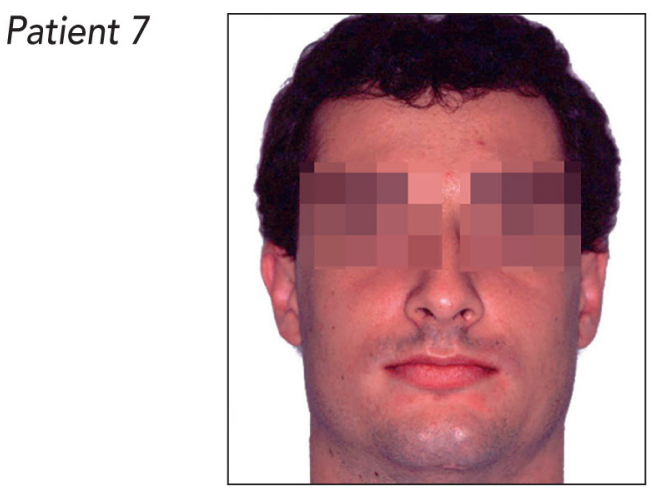

a

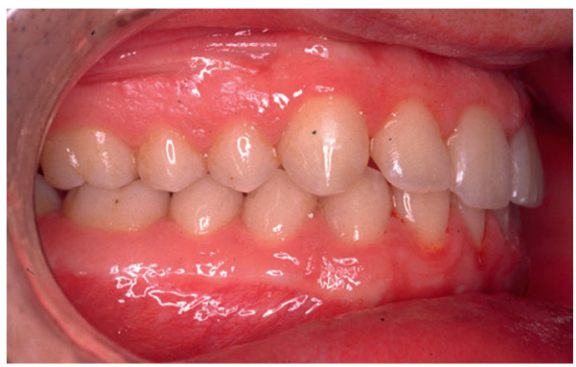

d

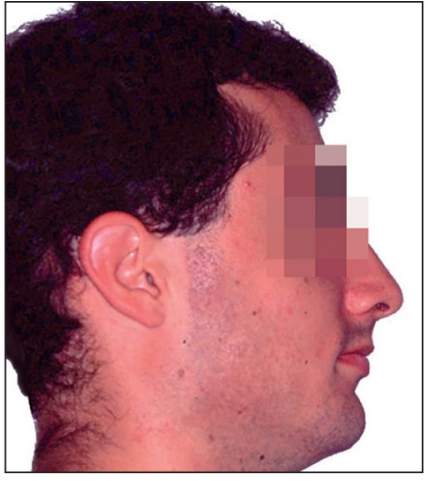

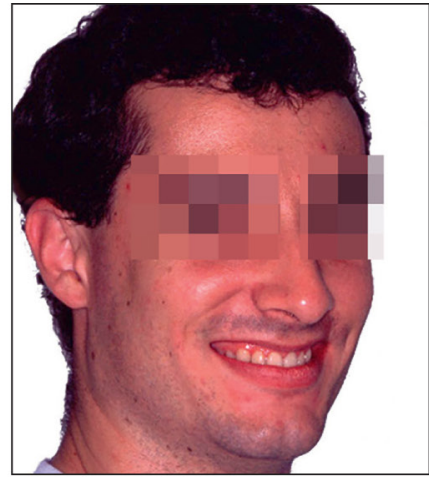

C

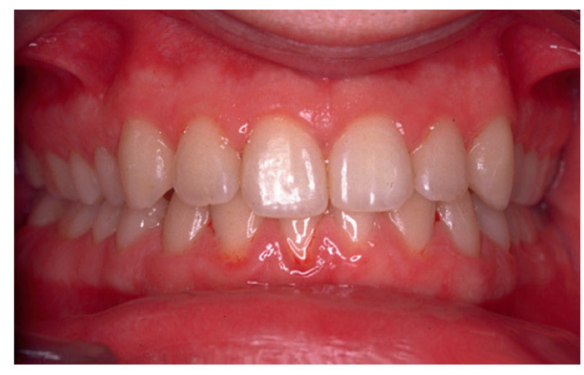

e

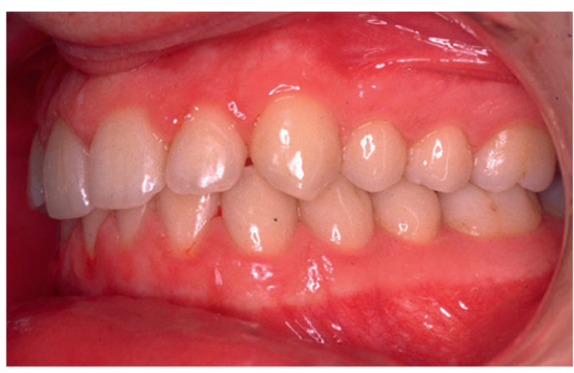

f

Figure 30a-f

Despite slight anterior relapse, occlusion was satisfactory 7.5 years later.

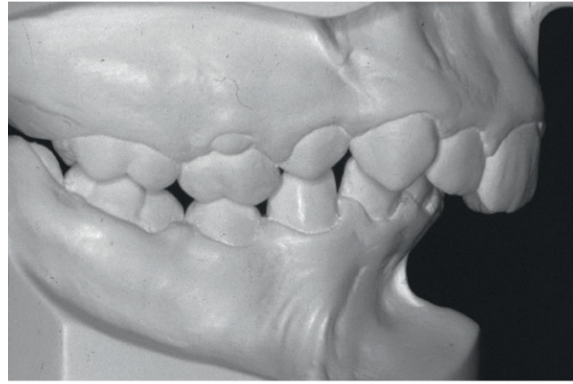

a

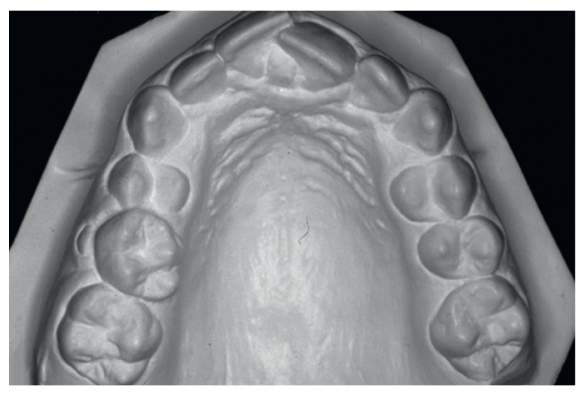

d

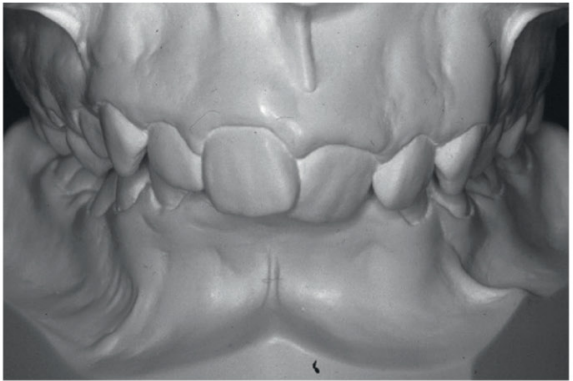

b

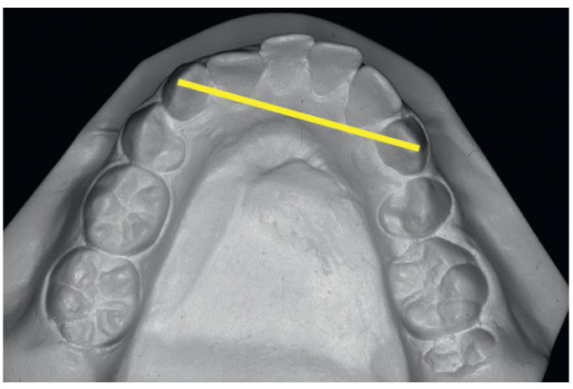

e

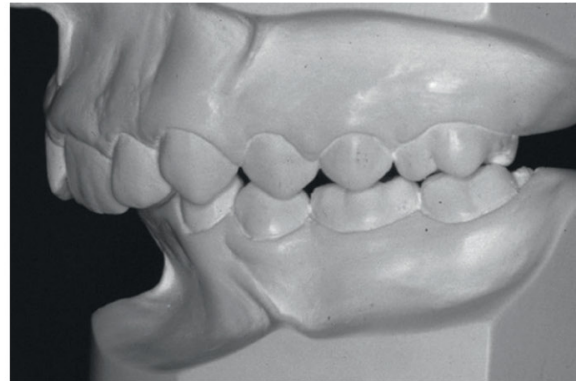

C

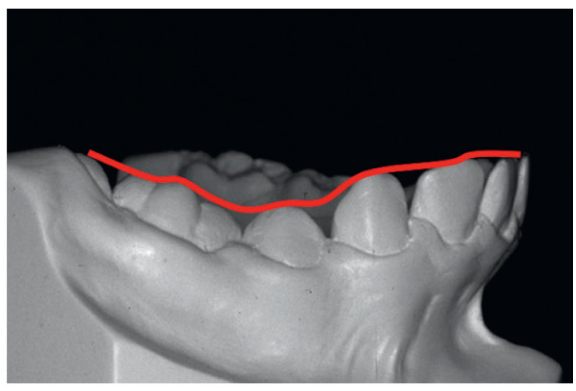

f

Figure 31a-f

Molds show right molar class I and canine class II and left molar and canine class II, severe incisor malpositioning, and closed bite. Very asymmetric inferior arcade at canines, with Spee curve and severe lack of room on the right. 


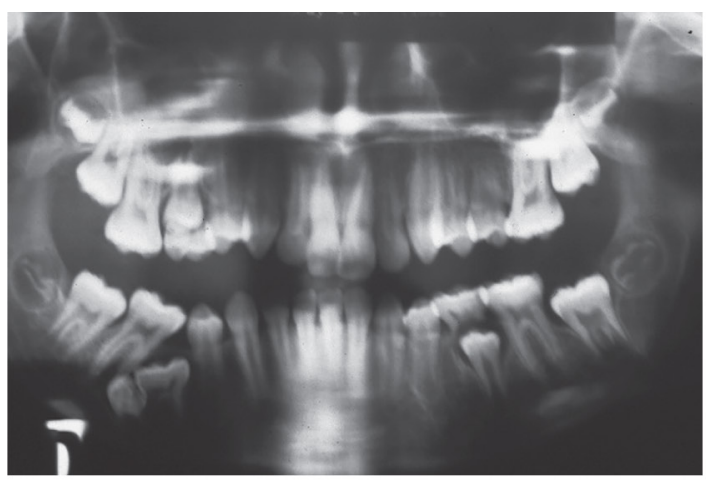

g

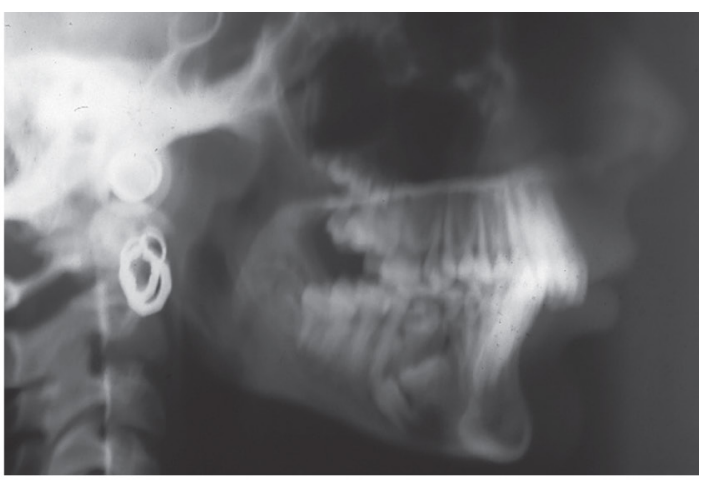

h

Figure 31g-h

Panoramic examination shows the origin of the problems: reinclusion of 85 and inclusion of 45 inducing strong version of 46. Teleradiography confirmed severe dental and skeletal class II
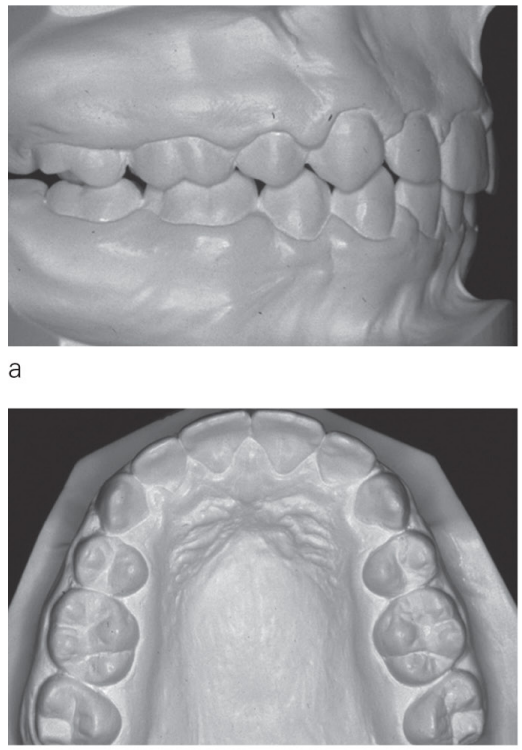

d

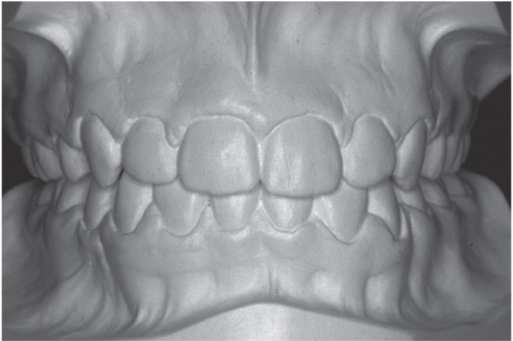

b

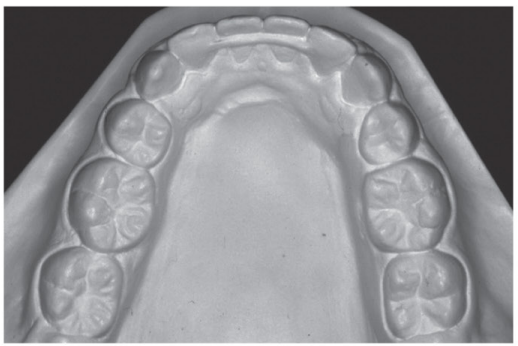

e

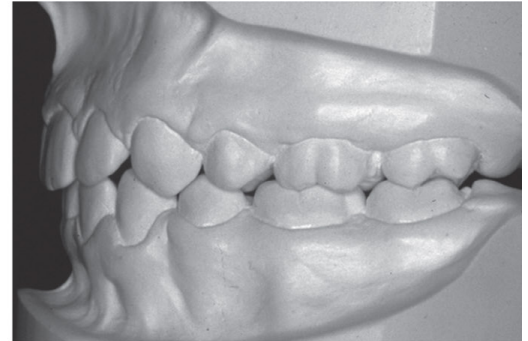

C

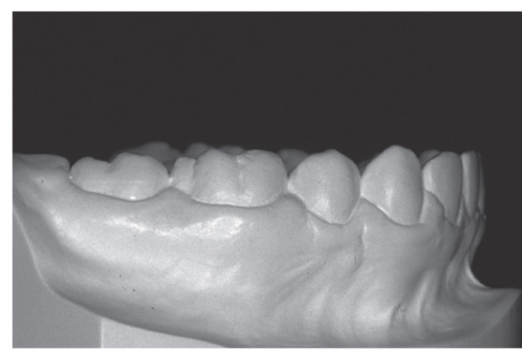

$f$

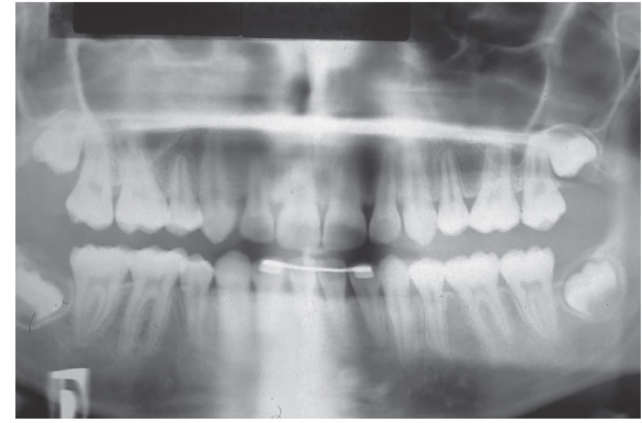

g

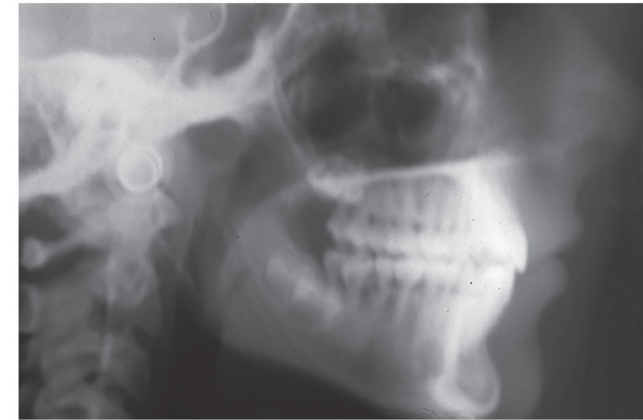

h

Figure 32a-h

After extraction of 142434 and 85 and 45 germectomy, interarcade relations are resolved by leveling the Spee curve; canine arcade symmetry, satisfactory dental axes and resolution of skeletal pathology, with functional incisor angle. 


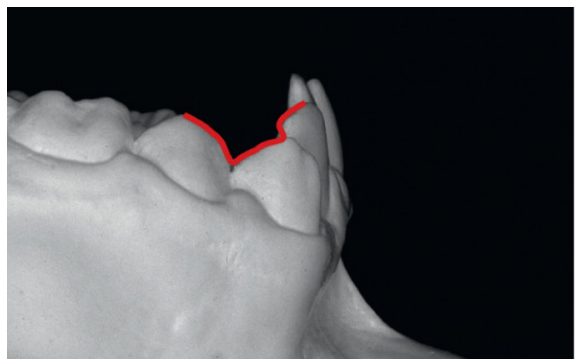

a

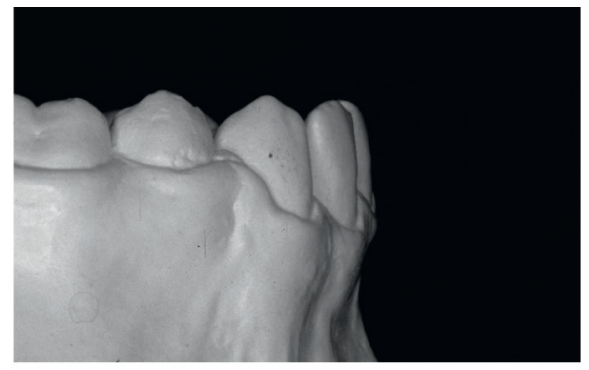

b

Figure 33a-b

Spee curve expressed in anterior part of inferior arcade, and resolution.

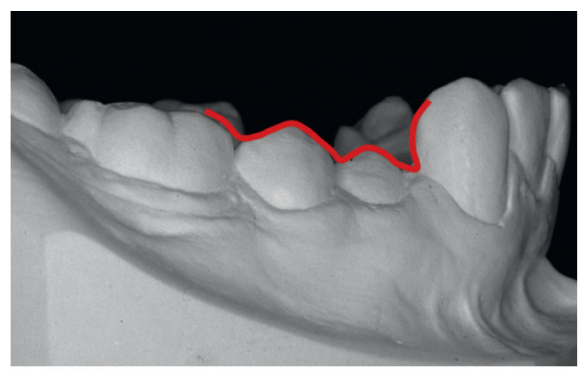

a

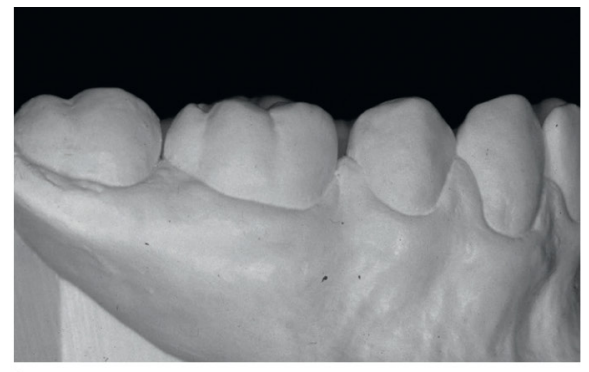

$\mathrm{b}$

Figure $34 a-b$

Spee curve expressed in medial part of inferior arcade, and resolution.

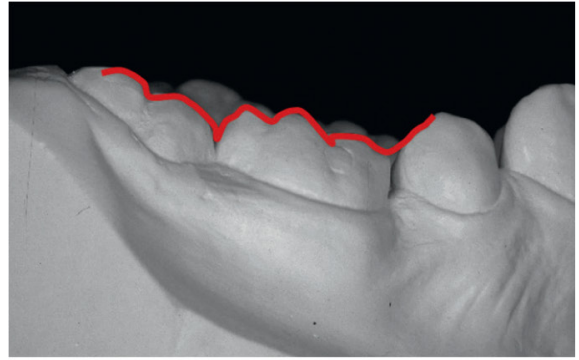

a

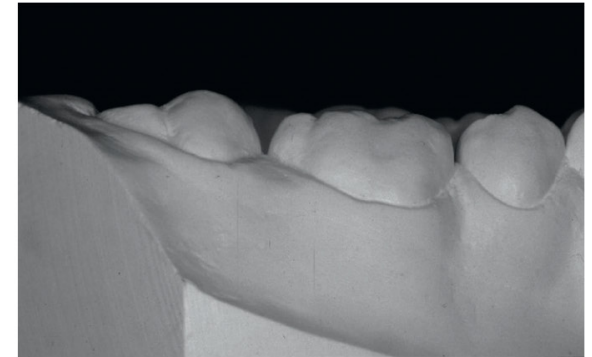

b

Figure 35a-b

Spee curve expressed in posterior part of inferior arcade, and resolution.
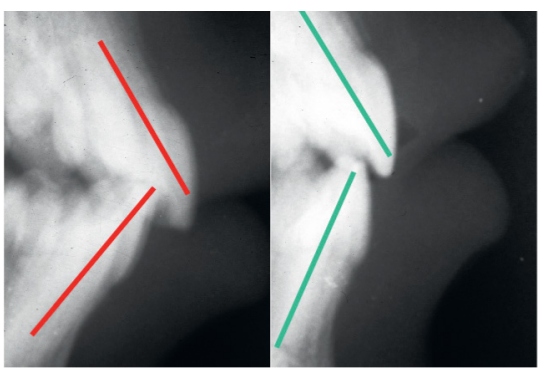

Figure 36a

Functional interincisor angle achieved by uprighting inferior incisor when too vestibular.

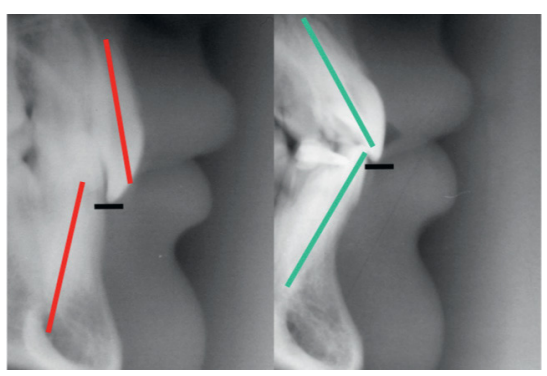

Figure $36 b$

Great improvement in incisor axes and interincisor angle, and impact of improved superior incisor free edge position on stomion. 
(start and end of treatment) and fig. 44a-h (long-term follow-up)].

It is easy to blame wisdom teeth, but there is no evidence implicating them in recurrence of malpositioning, except in case of oblique progression of wisdom teeth which lack room.

* Respecting the vertical dimension
There is a close correlation between this criterion and the preceding. In diagnosis, the impact of anteroposterior incisor position on profile needs to be assessed according to vertical skeletal typology. It is also essential to carefully examine the smile line and the facial integration of the incisors, to determine precisely the site

\section{Patient 8}

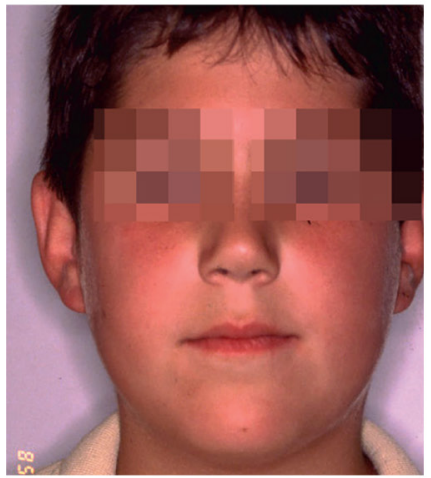

a

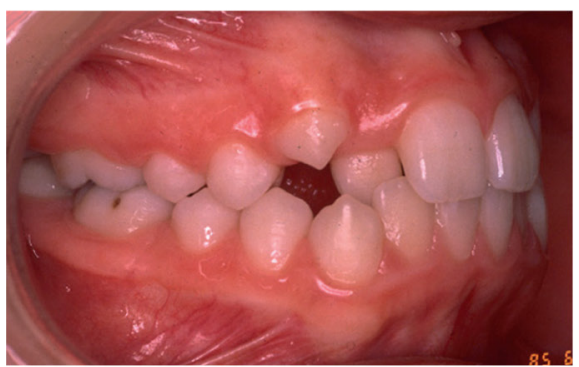

e

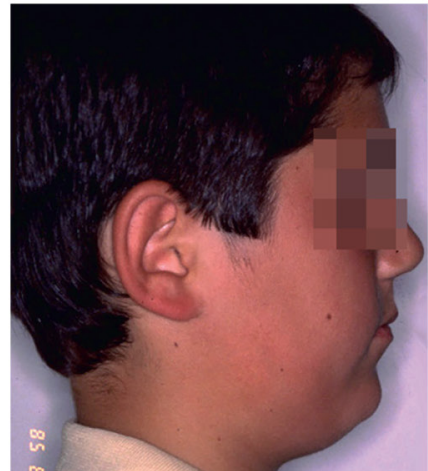

b

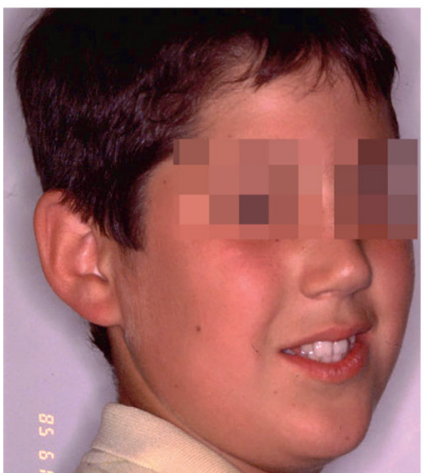

C

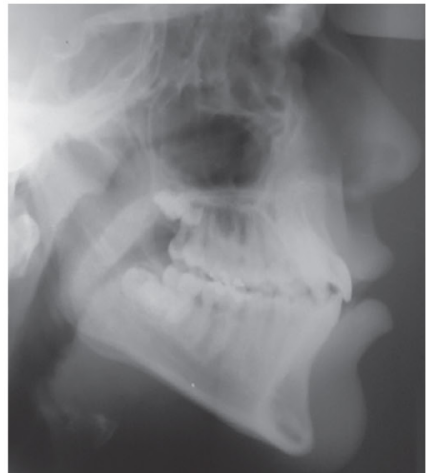

d

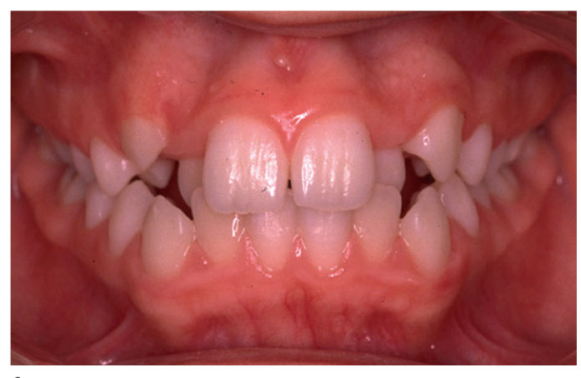

f

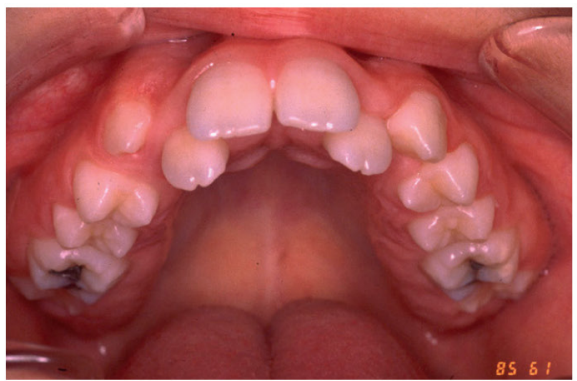

h

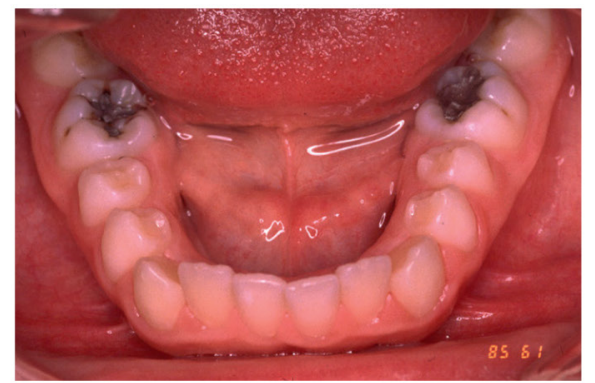

i

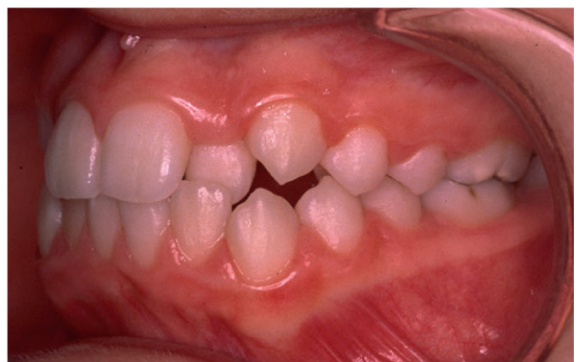

g

Figure 37a-i

Lax, incomplete diagnosis, leading to treatment without premolar extraction. Crowding, Spee curve and incisor vestibular version underestimated. 


\section{Patient 8}

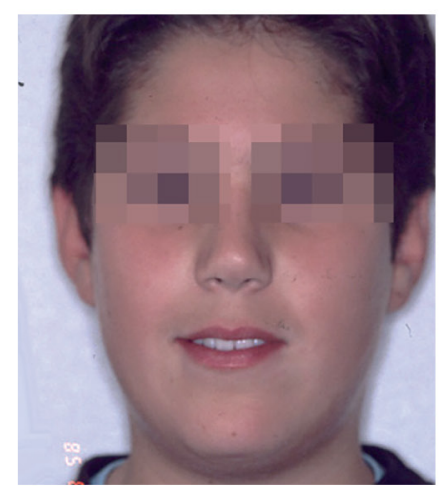

a

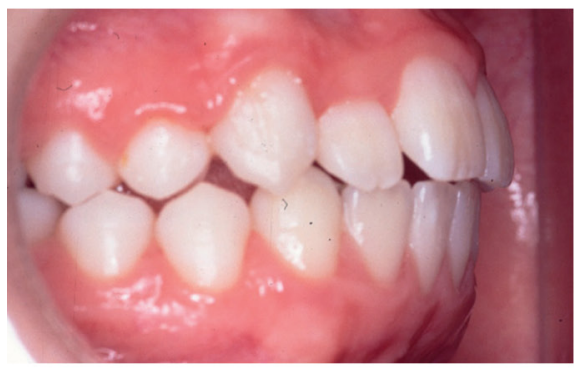

d

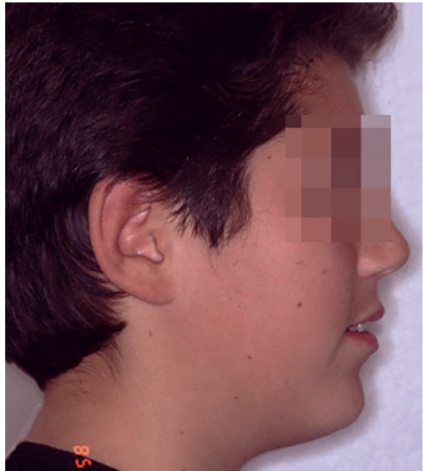

$\mathrm{b}$

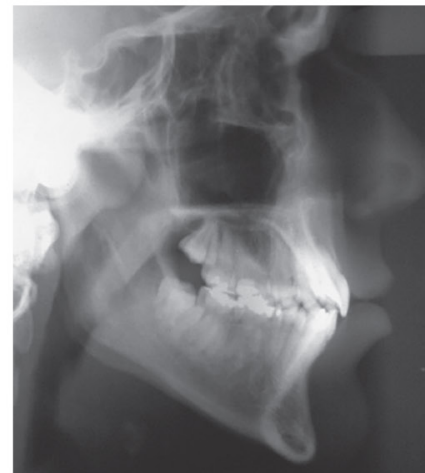

C

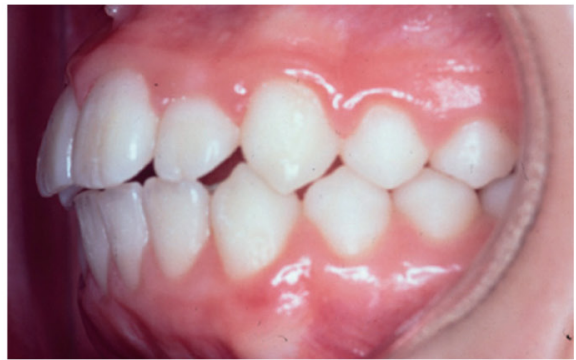

f

Figure 38a-f

Insufficient occlusal and esthetic result. latrogenesis helped worsen the situation into bilabioversion, impairing lip function. A mandibular 3/3 retention device was fitted...

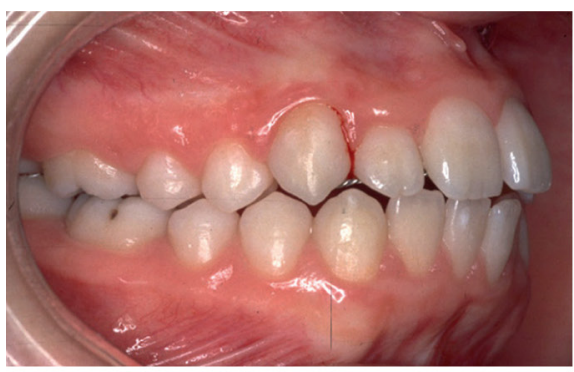

a

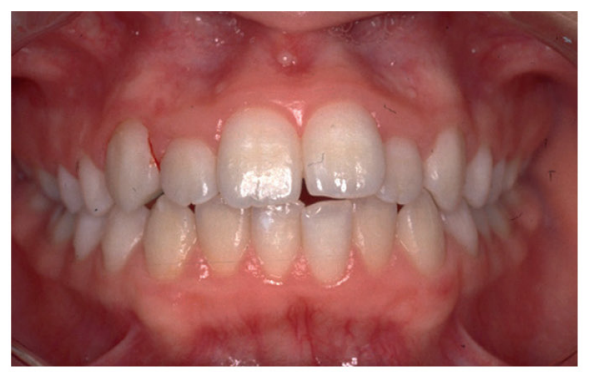

b

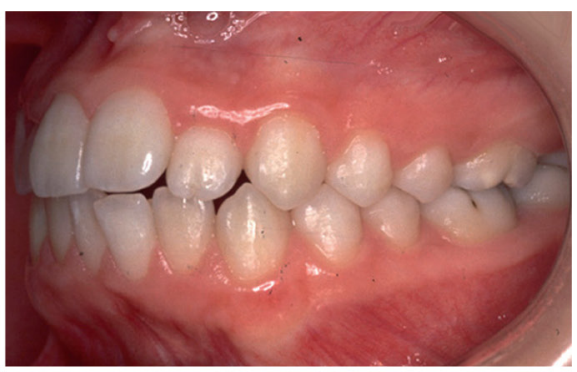

C

Figure 39a-c

...soon followed by maxillary retention in view of anterior instability. Dental pressure at the incisors was probably strong, with some teeth regularly detaching from retention. In view of this failure, we proposed revision treatment with extraction of 14243444. 


\section{Patient 8}
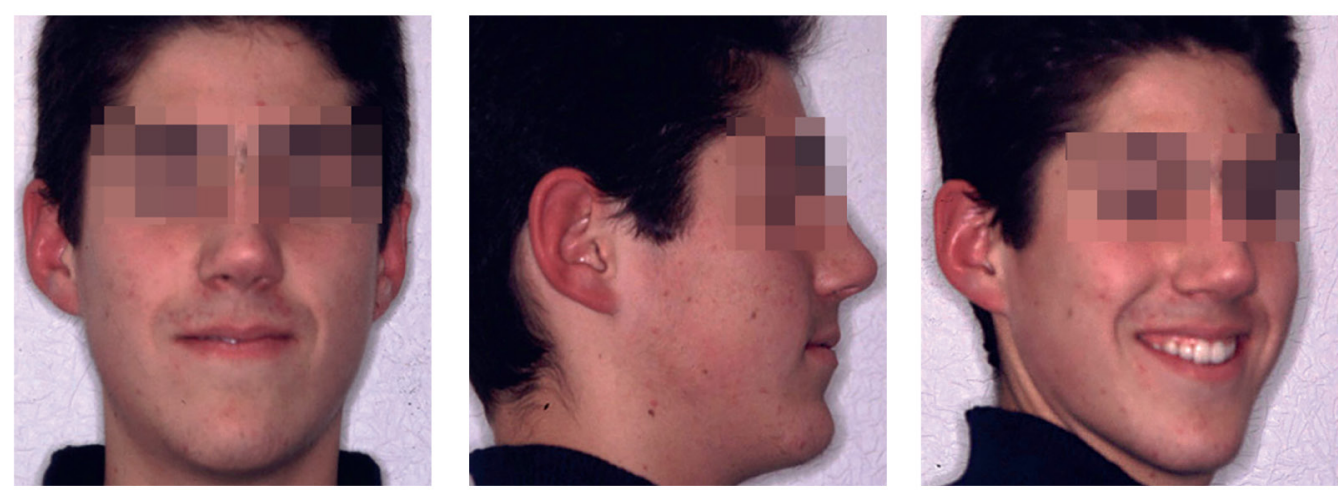

a

b

C

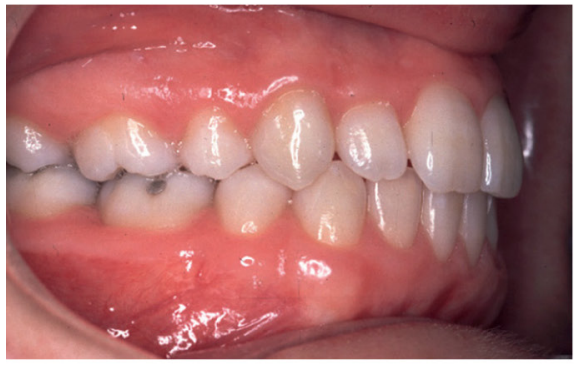

d

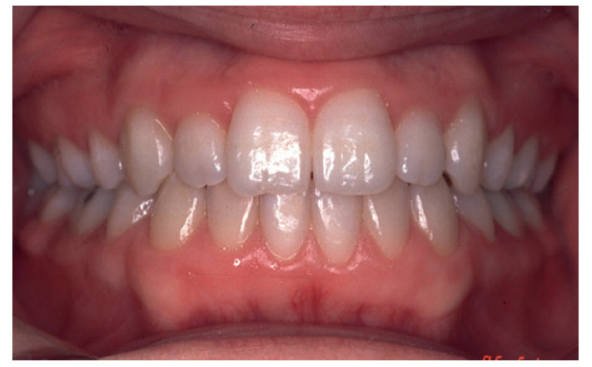

e

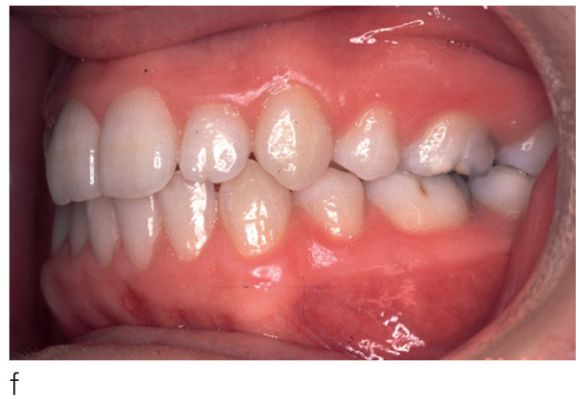

Figure 40a-f

After revision, the esthetic and occlusal result could be said to be satisfactory.

No retention was applied.

for orthodontic action and the degree of correction ${ }^{40}$.

Treatment sought to limit the dental expression and facial repercussion of the skeletal pattern, by controlling the occlusion plane.

In hypodivergence, the strategy takes care to avoid closure of the planes, which would induce anterior mandibular rotation, worsening facial esthetics. In class II, controlling incisor positioning is primordial (figs 28b, $d$ and $29 b, d$ ).
In class III, hypodivergence accentuates the excessively anterior position of the chin. In orthodontic treatment, the skeletal contribution is limited and alveolar compensation is required, bearing in mind the unfavorable time factor due to difference in maxillary and mandibular growth (fig. 45a-d).

In hyperdivergence, the extent of reduction in anteroposterior skeletal pathology depends on vertical control, the key to occlusal and esthetic 


\section{Patient 8}

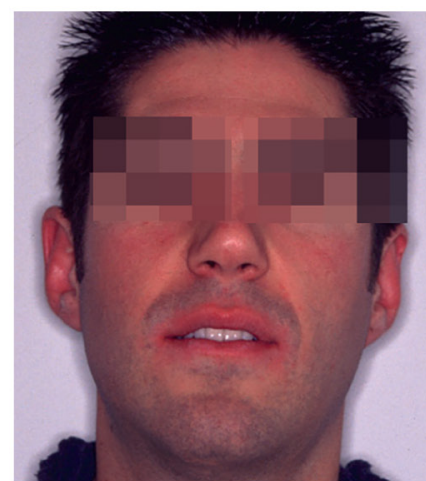

a

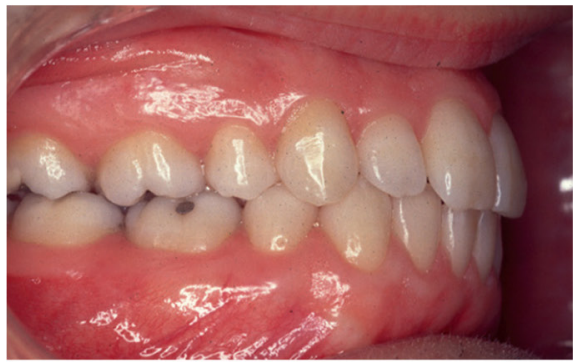

d

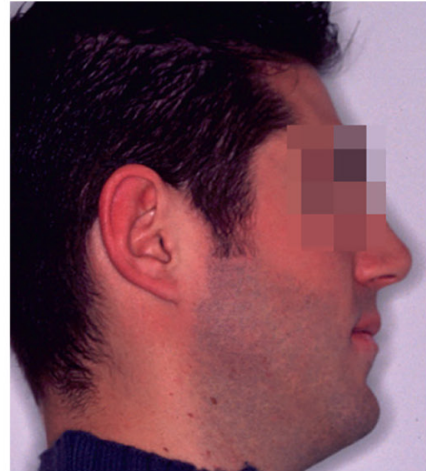

b

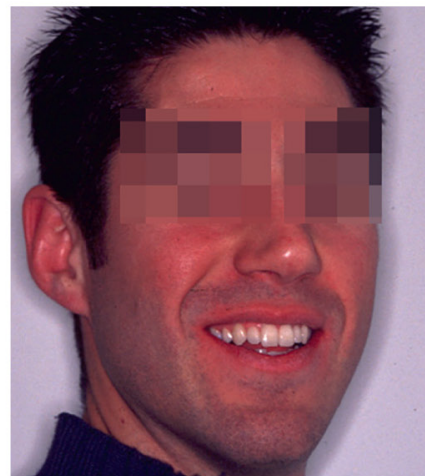

C

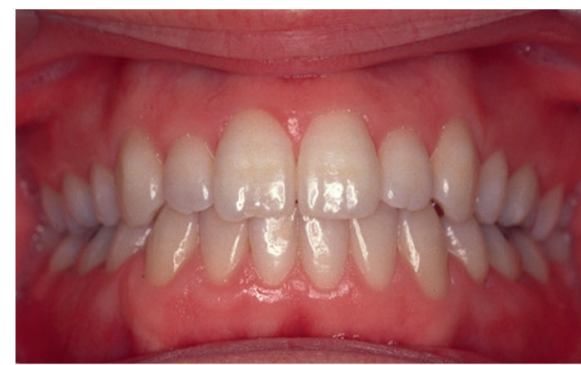

e

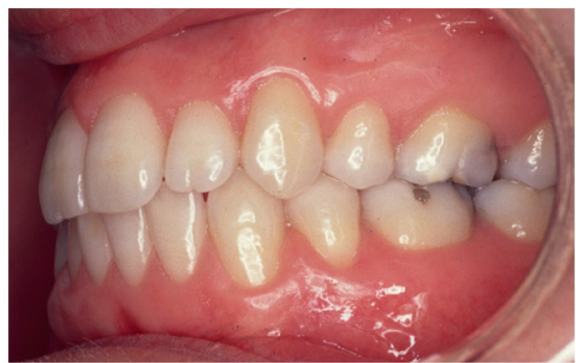

f

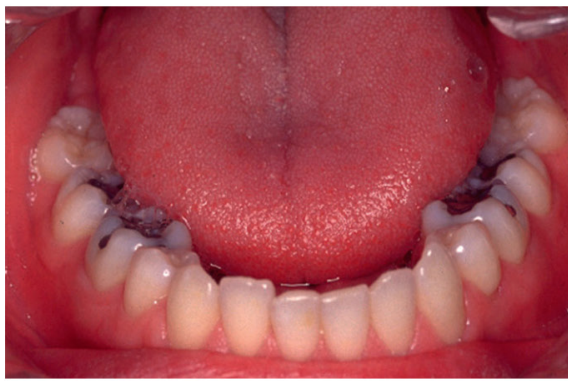

h

Figure 41a-h

The patient, fully satisfied with a family member's treatment, despite onset of slight malpositioning of 42 , called to thank us. Ten and a half years after end of his revision treatment: functional wisdom teeth.

success. In bilabioversion, the requisite incisor repositioning reduces labial protrusion, with remodeling of the labio-mental region (fig. 46a-c). Hyperdivergence, especially in class II, accentuates dental, skeletal and esthetic pathology. Maintaining or closing mandibular compass induces upward and forward projection of the chin, improving esthetic outcome and enabling reduction of dental and skeletal class II ${ }^{39}$ (fig. 47a-c). It contributes to natural functional reharmonization by relaxing the muscles (fig.48a-c). The parasitic vertical effects of class II or III elastics should be offset by 


\section{Patient 9}

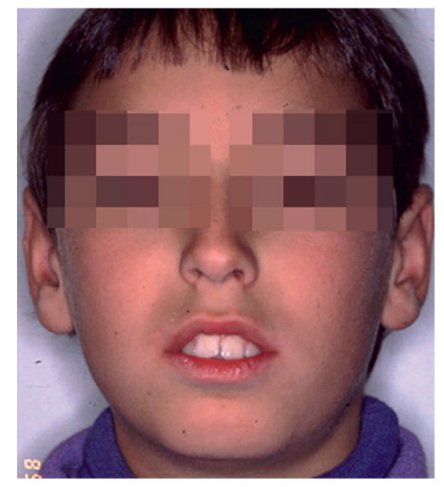

a

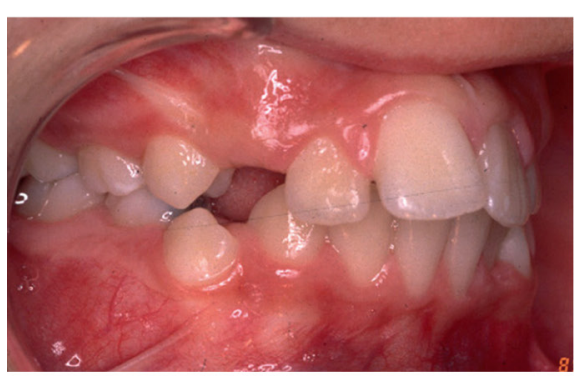

e

b
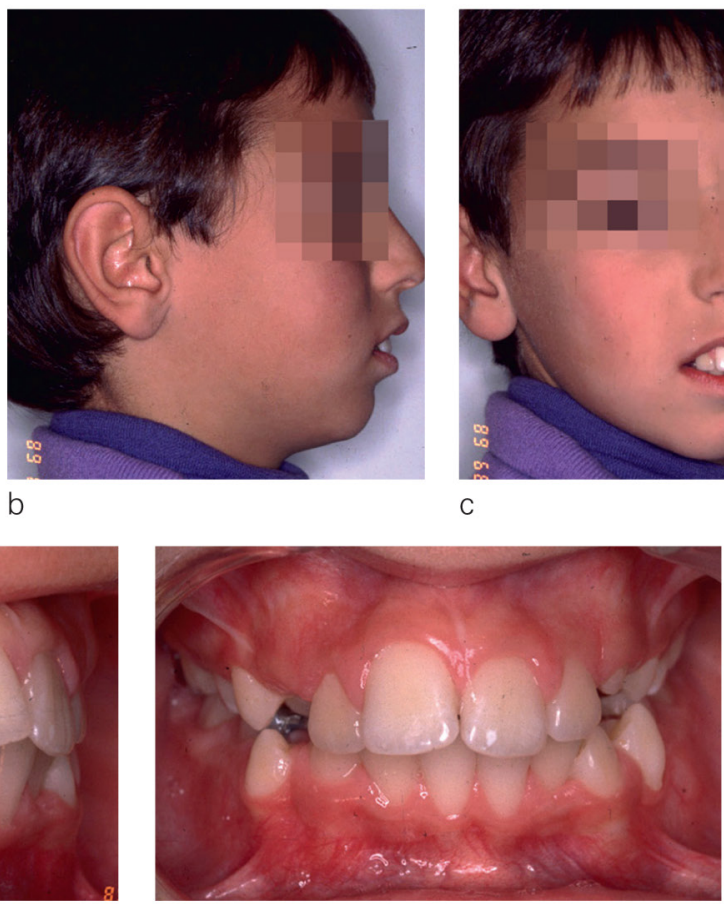

$f$

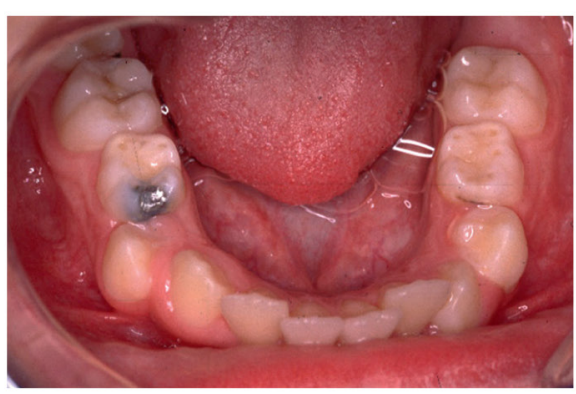

h

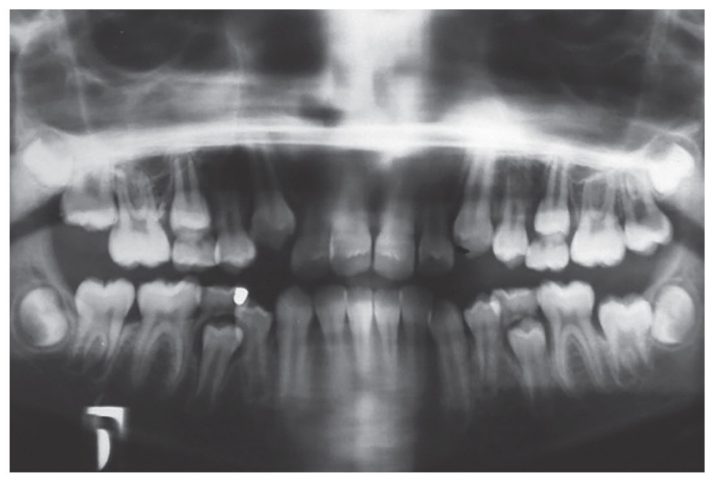

Figure 42a-i

Severe labial incompetence due to bilabioversion, confirmed on teleradiography, is aggravated by a short upper lip and maintained by oral breathing, necessitating treatment. Arcade views show malpositioning in anterior and lateral segments. Inferior wisdom tooth germs are oblique, lacking room. 


\section{Patient 9}

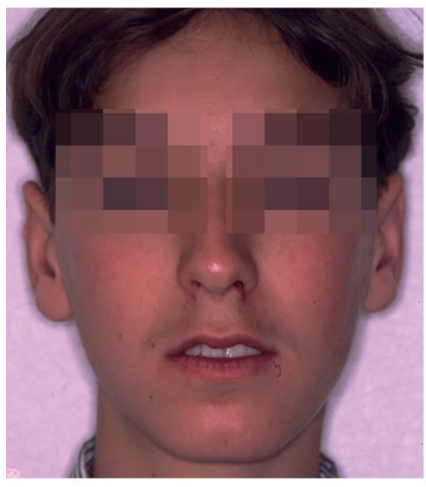

a

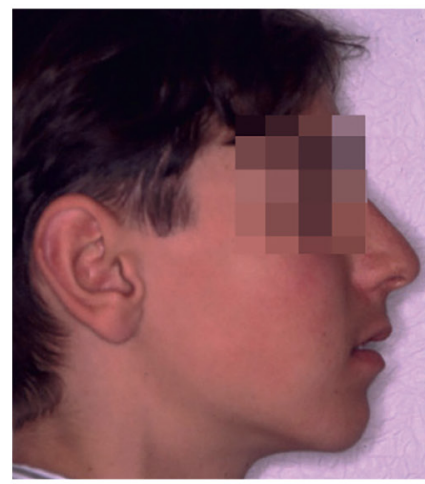

b

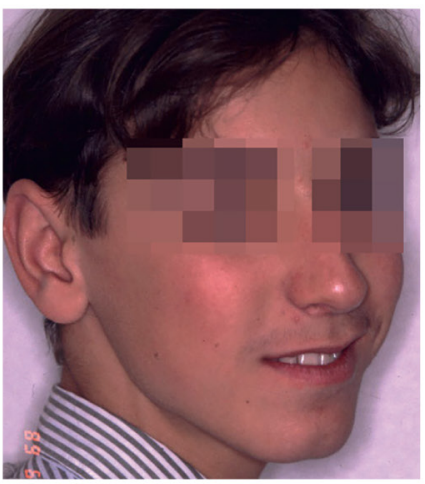

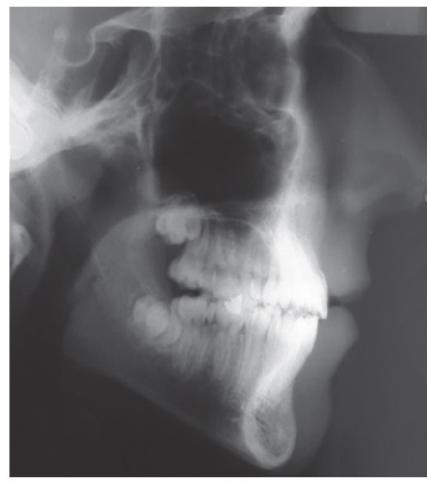

d

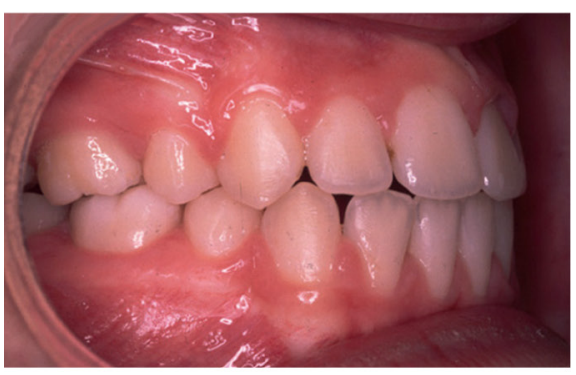

e

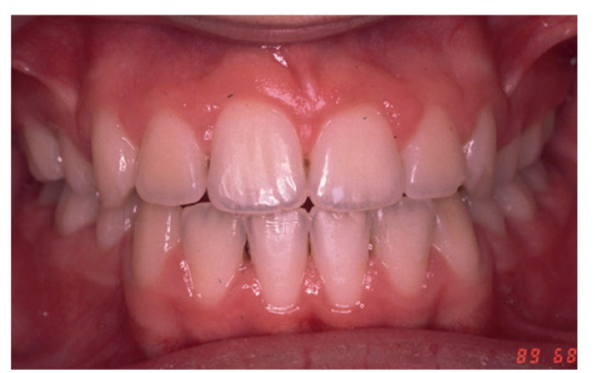

f

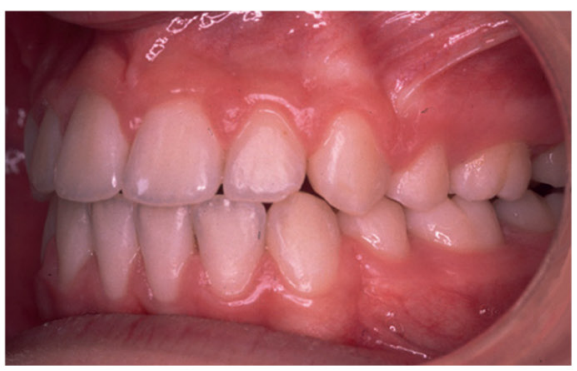

g

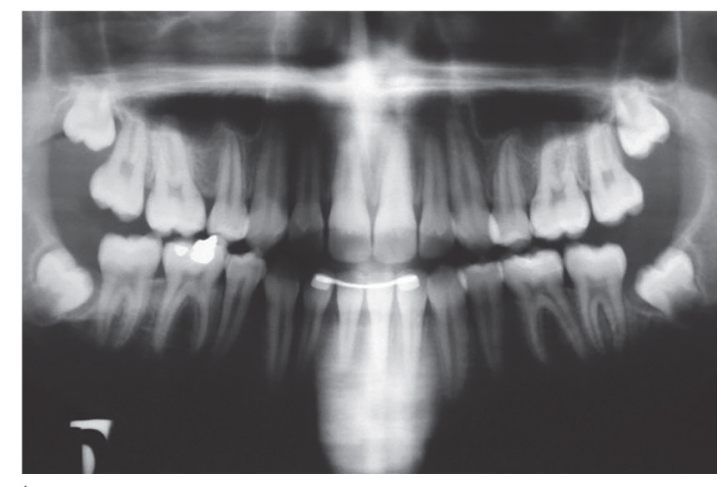

h

Figure 43a-h

The face is much more harmonious, but slight labial incompetence persists. Occlusion meets objectives; bilabioversion is reduced; wisdom tooth germs seem not to have progressed, as confirmed on Tweed analysis.

purely mechanical devices to alter the arches appropriately or by extra-oral accessories (directional forces).

* Respecting the transverse dimension The arcades tend to relapse toward pretreatment forms ${ }^{9-36-37-56}$. Many of the above-cited authors reported reduced intercanine width after treat- ment, which they sought to maintain. Zachrisson $^{56}$ recommended inclining the mandibular incisors, without lingual version, while maintaining arcade form. He stressed the need for a gradual visibility curve from front to back, and added that the prime rule for stability is to respect proximal 


\section{Patient 9}

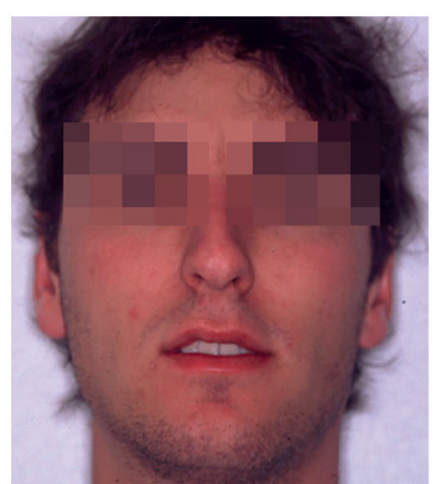

a

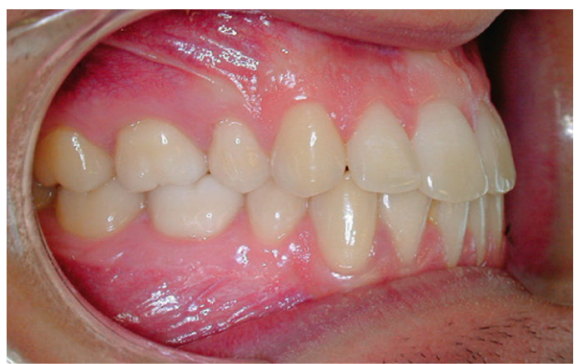

d

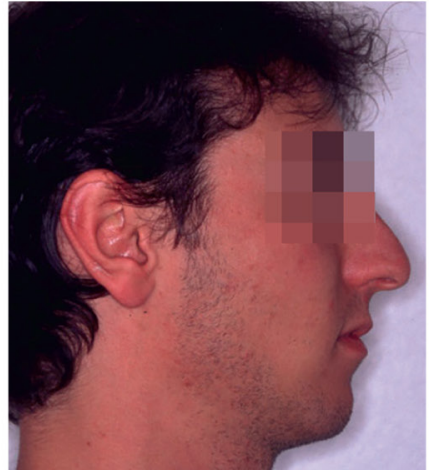

b

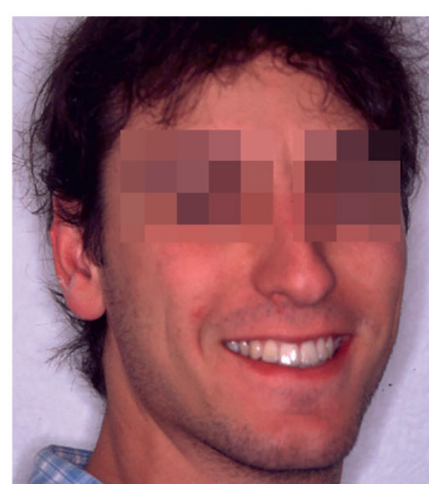

c

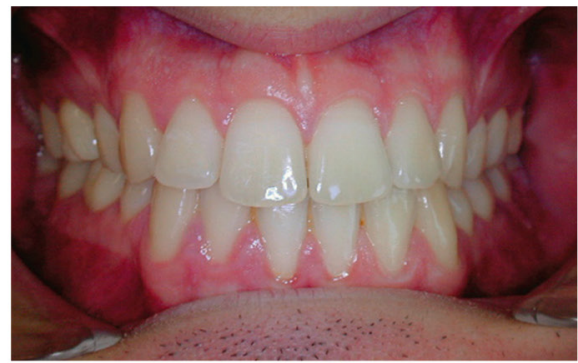

e

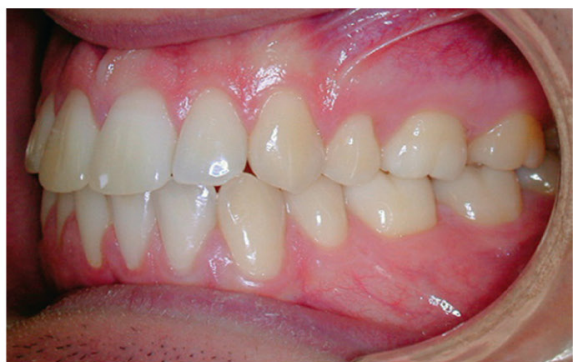

f

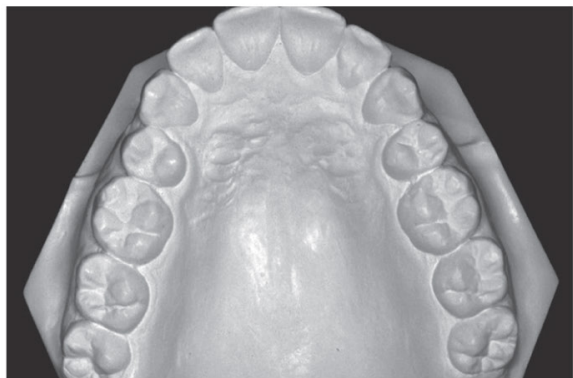

g

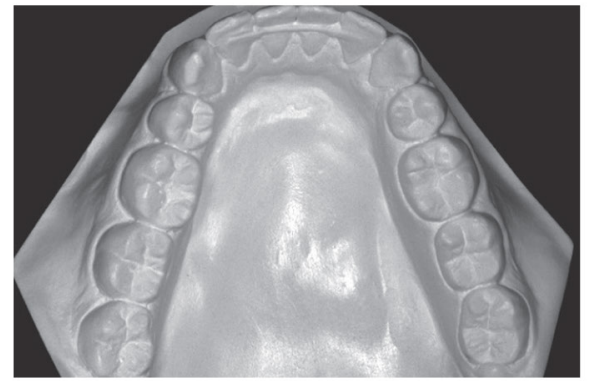

h

Figure 44a-h

10.5 years after end of treatment, slight labial incompetence persists; occlusion is perfectly stable, with natural recovery of overbite; wisdom teeth are perfectly functional. 2/2 still in place.

contact point continuity to control lateral forces and maintain arcade form. This seems to us essential for an esthetically satisfactory smile.

For Alexander ${ }^{2}$, excessive mandibular canine expansion, inferior incisor coronovestibular version, failure to level the inferior arcade and loss of vertical control risk durably impairing tooth stability.
In conclusion, although occlusion stability is multifactorial, implementing an effective, reproducible, individualized technique can control reorganization of the arcades and face; long-term stability depends on this.

Retention devices, of whatever kind, are indicated only if objectives have been met, especially regarding occlusion. Retention is universally 


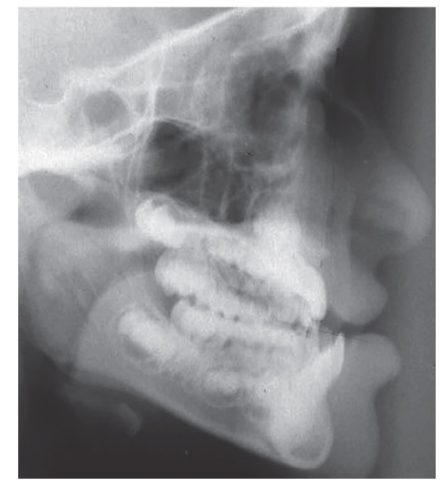

a

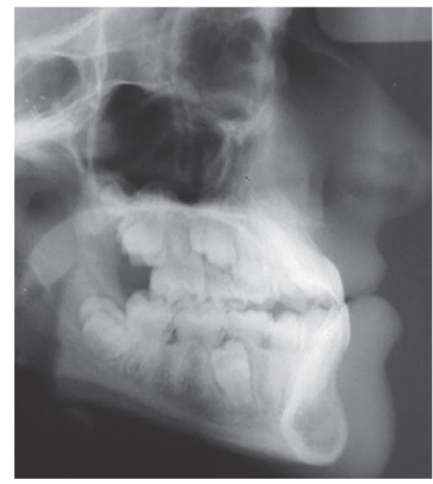

b

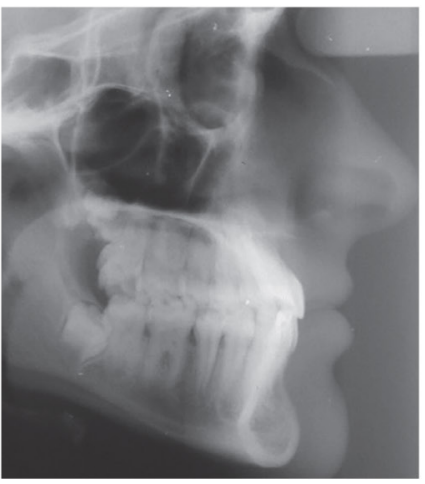

C

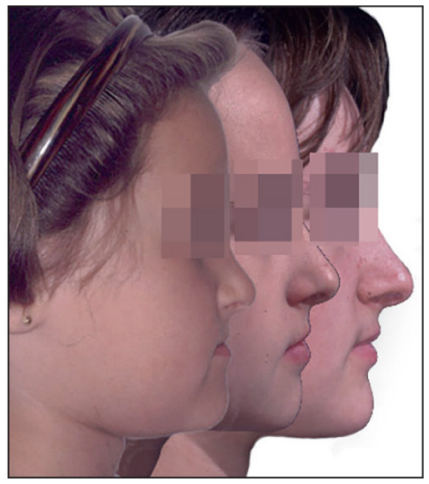

d

Figure 45

a) Control in hypodivergent class III. Treatment involved an interceptive phase with deciduous dentition. b) Improved occlusion with renewed treatment of permanent dentition. c-d) The outcome will be subject to the vagaries of residual growth.

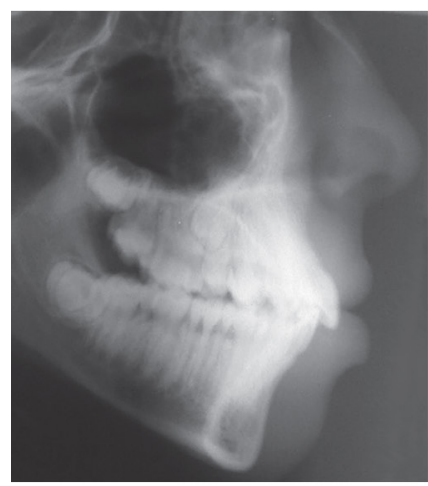

a

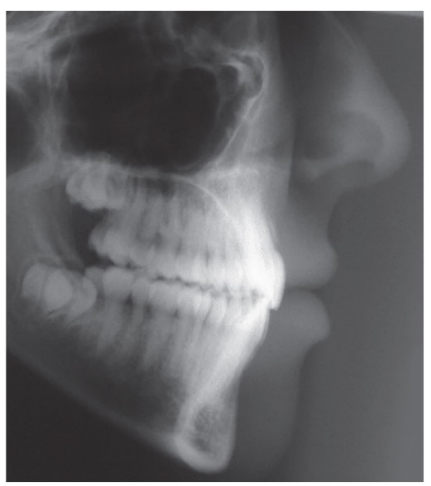

b

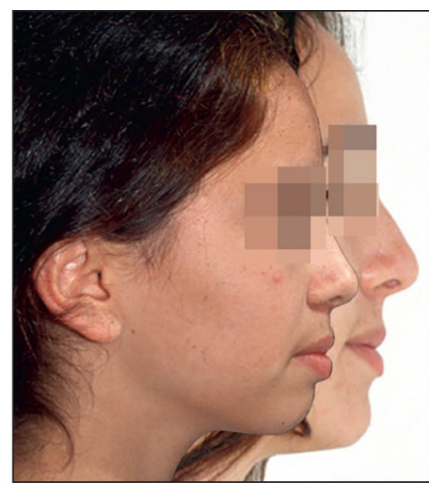

C

Figure 46a-c

Control in class I hyperdivergent bilabioversion.

agreed to be the mean of maintaining end-of-treatment results, to prevent relapse, in a pattern of dental, skeletal and functional balance, taking account of growth factors even if these cannot be controlled ${ }^{14}$.

Satisfactory results are partly a matter of the satisfaction of the patient, who plays an active role by wearing the retention devices ${ }^{41}$. Sheridan speaks of a transfer of responsibility from practitioner to patient ${ }^{51}$.

When we almost systematically implemented mandibular retention, we at first chose flexible devices glued to each tooth; these countered rotation force, which would induce relapse, and left almost physiological freedom for the teeth. The glue and adhesion surfaces were subject to 


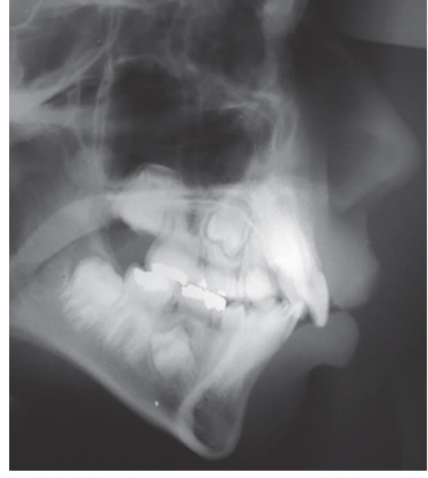

a

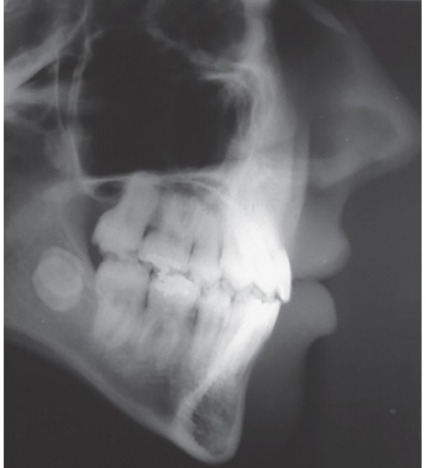

b

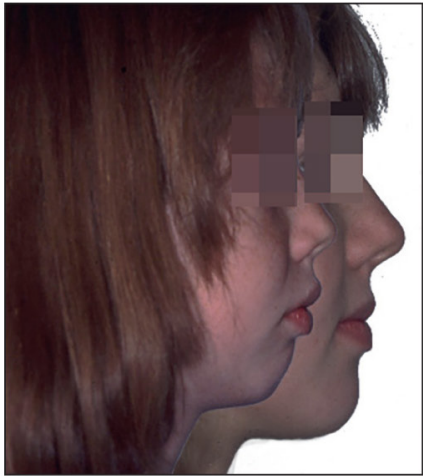

Figure 47a-c

Vertical control in hyperdivergent class II allows closure of the mandibular compass and forward projection of the chin. It contributes to restoring a functional interincisor angle and improving esthetics.

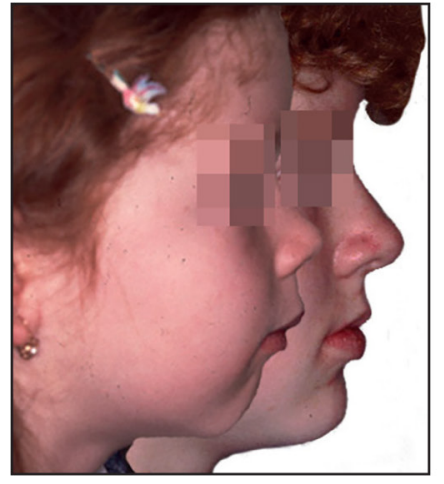

a

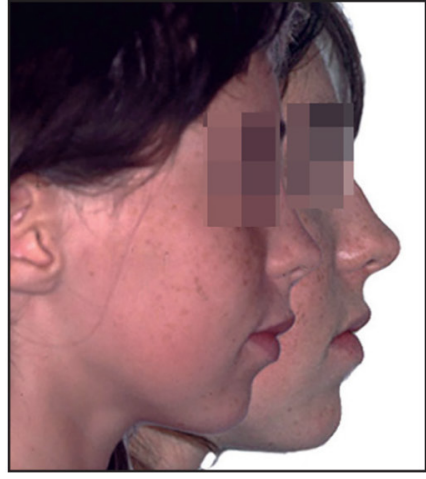

Figure 48a-c

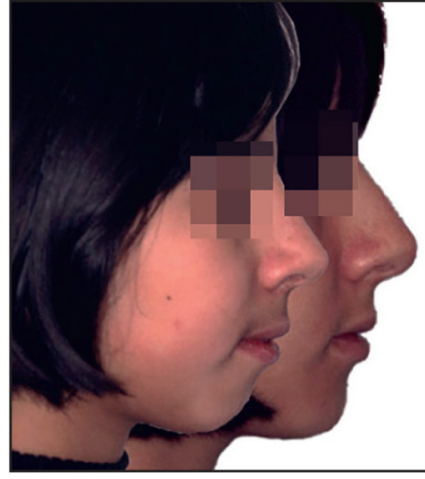

C

This projection relaxes the lips, avoiding forced stretching of the chin muscles.

little stress, and the gluing surface could be small53. We used a wire of several twisted strands, which was fairly supple and partly without glue, leaving a certain physiological mobility for each tooth, covered by a thin layer of glue. The irregularities of the wire, the ends of which were blunted, prevented lateral slide (fig. 49). Each tooth being glued, total detachment of the device was rare; manufacture and fitting, on the other hand, were tricky.
Later, we adopted classic rigid $3 / 3$ or $2 / 2$ retention, with the attachment base welded to the ends, which were connected by a .036 steel wire, which was easier to glue directly. The mandibular 3/3 was not, in principle, glued to the incisors and thus did not counter rotation and was also subject to deformation under stress caused by the patient (fig. 50).

2/2 devices are more rigid, but lack of canine support may allow parasitic movement there (fig. 51). They are 


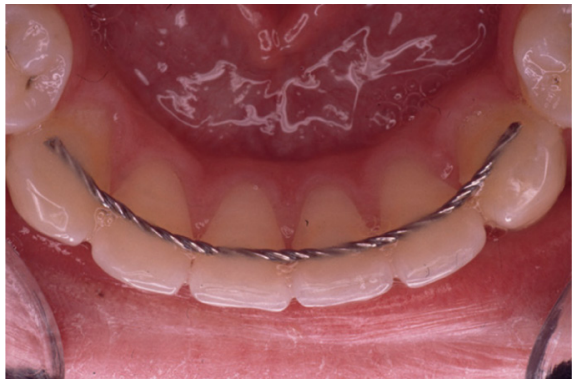

Figure 49

Mandibular retention by glued 3/3 twisted wire.

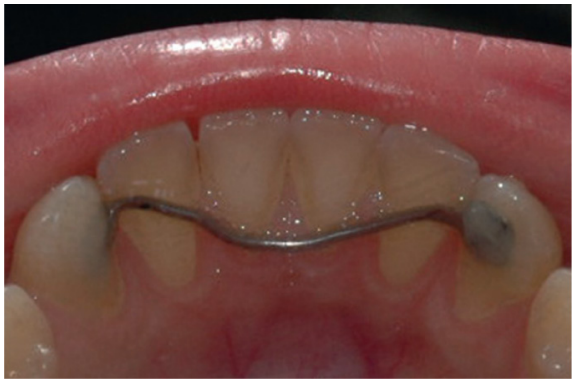

Figure 50

Deformation of 3/3 mandibular device.

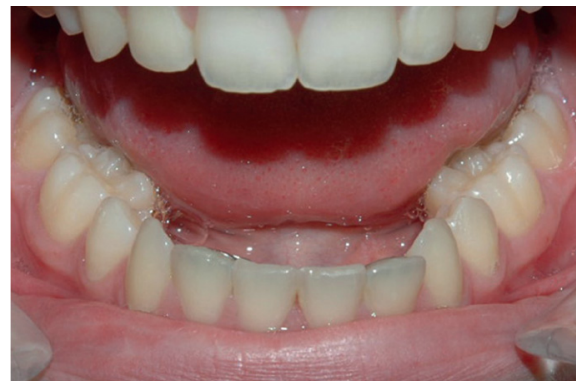

Figure 51

Retention by glued 2/2 device, with parasitic canine movement.

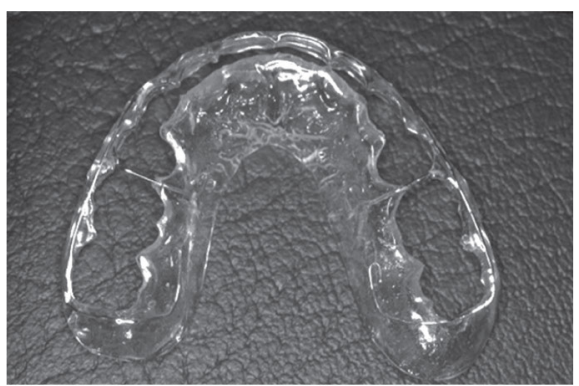

a

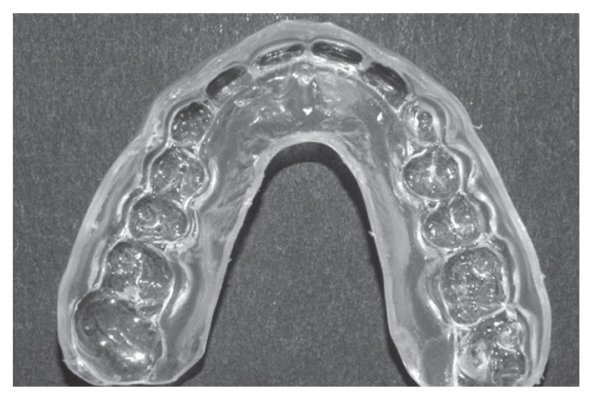

b

Figure 52

a) Indented retainer. b) Thermoformed Osamu retainer.

surprisingly long-lasting, as gluing is rigorous. Yearly check-up is recommended.

For the superior arcade, we opted for Hawley plates, as thin as possible, mounting the lingual sides of the teeth to maintain rotation correction in lateral sectors, leaving room for the second molars posteriorly ${ }^{54}$; however, they do not provide control of anterior tooth rotation, so that we sometimes chose indented retainers at the occlusal level, especially to maintain class $1 /$ division 2 incisor axes (fig. 52a), or thermoformed maxillary splints covering all the 
teeth, leaving room for second molar recovery (fig. 52b). They are not very bulky, transparent, easy to make and economic, although they discolor quickly and may need replacing during retention. Whatever the maxillary device, we systematically opted for purely nocturnal use, for just 1 year, then decreasing, with check-up every 3 months. In a study of 67 consecutive patients, full- or part-time use of a Hawley plate made no significant difference ${ }^{50}$

\section{CONCLUSION}

Skeletal and muscular balance and occlusal finishing quality determine the success of treatment. Long-term stability, especially anteroinferiorly, is hypothetical, as physiological and psychological changes during adolescence and adulthood are unforeseeable. Even so, the prime task of the orthodontist is to establish balanced occlusion, the key to stability. There will be no stability if diagnosis is incomplete or mistaken, if the treatment plan is not adapted and personalized, and if treatment induces tilting planes, lack of 3-dimensional control and poor muscle adaptation. Results will not be stable if bad habits and oral breathing persist and growth continues to be unfavorable.

Once treatment has been successful, it is important to remind the patient that the teeth will bear the ravages of time, just like for anyone who has not had orthodontic treatment. It is largely up to the patient to take charge of oral health and conserve the gains acquired.

Conflict of interest: The author declares no conflicts of interest.

\section{REFERENCES}

1. Alessio RA. Malocclusion de classe III Extractions 15-25-34-44. J Edg 1991;24:135142.

2. Alexander R.G. Le système Alexander et le recherche de la stabilité à long terme. International Orthodontics 2004;3:183-208.

3. Artun J, Garol JD, Little RMm. Long terme stability of mandibular incisors following successfull treatment of Class II division 1 malocclusions. Angle Orthod 1996;66:229238.

4. Behrents RG, Harris EF, Vaden JL, Williams RA, Kemp DH. Relapse of orthodontic treatment results: growth as an etiologic factor. J Tweed 1989;17:65-78.

5. Bettinelli D, Deblock L. Effets du vieillissement sur les arcades dentaires adultes. Orthod Fr 2004,75:179-183.

6. Boese L. Commentary: Bad news is good news. Angle Orthod 1999;61:144. 
7. Boley JC, Boley S. Extractions programmées : Une alternative à l'expansion en denture mixte. Évaluation à long terme. J Edg 1997;35:25-36.

8. Boley JC. Stabilité à long terme après traitement selon la technique de Tweed. JEdg 1997;35:36-45.

9. Boley J. La stabilité postcontention : un point de vue optimiste. International Orthodontics 2004;3:209-228.

10. Bourgoin G, Filleul MP, Polacco C, Roger J. La récidive en ODF. Orthod Fr 1985;56:29-110.

11. Cretot M. Vieillissement de profil facial chez l'adulte resté denté et équilibré $\mathrm{J}$ Edg 1992;26:7-42.

12. De Baets J. Une réévaluation du concept traditionnel de l'occlusion normale. Rev Orthop Dento Fac 1998;32:235-274.

13. De Freitas KM, Janson J, De Freitas MR, Pinzan A, Henriques JF, Pinzan-Vercelino CR. Influence of the quality of the finished occlusion on postretention occlusal relapse. Am J Orthod Dentofacial Orthop 2007;132:9-14.

14. Derose D, Abs MP, Defais F, Lopez Y. De la contention : évolution des concepts et des techniques. Orthod Fr 1999;70:147-203.

15. Dyer KC, Vaden JL, Harris EF. Relapse revisited-again. Am J Orthod Dentofacial Orthop 2012;142:221-227.

16. Giordanetto J. Classe II et repositionnement incisif. Orthod Fr 1985;56:433-439.

17. Giordanetto J. Traitement d'une classe II 1 avec repositionnement incisif. J Edg 1985;12:83-109.

18. Guillot E. Traitement d'une classe II division 1. J Edg 1987;16:125-135.

19. Hamou E, Ortial JP, Richier D. Finitions des cas orthodontiques. J Edg 1990;21:49-67.

20. Horn AJ. La technique de Tweed-Merrifield: une tech- nique reproductible pour un traitement individuel. J Edg 1988;17:59-87.

21. Horn AJ. Thérapeutique Edgewise Tweed-Merrifield. Orthod Fr 1990; 61:121-160.

22. Horn AJ. Edgewise today. J Tweed 2010;9:3-12.

23. Horn A, Jegou I. Une nouvelle technique : I'edgewise Tweed-Merrifield. Rev Orthop Dento Fac 1995;29:511-527.

24. Jegou I. Traitement d'une classe II division 1. J Edg 1985;11:117-131.

25. Kim TW, Little RM. Évaluation après contention de la correction des supraclusions sévères dans les malocclusions de classe II division 2 (nouvelles conclusions). Rev Orthop Dent Fac 2001;35:107-128.

26. Kohaut JC. Le guide antérieur - mouvements et stabilité. International Orthodontics 2014;12:281-290.

27. Labarrere H. Les finitions du traitement orthodontique. J Edg 2002;45:7-47.

28. Lamarque S, Videau MC. Traitement d'une classe II division 1. J Edg 1988;18:125-134.

29. Lamarque S, Videau MC. Traitement d'une classe II division 1 hyperdivergente par extractions de 14-24-35-45. J Edg 1989;20:169-175.

30. Le Goff C, Lautrou A. Modifications dento-squelettiques après traitement par activateur monobloc associé à une force extra-orale. Rev Orthop Dento Fac 2003;37:407427.

31. Little RM, Wallen TR, Riedel RA. Stability and relapse of mandibular anterior alignment first premolar extraction cases treated by traditional edgewise orthodontics. Am J Orthod Dentofacial Orthop 1981;80:349-365.

32. Little RM, Riedel RA, Artun J. An evaluation of changes in mandibular anterior alignment from 10 to 20 years postretention. Am J Orthod Dentofacial Orthop 1988;93:423-428.

33. Little RM, Riedel RA. Postretention evaluation of stability and relapse mandibular arches with geénéralised spacing. Am J Orthod Dentofacial Orthop 1989;95:37-41. 
34. Little RM, Riedel RA, Stein A. Mandibular arch lengthht increase during the mixed dentition: postreatment evaluation of stability and relapse. Am J Orthod Dentofacial Orthop 1990;97:393-404.

35. Little RM, Riedel RA, Engst ED. Serial extractions of thirst premolars - posterretention evaluation of stability and relapse. Angle Orthod 1990;60:255-262.

36. Little RM \& allall. Long term changes in arch form after orthodontic treatment and retention. Am J Orthod Dentofacial Orthop 1995.

37. Little RM. Stabilité et récidive de la forme d'arcade et de l'alignement dentaire. J Edg 1996;34:53-67.

38. Martin M. Courbe de Spee et thérapeutique J Edg 1991;23:45-59.

39. Martin M. Technique de Tweed-Merrifield et dimension verticale dans les classes II hyperdivergentes. Orthod Fr 2005;76:13-25.

40. Martin M. Stratégie thérapeutique dans les classes II division 2 chez I'adolescent. International Orthodontics 2006;4:16-50.

41. Mollov ND, Lindauer SJ, Best AM, Shroff B, Tufekci E. Patient attitudes toward retention and perceptions of treatment success. Angle Ortho. 2010;80:468-473.

42. Ortial JP. L'edgewise par le système des forces directionnelles. Orthod Fr 1985;56:433439.

43. Philippe J. Récidive orthodontique et dérive centripète. Rev Orthop Dento Fac 1989;23:317-328.

44. Philippe J. De la contention. Orthod Fr 2010;81:221-226.

45. Quaglio CL, De Freitas KM, De Freitas MR, Janson G, Henriques JF. Stability and relapse of maxillary ante- rior crowding treatment in class I and class II Division 1 malocclusions. Am J Orthod Dentofacial Orthop 2011;139:768-774.

46. Radziminski G. Traitement d'une classe II division 2. J Edg 1985;11:166-177.

47. Richter O. La technique bidimensionnelle : une mise à jour. J Edg 2004;2:7-38.

48. Root T. Concepts d'ancrage et finition des cas orthodontiques. J Edg 1980;1:11-29.

49. Savastano C. Technique edgewise et dysfonctions des ATM. J Edg 1990;21:137-144.

50. Shawesh M, Bhatti B, Usmani T, Mandall N. Hawley retainers full or part time? A randomized clinical trial. Eur J Orthod 2010;32:165-170.

51. Sheridan J.J. \& all at (Gaylord, Hamula, Hickam, Kokich, Tuverson) J Clin Orthod 1992;26:551-564.

52. Sinclair PM, Little RM. Maturation of untreated normal occlusions. Am J Orthod Dentofacial Orthop 1983;83:114-123.

53. Theuveny E, Bassigny F. La contention collée en orthodontie. Rev Orthop Dento Fac 1988;22:249-263.

54. Van Der Linden FPGM. Mythes et légendes en orthodontie. European Journal of Orthodontics 2008;30:449-468.

55. Williams R. Comment éviter la contention mandibulaire. Rev Orthop Dento Fac 1986;20:39-51.

56. Zachrisson BU. L'excellence en orthodontie. Orthod Fr 2000,71:317-324. 